\title{
Economic Sulfur Conversion to Functional Polythioamides Through Catalyst-free Multicomponent Polymerizations of Sulfur, Acids, and Amines
}

\author{
Wenxia Cao, ${ }^{\dagger}$ Fengying Dai, ${ }^{\#}$ Rongrong Hu, ${ }^{* \dagger}$ and Ben Zhong Tang ${ }^{\dagger, t}$
}

‘State Key Laboratory of Luminescent Materials and Devices, Center for AggregationInduced Emission, \#Analytical and Testing Center, South China University of Technology, Guangzhou 510640, China.

Department of Chemistry, Hong Kong Branch of Chinese National Engineering Research Center for Tissue Restoration and Reconstruction, The Hong Kong University of Science \& Technology, Clear Water Bay, Kowloon, Hong Kong, China.

\section{Table of Contents}

Materials and instruments

Synthetic procedures and characterization data

Procedures for gold enrichment and recovery test

Table S1. Effect of monomer ratio on the MCP

Table S2. Effect of monomer concentration on the MCP

Table S3. Effect of polymerization time on the MCP

Table S4. Effect of temperature on the MCP

Table S5. Effect of different monomers on the polymerization ${ }^{a}$

Figure S1. GPC curves of polymers P1-P12.

Figure S2. (A) The reaction between $\mathbf{1}$ and 3a in DMSO at room temperature and the reaction phenomena. (B) The reaction between 1 and $3 \mathbf{e}$ in DMSO at $100{ }^{\circ} \mathrm{C}$ and the reaction phenomena. (C) The reaction between $\mathbf{1}, \mathbf{3 e}$ and $\mathrm{K}_{2} \mathrm{CO}_{3}$ in DMSO at $100{ }^{\circ} \mathrm{C}$ 
and the reaction phenomena.

Table S6. Effect of base on the polymerization of $\mathbf{1}, \mathbf{2 b}$, and $\mathbf{3} \mathrm{e}^{a}$

Scheme S1. The synthetic routes of monomer $2 \mathbf{c}$.

Table S7. Effect of different scales on the MCP

Scheme S2. Proposed mechanism for the multicomponent reaction of sulfur, carboxylic acid and amine.

Figure S3. The synthetic routes of model compounds (A) 4 and (B) 5, (C) single crystal structure of model compound $\mathbf{5}$.

Table S8. Single crystal data and structure refinement for model compound $\mathbf{5}$

Figure S4. FT-IR spectra of (A) 2a, (B) 3a, (C) 4, and (D) P1.

Figure S5. FT-IR spectra of (A) 2b, (B) 3e, (C) 5, and (D) P8.

Figure S6. ${ }^{1} \mathrm{H}$ NMR spectra of (A) 2b, (B) 3e, (C) 5, and (D) P8 in DMSO- $d 6 \cdot{ }^{13} \mathrm{C}$ NMR spectra of (E) 2b, (F) 3e, (G) 5, and (H) P8 in DMSO- $d_{6}$. The solvent peaks were marked with asterisks.

Figure S7. FT-IR spectra of (A) P1, (B) P2, (C) P3, and (D) P4.

Figure S8. FT-IR spectra of (A) P5, (B) P6, (C) P7, (D) P8, (E) P9, and P10.

Figure S9. FT-IR spectra of (A) 2c, (B) P11, and (C) P12.

Figure S10. (A) ${ }^{1} \mathrm{H}$ NMR and (B) ${ }^{13} \mathrm{C}$ NMR spectra of ammonium salt formed from $2 \mathbf{a}$ and 3a in $\mathrm{D}_{2} \mathrm{O}$. The solvent peak was marked with asterisk.

Figure S11. (A) ${ }^{1} \mathrm{H}$ NMR spectrum of $\mathrm{P} 5$ in DMF- $d_{7}$. (B) Solid state ${ }^{13} \mathrm{C}$ NMR spectrum of P5.

Figure S12. ${ }^{1} \mathrm{H}$ NMR spectra of (A) P1, (B) P2, (C) P3, and (D) P4 in DMSO- $d 6 .{ }^{13} \mathrm{C}$ NMR spectra of (E) P1, (F) P2, (G) P3, and (H) P4 in DMSO-d6. The solvent peaks were marked with asterisks.

Figure S13. ${ }^{1} \mathrm{H}$ NMR spectra of (A) P6 in DMF- $d_{7}$, (B) P7, (C) P8, (D) P9, and (E) P10 in DMSO- $d_{6} .{ }^{13} \mathrm{C}$ NMR spectra of (F) P6 in DMF- $d 7,(\mathrm{G}) \mathrm{P7},(\mathrm{H}) \mathrm{P8}$, (I) P9, and (J) P10 in DMSO- $d_{6}$. The solvent peaks were marked with asterisks.

Figure S14. ${ }^{1} \mathrm{H}$ NMR spectra of (A) 2c, (B) P11, and (C) P12 in DMSO- $d_{6} .{ }^{13} \mathrm{C}$ NMR spectra of (D) 2c, (E) P11, and (F) P12 in DMSO- $d_{6}$. The solvent peaks were marked with asterisks. 
Figure S15. S 2p XPS of elemental sulfur, model compound 5, P1, P5, and P8.

Figure S16. Solubility comparison of (A) PPTA and (B) P5 with $10 \mathrm{mg}$ polymer in 2 mL DMF.

Figure S17. (A) TGA curves of polythioamides P1-P12 with a heating rate of $10{ }^{\circ} \mathrm{C} / \mathrm{min}$ under nitrogen. (B) DSC curves of polythioamides with a heating rate of $10{ }^{\circ} \mathrm{C} / \mathrm{min}$ from 30 to $270{ }^{\circ} \mathrm{C}$ under nitrogen.

Table S9. Gold extraction with different dosages of polythioamides

Table S10. Time-dependent gold extraction

Table S11. Gold extraction efficiency of DMF solution of P8 with different initial concentrations of $\mathrm{Au}^{3+}$

Figure S18. Extraction efficiency of $\mathrm{Au}^{3+}$ with $\mathrm{P8}$ at different $\mathrm{pH}$ values with $10 \mathrm{~mL}$ of $\mathrm{Au}^{3+}$ solution $(100 \mathrm{mg} / \mathrm{L})$.

Figure S19. The extraction efficiency of different metal ions using solid powder of P8. $m_{\mathrm{P} 8}=10 \mathrm{mg}, \mathrm{V}_{\mathrm{M}^{\mathrm{n}}}=10 \mathrm{~mL},\left[\mathrm{M}^{\mathrm{n}+}\right]=100 \mathrm{mg} / \mathrm{L}$. Polymer powder and the aqueous solution of metal ions were stirred at room temperature for $1 \mathrm{~h}$ before centrifugation.

Table S12. The extraction efficiency of solid powder of P8 with different metal ions

Table S13. Gold extraction from discarded CPU by P8

Figure S20. (A) S 2p XPS of model compound 5 and 5-Au ${ }^{3+}$ and (B) N 1s XPS of model compound $\mathbf{5}$ and $\mathbf{5}-\mathrm{Au}^{3+}$.

Figure S21. ${ }^{1} \mathrm{H}$ NMR spectra of (A) 5 and (B) 5- $\mathrm{Au}^{3+}$ in DMSO- $d_{6} \cdot{ }^{13} \mathrm{C}$ NMR spectra of (C) 5 and (D) $5-\mathrm{Au}^{3+}$ in DMSO- $d_{6}$.

Figure S22. MALDI-TOF MS spectrum of complex 5- $\mathrm{Au}^{3+}$.

Figure S23-S60. The original spectra of ${ }^{1} \mathrm{H}$ and ${ }^{13} \mathrm{C}$ NMR spectra of monomers, model compounds, and polymers. 
Materials. Sublimed sulfur 1, $\mathrm{KOH}, \mathrm{Ca}\left(\mathrm{NO}_{3}\right)_{2} \cdot 4 \mathrm{H}_{2} \mathrm{O}, \mathrm{HgCl}_{2}, \mathrm{NaCl}, \mathrm{KCl}, \mathrm{ZnCl}_{2}, \mathrm{HNO}_{3}$ (65-68 wt $\%$ ), and $\mathrm{HCl}(36-38 \mathrm{wt} \%)$ were purchased from Guangzhou Chemical Reagent Factory; dicarboxylic acids $\mathbf{2 a - b}$, diamines $\mathbf{3 a}-\mathbf{h}$ and $\mathrm{K}_{2} \mathrm{CO}_{3}$ were purchased from TCI.; $p$-anisidine 8, $\mathrm{CoCl}_{2}, \mathrm{CuCl}_{2}, \mathrm{NiCl}_{2} \cdot 6 \mathrm{H}_{2} \mathrm{O}, \mathrm{MgCl}_{2}, \mathrm{FeCl}_{3}, \mathrm{CeCl}_{3} \cdot 7 \mathrm{H}_{2} \mathrm{O}$, $\mathrm{CrCl}_{3} \cdot 6 \mathrm{H}_{2} \mathrm{O}$, and $\mathrm{Pb}\left(\mathrm{NO}_{3}\right)_{2}$ were purchased from Energy Chemical; $t$-BuOK, $\mathrm{Na}_{2} \mathrm{CO}_{3}, \mathrm{Cs}_{2} \mathrm{CO}_{3}$ were purchased from TCI.; KF, $\mathrm{KOH}$, DABCO were purchased fro m Energy Chemical; phenylacetic acid 6 was purchased from Keyorganic; hexylamine 7 and $\mathrm{MnCl}_{2}$ were purchased from Aladdin; gold standard solution $\left(\left[\mathrm{Au}^{3+}\right]=1000 \mathrm{mg} / \mathrm{L}\right.$, $[\mathrm{HCl}]=1.5 \mathrm{~mol} / \mathrm{L}$, with trace amount of $\mathrm{HNO}_{3}$ ) was purchased from Meryer; $\mathrm{CdCl}_{2}$, dimethyl sulfoxide were purchased from 3A Chemicals; 2,2'-(9,9-dimethyl-9Hfluorene-2,7-diyl)bis(4,4,5,5-tetramethyl-1,3,2-dioxaborolane) 9 and methyl 2-(4bromophenyl)acetate 10 were purchased from Bidepharm; $\mathrm{Pd}\left(\mathrm{PPh}_{3}\right)_{4}$ was purchased from J\&K Scientific Ltd; Tetrahydrofuran (THF) was distilled from sodium benzophenone ketyl under a nitrogen atmosphere immediately prior to use. All reactants and reagents were used without further purification.

Instruments. ${ }^{1} \mathrm{H}$ and ${ }^{13} \mathrm{C}$ NMR spectra were estimated on a Brucker Avance 400 or 500 MHz NMR spectrometer using deuterated dimethyl sulfoxide (DMSO-d6) or $N, N$ dimethylformamide (DMF- $d_{7}$ ) as solvent and tetramethylsilane (TMS, $\left.\delta=0\right)$ as internal reference. FT-IR spectra were determined on a Bruker Vector 33 FT-IR spectrometer. High resolution mass spectra measurements were carried out on a Bruker maxis impact mass spectrometer. The number- $\left(M_{\mathrm{n}}\right)$ and weight- $\left(M_{\mathrm{w}}\right)$ average molecular weights and polydispersity indices $\left(\mathrm{PDI}=M_{\mathrm{w}} / M_{\mathrm{n}}\right)$ of the polymers were estimated by a Waters 1515 gel permeation chromatography system. $\mathrm{DMF} / \mathrm{LiBr}$ solution $(0.05 \mathrm{M}$ of $\mathrm{LiBr})$ was used as eluent at a flow rate of $1 \mathrm{~mL} / \mathrm{min}$. A set of monodispersed polystyrenes, covering the $M_{\mathrm{w}}$ range of $10^{3}-10^{7} \mathrm{~g} / \mathrm{mol}$, were utilized as standards for molecular weight calibration. Thermogravimetric analysis was carried out on Netzsch TG 209 F3 and Netzsch DSC $200 \mathrm{~F} 3$ under nitrogen atmosphere at a heating rate of $10{ }^{\circ} \mathrm{C} / \mathrm{min}$. Single crystal X-ray diffraction patterns were measured by an X'pert Pro Panalytical X-ray diffractometer at an incident angle ranging from 5 to $50^{\circ}$. X-ray photoelectron spectroscopy was performed using a Kratos Axis Ultra DLD spectrometer with a monochromated Al Ka 
$\mathrm{X}$-ray source at a residual pressure of $5 \times 10^{-9}$ torr. The concentrations of metal ions were measured by Z-2000 atomic absorption spectrophotometer (AAS). The concentration of mercury ion was measured by AFS-8530 atomic fluorescence spectrometer. The concentration of $\mathrm{Ce}^{3+}$ was measured by UV500 UV-vis spectrophotometer.

Synthetic procedure of 2,2'-[(9,9-dimethyl-9H-fluorene-2,7-diyl)bis(1,4phenylene)]diacetic acid 2c. 2,2'-(9,9-dimethyl-9H-fluorene-2,7-diyl)bis(4,4,5,5tetramethyl-1,3,2-dioxaborolane) $(9,4.5 \mathrm{~g}, 10 \mathrm{mmol})$, methyl 4-bromophenylacetate (10, $5.1 \mathrm{~g}, 22 \mathrm{mmol}), \mathrm{K}_{2} \mathrm{CO}_{3}(5.5 \mathrm{~g}, 40 \mathrm{mmol})$ and $\mathrm{Pd}\left(\mathrm{PPh}_{3}\right)_{4}(0.7 \mathrm{~g}, 0.6 \mathrm{mmol})$ were added to a $250 \mathrm{~mL}$ flask with a stirrer bar. $80 \mathrm{~mL}$ of THF and $20 \mathrm{~mL}$ of $\mathrm{H}_{2} \mathrm{O}$ were injected and the solution was reacted at $80{ }^{\circ} \mathrm{C}$ under nitrogen for $36 \mathrm{~h}$. The reaction mixture was then allowed to cool to room temperature, followed by the addition of 30 $\mathrm{mL}$ of water and extraction with ethyl acetate $(3 \times 50 \mathrm{~mL})$. The organic layers were combined and the solvent was removed under reduced pressure. The product was purified by column chromatography on silica gel using petroleum ether/ $\mathrm{CH}_{2} \mathrm{Cl}_{2}$ mixture (v/v, 1/1) as eluent. A yellow solid 11 was obtained in 85\% yield. ${ }^{1} \mathrm{H}$ NMR (400 MHz, DMSO- $\left.d_{6}\right), \delta$ (TMS, ppm): $7.92(\mathrm{~d}, J=8.0 \mathrm{~Hz}, 2 \mathrm{H}), 7.86(\mathrm{~d}, J=1.2 \mathrm{~Hz}, 2 \mathrm{H}), 7.71(\mathrm{~d}$, $J=8.0 \mathrm{~Hz}, 4 \mathrm{H}), 7.65\left(\mathrm{dd}, J_{1}=7.8 \mathrm{~Hz}, J_{2}=1.2 \mathrm{~Hz}, 2 \mathrm{H}\right), 7.38(\mathrm{~d}, J=8.0 \mathrm{~Hz}, 4 \mathrm{H}), 3.75$ (s, 4H), 3.64 (s, 6H), 1.55 (s, 6H). ${ }^{13} \mathrm{C}$ NMR (125 MHz, DMSO- $\left.d_{6}\right), \delta$ (TMS, ppm): $171.64,154.50,139.15,139.09,137.52,133.47,129.93,126.79,125.75,121.11,120.68$, $51.75,46.76,39.77,26.86$.

Compound 11 was then reacted with $\mathrm{KOH}(3.5 \mathrm{~g}, 60 \mathrm{mmol})$ in $\mathrm{THF} / \mathrm{CH}_{3} \mathrm{OH} / \mathrm{H}_{2} \mathrm{O}$ $\left(30 \mathrm{~mL} / 20 \mathrm{~mL} / 10 \mathrm{~mL}\right.$ ) at $100{ }^{\circ} \mathrm{C}$ for $5 \mathrm{~h}$. The mixture was cooled to room temperature and concentrated hydrochloric acid was added slowly to tune the $\mathrm{pH}$ value to 3 . White product $2 \mathbf{c}$ was obtained after filtration and drying at $55^{\circ} \mathrm{C}$ under vacuum in $99 \%$ yield. IR (KBr disk), $v\left(\mathrm{~cm}^{-1}\right):$ 3028, 2959, 2925, 2657, 2550, 1723, 1649, 1515, 1465, 1435, 1405, 1292, 1248, 1149, 936, 905, 803, 749, 724, 643, 596, 526, 450. ${ }^{1} \mathrm{H}$ NMR (400 MHz, DMSO- $d_{6}$ ), $\delta$ (TMS, ppm): 12.38 (s, 2H, $\left.-\mathrm{COOH}\right), 7.91$ (d, $\left.J=8.0 \mathrm{~Hz}, 2 \mathrm{H}\right), 7.86$ $(\mathrm{d}, J=1.6 \mathrm{~Hz}, 2 \mathrm{H}), 7.70(\mathrm{~d}, J=8.0 \mathrm{~Hz}, 4 \mathrm{H}), 7.65\left(\mathrm{dd}, J_{1}=7.6 \mathrm{~Hz}, J_{2}=1.6 \mathrm{~Hz}, 2 \mathrm{H}\right)$, $7.38(\mathrm{~d}, J=8.0 \mathrm{~Hz}, 4 \mathrm{H}), 3.64(\mathrm{~s}, 4 \mathrm{H}), 1.55(\mathrm{~s}, 6 \mathrm{H}) .{ }^{13} \mathrm{C}$ NMR (125 MHz, DMSO- $\left.d_{6}\right)$, 
$\delta$ (TMS, ppm): 172.73 (-COOH), 154.50, 139.24, 138.88, 137.50, 134.18, 129.97, $126.69,125.75,121.09,120.67,46.77,40.36,26.89$. MALDI-TOF MS: $m / z 462.1832$ $\left(\mathrm{M}^{+}\right.$, calcd. 462.1831).

Synthetic procedure of model compound 4. Sublimed sulfur (1, 641.2 mg, $20 \mathrm{mmol})$, phenylacetic acid $(6,680.8 \mathrm{mg}, 5 \mathrm{mmol})$, and hexylamine $(7,1.012 \mathrm{~g}, 10 \mathrm{mmol})$ were reacted in $10 \mathrm{~mL}$ DMSO under nitrogen at $100{ }^{\circ} \mathrm{C}$ for $10 \mathrm{~h}$ in a $50 \mathrm{~mL}$ Schlenk tube equipped with a magnetic stir bar. The solution was cooled to room temperature and $100 \mathrm{~mL}$ of water was added. Dichloromethane was then used to extract the solution for three times $(3 \times 50 \mathrm{~mL})$. The organic layers were combined and the solvent was removed by vacuum rotary evaporation. The crude product was then purified by silica gel column chromatography with petroleum ether/dichloromethane $(\mathrm{v} / \mathrm{v}=2 / 1)$ to produce compound 4 as a brown liquid in $92 \%$ yield. IR (KBr disk), $v\left(\mathrm{~cm}^{-1}\right): 3244$, 2956, 2928, 2857, 1525, 1488, 1450, 1390, 1337, 1243, 1066, 1030, 1000, 966, 938, 769, 693. ${ }^{1} \mathrm{H}$ NMR (500 MHz, DMSO- $\left.d_{6}\right), \delta$ (TMS, ppm): 10.23 (s, 1H, -NH-), 7.73$7.71(\mathrm{~m}, 2 \mathrm{H}), 7.49-7.45(\mathrm{~m}, 1 \mathrm{H}), 7.43-7.39(\mathrm{~m}, 2 \mathrm{H}), 3.69(\mathrm{td}, 2 \mathrm{H}), 1.70-1.65(\mathrm{~m}, 2 \mathrm{H})$, 1.36-1.33 (m, 2H), 1.32-1.29 (m, 4H), 0.87 (t, 3H). ${ }^{13} \mathrm{C}$ NMR (125 MHz, DMSO-d6), $\delta$ (TMS, ppm): $197.01(\mathrm{C}=\mathrm{S}), 141.47,130.41,127.91,127.16,46.13,30.98,27.08$, 26.22, 22.04, 13.91. MALDI-TOF MS: $m / z$ 222.1296 (M + $\mathrm{H}^{+}$, calcd. 222.1238).

Synthetic procedure of model compound 5. Sublimed sulfur (1, 641.2 mg, $20 \mathrm{mmol})$, phenylacetic acid $(\mathbf{6}, 680.8 \mathrm{mg}, 5 \mathrm{mmol})$, $p$-anisidine $(\mathbf{8}, 615.8 \mathrm{mg}, 5 \mathrm{mmol})$, and $\mathrm{K}_{2} \mathrm{CO}_{3}$ $(1.382 \mathrm{~g}, 10 \mathrm{mmol})$ were reacted directly in $10 \mathrm{~mL}$ DMSO under nitrogen at $100{ }^{\circ} \mathrm{C}$ for $13 \mathrm{~h}$ in a $50 \mathrm{~mL}$ Schlenk tube equipped with a magnetic stir bar. The solution was cooled to room temperature and $100 \mathrm{~mL}$ of water was added. Dichloromethane was used to extract the solution for three times $(3 \times 50 \mathrm{~mL})$. The organic layers were combined and the solvent was removed by vacuum rotary evaporation, and the crude product was then purified by silica gel column chromatography with petroleum ether/ dichloromethane $(\mathrm{v} / \mathrm{v}=2 / 1)$ to produce compound $\mathbf{5}$ as a yellow solid in $95 \%$ yield. IR (KBr disk), $v\left(\mathrm{~cm}^{-1}\right):$ 3163, 3100, 2989, 2830, 1597, 1515, 1444, 1359, 1303, 1247, 1221, 1178, 1109, 1073, 1038, 988, 824, 745, 690, 622, 540, 511. ${ }^{1} \mathrm{H}$ NMR (500 MHz, DMSO- $\left.d_{6}\right), \delta(\mathrm{TMS}, \mathrm{ppm}): 11.63(\mathrm{~s}, 1 \mathrm{H},-\mathrm{NH}-), 7.82(\mathrm{~d}, J=7.0 \mathrm{~Hz}, 2 \mathrm{H}), 7.73(\mathrm{~d}, J=$ 
$9.0 \mathrm{~Hz}, 2 \mathrm{H}), 7.52(\mathrm{t}, 1 \mathrm{H}), 7.46(\mathrm{t}, 2 \mathrm{H}), 6.99(\mathrm{~d}, J=9.0 \mathrm{~Hz}, 2 \mathrm{H}), 3.78(\mathrm{~s}, 3 \mathrm{H}) .{ }^{13} \mathrm{C} \mathrm{NMR}$ (125 MHz, DMSO-d6), $\delta$ (TMS, ppm): 196.80 (C=S), 157.26, 142.59, 133.06, 130.60, 128.00, 127.40, 125.62, 113.57, 55.29. MALDI-TOF MS: $m / z 244.0792\left(\mathrm{M}+\mathrm{H}^{+}\right.$, calcd. 244.0718).

Typical procedure of the multicomponent polymerizations of sulfur, acids, and aliphatic diamines. Sublimed sulfur (1, $48.1 \mathrm{mg}, 1.50 \mathrm{mmol})$, 1,4-phenylenediacetic acid (2a, $145.6 \mathrm{mg}, 0.75 \mathrm{mmol})$ and hexamethylenediamine (3a, $58.1 \mathrm{mg}, 0.50 \mathrm{mmol})$ were reacted in $1 \mathrm{~mL}$ DMSO under nitrogen at $100{ }^{\circ} \mathrm{C}$ for $15 \mathrm{~h}$ in a $10 \mathrm{~mL}$ Schlenk tube equipped with a magnetic stir bar. The reaction solution was cooled to room temperature and was diluted with $4 \mathrm{~mL}$ of DMF, which was then added into $100 \mathrm{~mL}$ of methanol dropwise through a cotton filter to precipitate. The precipitates were filtered and washed with methanol for 5 times $(5 \times 20 \mathrm{~mL})$, which were then dried under vacuum to a constant weight, and a yellow polymer P1 was obtained in $96 \%$ yield. $M_{\mathrm{w}}$ $=54600 \mathrm{~g} / \mathrm{mol}, M_{\mathrm{w}} / M_{\mathrm{n}}=2.06$. IR (KBr disk), $v\left(\mathrm{~cm}^{-1}\right): 3271,2929,2854,1530,1495$, 1411, 1070, 938, 846. ${ }^{1} \mathrm{H}$ NMR (400 MHz, DMSO- $d_{6}$ ), $\delta$ (TMS, ppm): 10.35 (t, -NH-), $7.72(\mathrm{~s}, 4 \mathrm{H}), 3.70(\mathrm{dd}, 4 \mathrm{H}), 1.71$ (s, 4H), 1.41 (s, 4H). ${ }^{13} \mathrm{C}$ NMR (125 MHz, DMSO-d6), $\delta$ (TMS, ppm): $196.11(\mathrm{C}=\mathrm{S}), 142.75,126.78,46.19,27.10,26.34$.

Typical procedure of the multicomponent polymerizations of sulfur, acids, and aromatic diamines. Sublimed sulfur (1, $48.1 \mathrm{mg}, 1.50 \mathrm{mmol}), 1,3$-phenylenediacetic acid (2b, $97.1 \mathrm{mg}, 0.50 \mathrm{mmol}), 4,4^{\prime}$-oxydianiline (3e, $\left.100.1 \mathrm{mg}, 0.50 \mathrm{mmol}\right)$ and $\mathrm{K}_{2} \mathrm{CO}_{3}$ $(13.8 \mathrm{mg}, 0.1 \mathrm{mmol})$ were reacted in $1 \mathrm{~mL}$ DMSO under nitrogen at $100{ }^{\circ} \mathrm{C}$ for $25 \mathrm{~h}$ in a $10 \mathrm{~mL}$ Schlenk tube equipped with a magnetic stir bar. The reaction solution was cooled to room temperature and was diluted with $4 \mathrm{~mL}$ of DMF, which were then added to $100 \mathrm{~mL}$ of methanol dropwise through a cotton filter to precipitate. The precipitates were filtered and washed with methanol for 5 times $(5 \times 20 \mathrm{~mL})$, which was then dried under vacuum to a constant weight, and a yellow polymer P8 was obtained in 99\% yield. $M_{\mathrm{w}}=49400 \mathrm{~g} / \mathrm{mol}, M_{\mathrm{w}} / M_{\mathrm{n}}=1.89 . \mathrm{IR}\left(\mathrm{KBr}\right.$ disk), $v\left(\mathrm{~cm}^{-1}\right): 3340,3247,3040,1689$, 1598, 1496, 1356, 1239, 1164, 1102, 1011, 989, 832, 693, 508. ${ }^{1} \mathrm{H}$ NMR (500 MHz, DMSO- $\left.d_{6}\right), \delta$ (TMS, ppm): $11.91\left(\mathrm{~s}, 2 \mathrm{H},-\mathrm{NH}^{-}\right), 8.24(\mathrm{~s}, 1 \mathrm{H}), 7.99$ (d, 2H), 7.88 (d, 4H), 7.57 (t, 1H), 7.14 (d, 4H). ${ }^{13}$ C NMR (125 MHz, DMSO- $\left.d_{6}\right), \delta$ (TMS, ppm): 196.51 
$(\mathrm{C}=\mathrm{S}), 154.48,142.19,135.61,129.89,128.05,126.17,126.05,118.65$. The control experiment of the polymerization of $\mathbf{2 a}$ and 3a were carried out in DMSO without sulfur, which could not afford polymer product, proving that the incorporated sulfur in the polythioamide product is indeed from $\mathrm{S}_{8}$ and not from DMSO.

Preparation of PPTA. $p$-Phenylenediamine (540 mg, $5 \mathrm{mmol}$ ) was dissolved in 16.7 $\mathrm{mL}$ of hexamethylphosphoramide (HMPA) and $8.3 \mathrm{~mL}$ of $N$-methyl-2-pyrrolidone (NMP). The solution was cooled to $-15^{\circ} \mathrm{C}$, and powdered terephthaloyl chloride (1.015 $\mathrm{g}, 5 \mathrm{mmol}$ ) was then added. The mixture was stirred under nitrogen and was allowed to gradually warm to room temperature. After $6 \mathrm{~h}$, the reaction was worked up by agitating with methanol. The polymer was collected by filtration, washed thoroughly with hot methanol, and dried at $50{ }^{\circ} \mathrm{C}$ under vacuum with a yield of $81 \%$. IR ( $\mathrm{KBr}$ disk), $v\left(\mathrm{~cm}^{-1}\right)$ : 3323, 1649, 1571, 1517, 1451, 1394, 1320, 1262, 1110, 1039, 1016, 825, 744.

Model reaction of 5 and $\mathbf{A u C l}_{3} \mathbf{5}(243 \mathrm{mg}, 1.0 \mathrm{mmol})$ was dissolved in $16 \mathrm{~mL}$ ethanol and $\mathrm{AuCl}_{3}(152 \mathrm{mg}, 0.5 \mathrm{mmol})$ was dissolved in $4 \mathrm{~mL} \mathrm{H}_{2} \mathrm{O}$. The aqueous solution of $\mathrm{Au}^{3+}$ was added into the ethanol solution dropwise and stirred at room temperature for $1 \mathrm{~h}$ in air. After the reaction, black precipitate was formed in the solution which was removed by centrifugation. The solvent of the supernatant was removed under reduced pressure and a dark brown solid was obtained in $80 \%$ yield. ${ }^{1} \mathrm{H}$ NMR $(500 \mathrm{MHz}$, DMSO- $\left.d_{6}\right), \delta$ (TMS, ppm): $10.12,7.94,7.67,7.58,7.52,6.93,3.74 .{ }^{13} \mathrm{C}$ NMR $(125$ MHz, DMSO-d6), $\delta$ (TMS, ppm): 165.09, 155.53, 135.04, 132.22, 131.37, 128.34, 127.53, 121.96, 113.73, 55.18. MALDI-TOF MS: $m / z$ 683.1103 $\left(\mathrm{M}^{+}\right.$, calcd. 683.1085).

\section{Characterization data of polythioamides.}

P2. A yellow solid was obtained in $39 \%$ yield. $M_{\mathrm{w}}=13600 \mathrm{~g} / \mathrm{mol}, M_{\mathrm{w}} / M_{\mathrm{n}}=1.14$. IR (KBr disk), $v\left(\mathrm{~cm}^{-1}\right): 3212,3044,2928,2855,1528,1306,1070,694 .{ }^{1} \mathrm{H}$ NMR (400 MHz, DMSO- $d_{6}$ ), $\delta$ (TMS, ppm): 10.37 (s, 2H, -NH-), 8.01 (s, 1H), 7.78 (d, 2H), 7.44 $(\mathrm{t}, 1 \mathrm{H}), 3.70(\mathrm{~d}, 4 \mathrm{H}), 1.71(\mathrm{~s}, 4 \mathrm{H}), 1.41(\mathrm{~s}, 4 \mathrm{H}),{ }^{13} \mathrm{C}$ NMR (125 MHz, DMSO-d $), \delta$ (TMS, ppm): 196.46 (C=S), 141.18, 129.09, 127.68, 125.99, 46.28, 27.12, 26.38.

P3. A brown solid was obtained in $78 \%$ yield. $M_{\mathrm{w}}=31300 \mathrm{~g} / \mathrm{mol}, M_{\mathrm{w}} / M_{\mathrm{n}}=1.40$. IR (KBr disk), $v\left(\mathrm{~cm}^{-1}\right)$ : 3230, 3030, 2919, 2866, 1531, 1411, 1381, 1319, 1091, 970, 840. ${ }^{1} \mathrm{H}$ NMR (400 MHz, DMSO-d $\left.d_{6}\right), \delta$ (TMS, ppm): 10.40 (t, 2H, -NH-), 7.74 (s, 4H), 
3.88-3.85 (m, 4H), $3.72(\mathrm{t}, 4 \mathrm{H}), 3.59(\mathrm{~s}, 4 \mathrm{H}) .{ }^{13} \mathrm{C}$ NMR (125 MHz, DMSO- $\left.d_{6}\right), \delta$ (TMS, ppm): 196.69 (C=S), 142.59, 126.84, 69.63, 67.04, 46.04.

P4. A yellow solid was obtained in $85 \%$ yield. $M_{\mathrm{w}}=18700 \mathrm{~g} / \mathrm{mol}, M_{\mathrm{w}} / M_{\mathrm{n}}=1.29$. IR (KBr disk), $v\left(\mathrm{~cm}^{-1}\right): 3306,3024,2916,2228,1693,1605,1522,1493,1408,1379$, 1330, 1278, 1202, 1083, 1017, 939, 844. ${ }^{1} \mathrm{H}$ NMR (500 MHz, DMSO-d6), $\delta$ (TMS, ppm): 10.88 (t, 2H, -NH-), 7.79 (s, 4H), 7.36 (s, 4H), 4.97 (d, 4H). ${ }^{13} \mathrm{C}$ NMR (125 MHz, DMSO- $d_{6}$ ), $\delta$ (TMS, ppm): 196.80 (C=S), 142.61, 136.18, 127.77, 126.98, 48.89. P5. A yellow solid was obtained in $85 \%$ yield. $M_{\mathrm{w}}=14900 \mathrm{~g} / \mathrm{mol}, M_{\mathrm{w}} / M_{\mathrm{n}}=1.20$. IR (KBr disk), $v\left(\mathrm{~cm}^{-1}\right): 3332,3190,2975,1616,1507,1404,1339,1274,1169,1109$, 1014, 983, 830, 722, 507. ${ }^{1} \mathrm{H}$ NMR (400 MHz, DMSO- $d_{6}$ ), $\delta$ (TMS, ppm): 11.54, 8.66, $7.94,7.89,7.81,7.50,6.59,5.25$.

P6. A yellow solid was obtained in $69 \%$ yield. $M_{\mathrm{w}}=18200 \mathrm{~g} / \mathrm{mol}, M_{\mathrm{w}} / M_{\mathrm{n}}=1.32$. IR (KBr disk), $v\left(\mathrm{~cm}^{-1}\right)$ : 3342, 3236, 1587, 1491, 1406, 1346, 1207, 1177, 1114, 1081, 1012, 986, 823. ${ }^{1} \mathrm{H}$ NMR (500 MHz, DMF-d7), $\delta$ (TMS, ppm): 11.99 (s, 2H, -NH-), $8.16(\mathrm{~d}, 4 \mathrm{H}), 7.95(\mathrm{~d}, 4 \mathrm{H}), 7.54(\mathrm{~d}, 4 \mathrm{H}) .{ }^{13} \mathrm{C} \mathrm{NMR}\left(125 \mathrm{MHz}, \mathrm{DMF}-d_{7}\right), \delta$ (TMS, ppm): 197.46 (C=S), 196.93, 150.89, 145.21, 140.13, 136.80, 133.00, 131.45, 127.46, 127.42, $126.52,124.84,124.61,115.35$.

P7. A yellow solid was obtained in $93 \%$ yield. $M_{\mathrm{w}}=28600 \mathrm{~g} / \mathrm{mol}, M_{\mathrm{w}} / M_{\mathrm{n}}=1.53$. IR $(\mathrm{KBr}$ disk $), v\left(\mathrm{~cm}^{-1}\right): 3239,3023,1893,1656,1585,1490,1422,1345,1277,1175$, $1081,1037,1010,903,822,692,500 .{ }^{1} \mathrm{H}$ NMR (500 MHz, DMSO- $\left.d_{6}\right), \delta$ (TMS, ppm): $11.97\left(\mathrm{~s}, 2 \mathrm{H},-\mathrm{NH}^{-}\right), 8.21(\mathrm{~s}, 1 \mathrm{H}), 7.98(\mathrm{~d}, 2 \mathrm{H}), 7.92(\mathrm{~d}, 4 \mathrm{H}), 7.56(\mathrm{~s}, 1 \mathrm{H}), 7.43(\mathrm{~d}, 4 \mathrm{H})$. ${ }^{13} \mathrm{C}$ NMR (125 MHz, DMSO- $d_{6}$ ), $\delta$ (TMS, ppm): 196.72 (C=S), 142.26, 139.33, $132.26,131.00,129.99,128.05,126.11,124.97$.

P9. A yellow solid was obtained in $85 \%$ yield. $M_{\mathrm{w}}=16900 \mathrm{~g} / \mathrm{mol}, M_{\mathrm{w}} / M_{\mathrm{n}}=1.19$. IR (KBr disk), $v\left(\mathrm{~cm}^{-1}\right): 3270,3053,1684,1623,1590,1497,1424,1399,1338,1295$, 1182, 1148, 1103, 1071, 1013, 991, 906, 833, 763, 695, 639, 615, 555. ${ }^{1} \mathrm{H}$ NMR (400 MHz, DMSO- $d_{6}$ ), $\delta$ (TMS, ppm): 12.17 (s, $\left.2 \mathrm{H},-\mathrm{NH}-\right)$, 8.35-7.89, 7.57, 6.64, 6.19. ${ }^{13} \mathrm{C}$ NMR (125 MHz, DMSO- $\left.d_{6}\right), \delta$ (TMS, ppm): 197.82 (C=S), 197.58, 153.72, 144.32, $143.32,142.21,140.29,137.87,130.27,129.52,128.20,127.23,126.26,125.32$, $124.34,124.30,113.11$. 
P10. A yellow solid was obtained in $82 \%$ yield. $M_{\mathrm{w}}=16500 \mathrm{~g} / \mathrm{mol}, M_{\mathrm{w}} / M_{\mathrm{n}}=1.20$. IR (KBr disk), $v\left(\mathrm{~cm}^{-1}\right): 3242,3047,1645,1596,1514,1405,1343,1310,1278,1172$, 927, 853, 768, 690, 498. ${ }^{1} \mathrm{H}$ NMR (400 MHz, DMSO- $d_{6}$ ), $\delta$ (TMS, ppm): 12.18 (s, 2H, -NH-), 8.43-7.56, 6.63, 6.18. ${ }^{13} \mathrm{C}$ NMR (125 MHz, DMSO- $d_{6}$ ), $\delta$ (TMS, ppm): 197.38 $(\mathrm{C}=\mathrm{S}), 197.04,193.64,192.46,153.80,143.62$, 142.35, 134.39, 132.59, 130.37, 130.23, $129.48,128.09,126.16,123.76,123.31,123.20,119.62,112.62$.

P11. A dark yellow solid was obtained in $92 \%$ yield. $M_{\mathrm{w}}=22600 \mathrm{~g} / \mathrm{mol}, M_{\mathrm{w}} / M_{\mathrm{n}}=1.57$. IR (KBr disk), $v\left(\mathrm{~cm}^{-1}\right)$ : 3367, 3260, 3027, 2926, 2855, 1601, 1522, 1503, 1464, 1385, 1399, 1248, 1190, 1069, 1013, 943, 891, 849, 815, 743. ' H NMR (500 MHz, DMSO$\left.d_{6}\right), \delta(\mathrm{TMS}, \mathrm{ppm}): 10.33$ (s, -NH-, 2H), 7.95-7.38 (m, 14H), 3.77 (s, 4H), 1.77 (s, 4H), $1.57(\mathrm{~s}, 6 \mathrm{H}), 1.46(\mathrm{~s}, 4 \mathrm{H}) .{ }^{13} \mathrm{C}$ NMR (125 MHz, DMSO-d $), \delta$ (TMS, ppm): 196.31 $(\mathrm{C}=\mathrm{S}), 172.71,154.68,154.58,142.37,139.90,138.49,138.00,129.96,127.93,126.19$, 126.04, 121.23, 120.90, 46.87, 46.81, 46.21, 27.22, 26.82, 26.44.

P12. An orange solid was obtained in $95 \%$ yield. $M_{\mathrm{w}}=86200 \mathrm{~g} / \mathrm{mol}, M_{\mathrm{w}} / M_{\mathrm{n}}=2.09$. IR (KBr disk), $v\left(\mathrm{~cm}^{-1}\right):$ 3629, 3345, 3246, 3030, 2955, 1599, 1495, 1463, 1402, 1348 , 1242, 1211, 1164, 1114, 1037, 1010, 988, 876, 848, 814, 741, 624. ${ }^{1} \mathrm{H}$ NMR (500 MHz, DMSO- $\left.d_{6}\right), \delta$ (TMS, ppm): $11.84\left(\mathrm{~s}, 2 \mathrm{H},-\mathrm{NH}^{-}\right), 8.00-7.77,7.14,6.95,6.85,6.70,1.61$ (s, 6H). ${ }^{13} \mathrm{C}$ NMR (125 MHz, DMSO-d6), $\delta$ (TMS, ppm): 196.63 (C=S), 196.38, 154.77, 154.39 , 142.68, 141.08, 138.47, 138.10, 135.74, 128.24, 126.29, 126.11, 125.96, $121.29,120.99,120.88,118.53,116.39,115.77,46.94,26.85$.

The preparation of self-supporting thin film of P8. $1.0 \mathrm{~g}$ of P8 $\left(M_{\mathrm{w}}=27300 \mathrm{~g} / \mathrm{mol}\right)$ was dissolved in $10 \mathrm{~mL}$ of DMAc to form a clear solution. The solution was dropped and spread evenly on a copper sheet with a diameter of $2 \mathrm{~cm}$, and the solvent was slowly dried at $110{ }^{\circ} \mathrm{C}$. After baked for $4 \mathrm{~h}$ at $110^{\circ} \mathrm{C}$ until the solvent was evaporated. The copper sheet and the polymer film were gradually cooled to room temperature, and the film could be peeled off with a blade to form a self-supporting, smooth film with a diameter of $2 \mathrm{~cm}$.

\section{Procedures for gold enrichment and recovery test.}

(a) Gold extraction with different dosages of polythioamides. Into $10 \mathrm{~mL}$ aqueous solution of $\mathrm{Au}^{3+}$ with a concentration of $100 \mathrm{mg} / \mathrm{L}$ (the gold standard solution with 
the concentration of $1000 \mathrm{mg} / \mathrm{L}$ was diluted with $5 \mathrm{wt} \% \mathrm{HCl}$ solution to furnish the resultant solution) was added $0,0.5,1,2,5$, or $10 \mathrm{mg}$ solid powders of P1, P5, or P8, respectively. After the mixtures were stirred at room temperature for $1 \mathrm{~h}$, the suspensions were centrifuged for $10 \mathrm{~min}$ with the spin rate of $8000 \mathrm{r} / \mathrm{min}$ and the solid was filtered by a filter membrane with an aperture of $0.22 \mu \mathrm{m}$. The remaining concentration of $\mathrm{Au}^{3+}$ in the supernatant was then measured by AAS to calculate the extraction efficiency. The extraction efficiency of polymers was calculated to be $\eta=\left(\left[\mathrm{M}^{\mathrm{n}+}\right]_{0}-\left[\mathrm{M}^{\mathrm{n}+}\right]\right) /\left[\mathrm{M}^{\mathrm{n}+}\right]_{0} \times 100 \%$, where $\left[\mathrm{M}^{\mathrm{n}+}\right]_{0}$ is the initial concentration of metal ion, and $\left[\mathrm{M}^{\mathrm{n}+}\right]$ is the remaining concentration of metal ion. The extraction capacity of polymers was calculated to be $\mathrm{V}_{\mathrm{M}} \times\left[\mathrm{M}^{\mathrm{n}+}\right]_{0} \times \eta / \mathrm{m}_{\mathrm{p}}$, where $\mathrm{V}_{\mathrm{M}}$ is the volume of the gold solution, $\mathrm{m}_{\mathrm{p}}$ is the weight of the polymer.

(b) Time-dependent gold extraction. Into $10 \mathrm{~mL}$ aqueous solution of $\mathrm{Au}^{3+}(100 \mathrm{mg} / \mathrm{L})$ were added $10 \mathrm{mg}$ solid powders of P5 and P8, respectively. After the mixtures were stirred at room temperature for $1,2,5,10,20,30,40$, and $60 \mathrm{~min}$, respectively, the suspensions were centrifuged for $10 \mathrm{~min}$ with the spin rate of $8000 \mathrm{r} / \mathrm{min}$ and the solid was filtered by a filter membrane with an aperture of $0.22 \mu \mathrm{m}$. The remaining concentration of $\mathrm{Au}^{3+}$ in the supernatant was then measured by AAS to calculate the extraction efficiency.

(c) Sensitivity test of gold extraction. The gold standard solution (1000 mg/L) was diluted with $5 \mathrm{wt} \% \mathrm{HCl}$ solution to furnish solutions with different concentrations of $100 \mathrm{mg} / \mathrm{L}, 50 \mathrm{mg} / \mathrm{L}, 10 \mathrm{mg} / \mathrm{L}, 1 \mathrm{mg} / \mathrm{L}, 100 \mu \mathrm{g} / \mathrm{L}$, or $10 \mu \mathrm{g} / \mathrm{L}$. Into these solutions were added 300, 150, 30, 3, 0.3, or $0.03 \mu \mathrm{L}$ of DMF solution of P8 (33.3 mg/mL), respectively. After the mixtures were stirred at room temperature for $1 \mathrm{~h}$, the suspensions were centrifuged for $10 \mathrm{~min}$ with the spin rate of $8000 \mathrm{r} / \mathrm{min}$ and the solid was filtered by a filter membrane with an aperture of $0.22 \mu \mathrm{m}$. The remaining concentration of $\mathrm{Au}^{3+}$ in the supernatant was then measured by AAS to calculate the extraction efficiency.

(d) Selectivity test with single metal ion. Into $10 \mathrm{~mL}$ aqueous solutions of $\mathrm{NaCl}, \mathrm{KCl}$, $\mathrm{ZnCl}_{2}, \quad \mathrm{CoCl}_{2}, \quad \mathrm{~Pb}\left(\mathrm{NO}_{3}\right)_{2}, \mathrm{CuCl}_{2}, \mathrm{CdCl}_{2}, \quad \mathrm{MnCl}_{2}, \quad \mathrm{NiCl}_{2} \cdot 6 \mathrm{H}_{2} \mathrm{O}, \quad \mathrm{MgCl}_{2}$, $\mathrm{Ca}\left(\mathrm{NO}_{3}\right)_{2} \cdot 4 \mathrm{H}_{2} \mathrm{O}, \mathrm{FeCl}_{3}, \mathrm{CeCl}_{3} \cdot 7 \mathrm{H}_{2} \mathrm{O}, \mathrm{CrCl}_{3} \cdot 6 \mathrm{H}_{2} \mathrm{O}, \mathrm{HgCl}_{2}$, and $\mathrm{AuCl}_{3}\left(\left[\mathrm{M}^{\mathrm{n}+}\right]=100\right.$ 
$\mathrm{mg} / \mathrm{L}$, with $5 \mathrm{wt} \% \mathrm{HNO}_{3}$ ) were added $10 \mathrm{mg}$ solid powder of P8, respectively. After the mixtures were stirred at room temperature for $1 \mathrm{~h}$, the suspensions were centrifuged for 10 min with the spin rate of $8000 \mathrm{r} / \mathrm{min}$ and the solid was filtered by a filter membrane with an aperture of $0.22 \mu \mathrm{m}$. The remaining concentration of metal ions in the supernatant was then measured by AAS, atomic fluorescence spectrometer, or UV-vis spectrophotometer to calculate the extraction efficiency.

(e) Selectivity test with mixed metal ions. Into $10 \mathrm{~mL}$ aqueous solution including $\mathrm{NaCl}, \mathrm{KCl}, \mathrm{ZnCl}_{2}, \mathrm{CoCl}_{2}, \mathrm{~Pb}\left(\mathrm{NO}_{3}\right)_{2}, \mathrm{CuCl}_{2}, \mathrm{CdCl}_{2}, \mathrm{MnCl}_{2}, \mathrm{NiCl}_{2} \cdot 6 \mathrm{H}_{2} \mathrm{O}, \mathrm{MgCl}_{2}$, $\mathrm{Ca}\left(\mathrm{NO}_{3}\right)_{2} \cdot 4 \mathrm{H}_{2} \mathrm{O}, \mathrm{FeCl}_{3}, \mathrm{CeCl}_{3} \cdot 7 \mathrm{H}_{2} \mathrm{O}, \mathrm{CrCl}_{3} \cdot 6 \mathrm{H}_{2} \mathrm{O}, \mathrm{HgCl}_{2}$, and $\mathrm{AuCl}_{3}\left(\left[\mathrm{M}^{\mathrm{n}+}\right]=100\right.$ $\mathrm{mg} / \mathrm{L}$ for each metal ion, with $5 \mathrm{wt} \% \mathrm{HNO}_{3}$ ) was added $10 \mathrm{mg}$ solid powder of P8. After the mixtures were stirred at room temperature for $1 \mathrm{~h}$, the suspensions were centrifuged for $10 \mathrm{~min}$ with the spin rate of $8000 \mathrm{r} / \mathrm{min}$ and the solid was filtered by a filter membrane with an aperture of $0.22 \mu \mathrm{m}$. The remaining concentration of $\mathrm{Au}^{3+}$ in the supernatant was then measured by AAS to calculate the extraction efficiency.

(f) Gold extraction from electronic waste. From a discarded CPU from Intel Corporation, $0.30 \mathrm{~g}$ of metal scraps were obtained. The solution of pyridine (12.0 mmol, $0.97 \mathrm{~mL}$ ) and NBS (4.2 mmol, $0.75 \mathrm{~g}$ ) in $119 \mathrm{~mL}$ of deionized water was used to soak the scraps for 3 days to form a blue solution. The initial concentrations of $\mathrm{Cu}^{2+}, \mathrm{Ni}^{2+}$, and $\mathrm{Au}^{3+}$ were measured by AAS. After $10 \mathrm{mg}$ of $\mathrm{P} 8$ was added into $2 \mathrm{~mL}$ of the leaching solution, the mixtures were stirred at room temperature for 1 $\mathrm{h}$. The suspension was then centrifuged for $10 \mathrm{~min}$ with the spin rate of $8000 \mathrm{r} / \mathrm{min}$ and the solid was filtered by a filter membrane with an aperture of $0.22 \mu \mathrm{m}$. The remaining concentration of $\mathrm{Cu}^{2+}, \mathrm{Ni}^{2+}$, and $\mathrm{Au}^{3+}$ in the supernatant was then measured by AAS to calculate the extraction efficiency.

(g) Gold extraction under different $\mathbf{p H}$ conditions. Aqueous solutions with different $\mathrm{pH}$ values of $0.10,1.00,4.00$ and 7.00 were prepared by mixing dilute hydrochloric acid and sodium hydroxide solution with different proportions. Into $10 \mathrm{~mL}$ of each solution, $10 \mu \mathrm{L}$ aqueous solution of $\mathrm{AuCl}_{3}\left(\left[\mathrm{Au}^{3+}\right]=0.10 \mathrm{mg} / \mathrm{mL}\right)$ was added, respectively. After the mixtures were stirred at room temperature for $1 \mathrm{~h}$, the suspensions were centrifuged for $10 \mathrm{~min}$ with the spin rate of $8000 \mathrm{r} / \mathrm{min}$ and the 
solid was filtered by a filter membrane with an aperture of $0.22 \mu \mathrm{m}$. The remaining concentration of $\mathrm{Au}^{3+}$ in the supernatant was then measured by AAS to calculate the extraction efficiency.

(h) Gold recovery by pyrolysis. Into $200 \mathrm{~mL}$ of $\mathrm{Au}^{3+}$ solution $\left(\left[\mathrm{Au}^{3+}\right]=1000 \mathrm{mg} / \mathrm{L}\right)$ was added $250 \mathrm{mg}$ P8. The precipitate was centrifuged for $10 \mathrm{~min}$ with the spin rate of $8000 \mathrm{r} / \mathrm{min}$ and after the supernatant was removed, the solid was dried at $40{ }^{\circ} \mathrm{C}$ under vacuum oven overnight to afford $363 \mathrm{mg}$ yellow solid. The solid was then pyrolyzed in air at $1000{ }^{\circ} \mathrm{C}$ for $4 \mathrm{~h}$ with the heating rate of $10^{\circ} \mathrm{C} / \mathrm{min}$ to afford 109 mg yellow product with metallic luster, and the gold content of the sample was 91.64 wt $\%$ measured by AAS.

Table S1. Effect of monomer ratio on the $\mathrm{MCP}^{a}$

\begin{tabular}{ccccc}
\hline entry & $\begin{array}{c}1 / 8\left[\mathrm{~S}_{8}\right]:[\mathbf{2 a}]: \\
{[\mathbf{3 a}]}\end{array}$ & yield $(\%)$ & $M_{\mathrm{w}}(\mathrm{g} / \mathrm{mol})^{b}$ & $M_{\mathrm{w}} / M_{\mathrm{n}}{ }^{b}$ \\
\hline 1 & $2.0: 1.0: 1.0$ & 27 & 22500 & 1.62 \\
2 & $4.0: 1.0: 1.0$ & 28 & 24900 & 1.34 \\
3 & $4.0: 1.3: 1.0$ & 56 & 42700 & 1.66 \\
4 & $4.0: 1.5: 1.0$ & 78 & 47900 & 1.76 \\
5 & $4.0: 2.0: 1.0$ & 86 & 33000 & 1.65 \\
6 & $4.0: 3.0: 1.0$ & 68 & 16800 & 1.22 \\
7 & $4.0: 0.6: 1.0$ & 22 & 15200 & 1.36 \\
8 & $4.0: 0.8: 1.0$ & 25 & 19300 & 1.42 \\
$9^{c}$ & $4.0: 1.0: 1.0$ & 58 & 29700 & 1.67 \\
10 & $2.0: 1.5: 1.0$ & 58 & 32900 & 1.53 \\
11 & $3.0: 1.5: 1.0$ & 81 & 52300 & 1.90 \\
12 & $6.0: 1.5: 1.0$ & 56 & 27600 & 1.45
\end{tabular}

${ }^{a}$ Carried out at $100{ }^{\circ} \mathrm{C}$ under nitrogen in DMSO for $10 \mathrm{~h}$ and the yield was calculated based on the diamine monomer 3a. $[3 \mathbf{a}]=0.5 \mathrm{M} .{ }^{b} M_{\mathrm{w}}$ was determined by GPC in DMF based on polystyrene standard samples. ${ }^{c}$ Carried out in the presence of $0.5 \mathrm{M}$ benzoic acid. 
Table S2. Effect of monomer concentration on the $\mathrm{MCP}^{a}$

\begin{tabular}{ccccc}
\hline entry & {$[\mathbf{3 a}](\mathrm{M})$} & yield $(\%)$ & $M_{\mathrm{w}}(\mathrm{g} / \mathrm{mol})^{b}$ & $M_{\mathrm{w}} / M_{\mathrm{n}}{ }^{b}$ \\
\hline 1 & 0.1 & 38 & 17600 & 1.25 \\
2 & 0.3 & 77 & 28300 & 1.41 \\
3 & 0.4 & 75 & 35100 & 1.76 \\
$4^{c}$ & 0.5 & 81 & 52300 & 1.90 \\
5 & 0.6 & 79 & 52200 & 2.03 \\
6 & 0.8 & 72 & 40600 & 1.79 \\
7 & 1.0 & 69 & 43600 & 1.83
\end{tabular}

${ }^{a}$ Carried out at $100{ }^{\circ} \mathrm{C}$ under nitrogen in DMSO for $10 \mathrm{~h}$ and the yield was calculated based on the diamine monomer 3a. 1/8[ $\left.\mathrm{S}_{8}\right]:[\mathbf{2 a}]:[\mathbf{3 a}]=3.0: 1.5: 1.0 .{ }^{b} M_{\mathrm{w}}$ was determined by GPC in DMF based on polystyrene standard samples. ${ }^{c}$ Data were taken from Table S1, entry 11.

Table S3. Effect of polymerization time on the $\mathrm{MCP}^{a}$

\begin{tabular}{ccccc}
\hline entry & $t(\mathrm{~h})$ & yield $(\%)$ & $M_{\mathrm{w}}(\mathrm{g} / \mathrm{mol})^{b}$ & $M_{\mathrm{w}} / M_{\mathrm{n}}{ }^{b}$ \\
\hline 1 & 5 & 20 & 16900 & 1.24 \\
$2^{c}$ & 10 & 81 & 52300 & 1.90 \\
3 & 15 & 96 & 54600 & 2.06 \\
4 & 20 & 95 & 54300 & 2.18
\end{tabular}

${ }^{a}$ Carried out at $100{ }^{\circ} \mathrm{C}$ under nitrogen in DMSO and the yield was calculated based on the diamine monomer 3a. $1 / 8\left[\mathrm{~S}_{8}\right]:[\mathbf{2 a}]:[\mathbf{3 a}]=3.0: 1.5: 1.0,[\mathbf{3 a}]=0.5 \mathrm{M} .{ }^{b} M_{\mathrm{w}}$ was determined by GPC in DMF based on polystyrene standard samples. ${ }^{c}$ Data were taken from Table S1, entry 11.

Table S4. Effect of temperature on the $\mathrm{MCP}^{a}$

\begin{tabular}{ccccc}
\hline entry & $T\left({ }^{\circ} \mathrm{C}\right)$ & yield $(\%)$ & $M_{\mathrm{w}}(\mathrm{g} / \mathrm{mol})^{b}$ & $M_{\mathrm{w}} / M_{\mathrm{n}}{ }^{b}$ \\
\hline 1 & 90 & 37 & 19700 & 1.29 \\
$2^{c}$ & 100 & 96 & 54600 & 2.06 \\
3 & 120 & 94 & 26600 & 1.42
\end{tabular}

${ }^{a}$ Carried out under nitrogen in DMSO for $15 \mathrm{~h}$ and the yield was calculated based on the diamine monomer 3a. $1 / 8\left[\mathrm{~S}_{8}\right]$ : $[2 \mathrm{a}]:[3 \mathrm{a}]=3.0: 1.5: 1.0,[3 \mathrm{a}]=0.5 \mathrm{M} .{ }^{b} M_{\mathrm{w}}$ was determined by GPC in DMF based on polystyrene standard samples. ${ }^{c}$ Data were taken from Table S3, entry 3. 
Table S5. Effect of different monomers on the polymerization ${ }^{a}$

\begin{tabular}{|c|c|c|c|c|c|}
\hline entry & polymer & monomers & yield $(\%)$ & $M_{\mathrm{w}}(\mathrm{g} / \mathrm{mol})^{b}$ & $M_{\mathrm{w}} / M_{\mathrm{n}}{ }^{b}$ \\
\hline 1 & P1 & $\mathbf{1}+\mathbf{2 a}+\mathbf{3 a}$ & 96 & 54600 & 2.06 \\
\hline 2 & $\mathrm{P} 2$ & $\mathbf{1}+\mathbf{2} \mathbf{b}+\mathbf{3 a}$ & 39 & 13600 & 1.14 \\
\hline 3 & $\mathrm{P3}$ & $1+2 a+3 b$ & 78 & 31300 & 1.40 \\
\hline 4 & P4 & $1+2 a+3 c$ & 85 & 18700 & 1.29 \\
\hline $5^{c}$ & P5 & $1+2 a+3 d$ & 85 & 14900 & 1.20 \\
\hline $6^{d}$ & P6 & $1+2 a+3 f$ & 69 & 18200 & 1.32 \\
\hline $7^{e}$ & P7 & $1+2 b+3 f$ & 93 & 28600 & 1.53 \\
\hline $8^{e}$ & P8 & $1+2 b+3 e$ & 99 & 49400 & 1.89 \\
\hline $9^{e}$ & P9 & $1+2 b+3 g$ & 85 & 16900 & 1.19 \\
\hline $10^{e}$ & P10 & $1+2 b+3 h$ & 82 & 16500 & 1.20 \\
\hline 11 & P11 & $1+2 c+3 a$ & 92 & 22600 & 1.57 \\
\hline $12^{f}$ & $\mathrm{P} 12$ & $1+2 c+3 e$ & 95 & 86200 & 2.09 \\
\hline
\end{tabular}

${ }^{a}$ Carried out at $100{ }^{\circ} \mathrm{C}$ under nitrogen in DMSO for $15 \mathrm{~h}$ and the yield was calculated based on the diamine monomers. $[\mathbf{3 a}-\mathbf{h}]=0.5 \mathrm{M} .1 / 8\left[\mathrm{~S}_{8}\right]:[\mathbf{2 a - c}]:[\mathbf{3 a}-\mathbf{c}]=3.0: 1.5: 1.0$. ${ }^{b} M_{\mathrm{w}}$ was determined by GPC in DMF based on polystyrene standard samples. ${ }^{c}$ Reacted for $5 \mathrm{~h}$ with $0.1 \mathrm{M} \mathrm{K}_{2} \mathrm{CO}_{3} .1 / 8\left[\mathrm{~S}_{8}\right]$ : [2a]: [3d] = 3.0: 1.0: 1.0. ${ }^{d}$ Reacted for $12 \mathrm{~h}$ with 0.1 $\mathrm{M} \mathrm{K}_{2} \mathrm{CO}_{3} .1 / 8\left[\mathrm{~S}_{8}\right]$ : [2a]: [3f] $=3.0: 1.0: 1.0 .{ }^{e}$ Reacted for $25 \mathrm{~h}$ with $0.1 \mathrm{M} \mathrm{K}_{2} \mathrm{CO}_{3}$. $1 / 8\left[\mathrm{~S}_{8}\right]:[\mathbf{2 b}]:[3 \mathbf{e}-\mathbf{h}]=3.0: 1.0: 1.0 .{ }^{f}$ Reacted for $12 \mathrm{~h}$ with $0.1 \mathrm{M} \mathrm{K}_{2} \mathrm{CO}_{3} .1 / 8\left[\mathrm{~S}_{8}\right]:[\mathbf{2 c}]$ : $[3 \mathbf{e}]=3.0: 1.0: 1.0$.

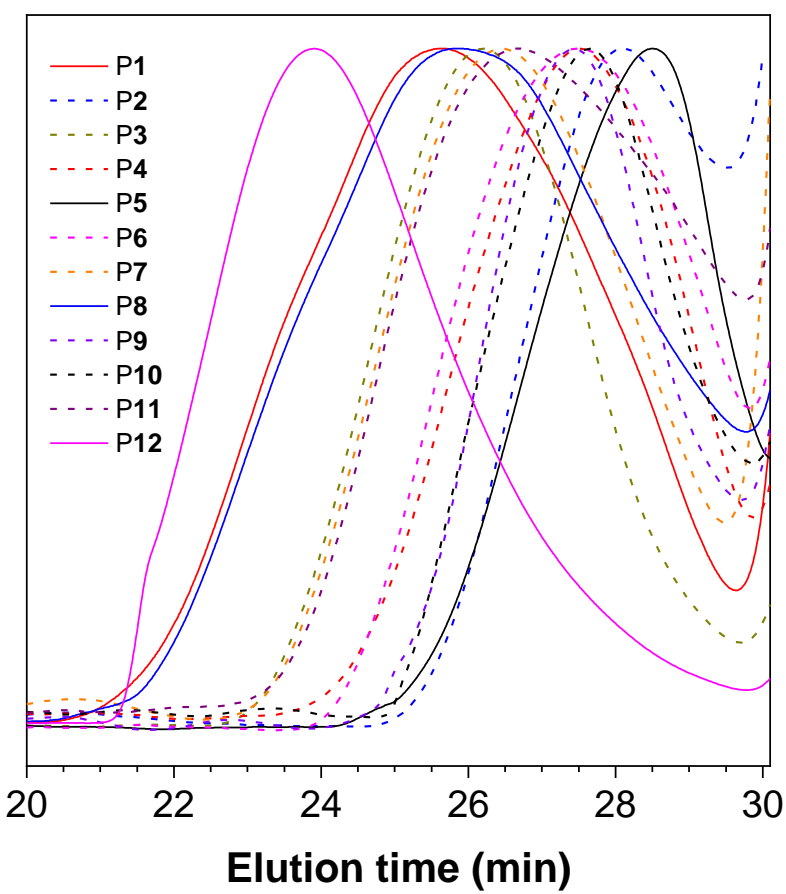

Figure S1. GPC curves of polymers P1-P12. 


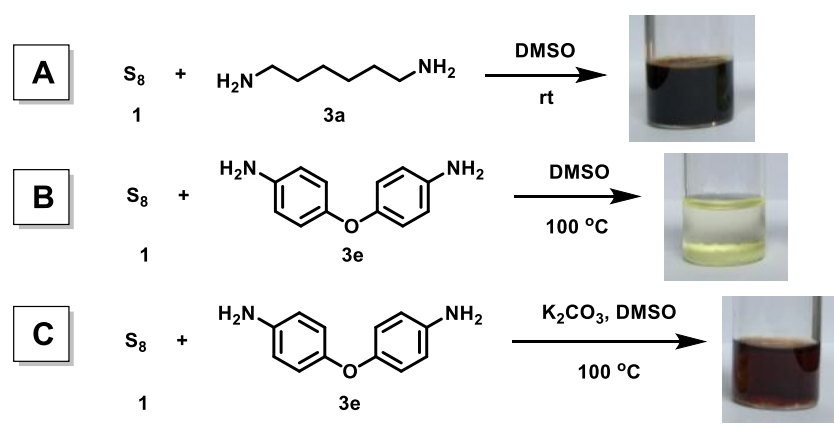

Figure S2. (A) The reaction between 1 and 3a in DMSO at room temperature and the reaction phenomena. (B) The reaction between 1 and $3 \mathrm{e}$ in DMSO at $100{ }^{\circ} \mathrm{C}$ and the reaction phenomena. (C) The reaction between $\mathbf{1}, \mathbf{3 e}$ and $\mathrm{K}_{2} \mathrm{CO}_{3}$ in DMSO at $100{ }^{\circ} \mathrm{C}$ and the reaction phenomena.

Table S6. Effect of base on the polymerization of $\mathbf{1}, \mathbf{2} \mathbf{b}$, and $\mathbf{3 e} \mathbf{e}^{a}$

\begin{tabular}{llccl}
\hline entry & base & yield $(\%)$ & $M_{\mathrm{w}}(\mathrm{g} / \mathrm{mol})^{b}$ & $M_{\mathrm{w}} / M_{\mathrm{n}}{ }^{b}$ \\
\hline 1 & $\mathrm{~K}_{2} \mathrm{CO}_{3}$ & 99 & 49400 & 1.89 \\
2 & $\mathrm{KOH}$ & 36 & 8100 & 1.25 \\
3 & $\mathrm{Na}_{2} \mathrm{CO}_{3}$ & 97 & 29100 & 1.80 \\
4 & $\mathrm{KF}$ & 99 & 17300 & 1.52 \\
5 & $t-\mathrm{BuOK}_{6}$ & 75 & 18100 & 1.56 \\
6 & $\mathrm{Cs}_{2} \mathrm{CO}_{3}$ & 96 & 34800 & 1.91 \\
7 & $\mathrm{DABCO}$ & 94 & 37600 & 2.48
\end{tabular}

${ }^{a}$ Carried out at $100{ }^{\circ} \mathrm{C}$ under nitrogen in DMSO for $25 \mathrm{~h}$ and the yield was calculated based on the diamine monomer 3e. [base] $=0.1 \mathrm{M}, 1 / 8\left[\mathrm{~S}_{8}\right]:[\mathbf{2 b}]:[3 \mathbf{e}]=3.0: 1.0: 1.0$, $[\mathbf{2 b}]=[3 \mathbf{e}]=0.5 \mathrm{M} \cdot{ }^{b} M_{\mathrm{w}}$ is determined by GPC in DMF based on polystyrene standard samples.

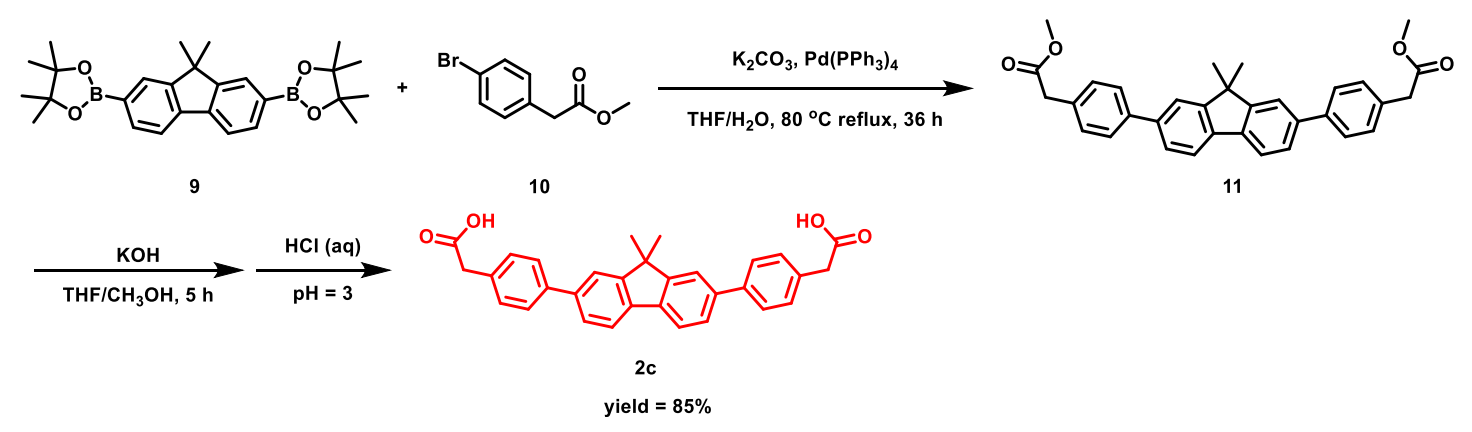

Scheme S1. The synthetic routes of monomer 2 c. 
Table S7. Effect of different scales on the $\mathrm{MCP}^{a}$

\begin{tabular}{|c|c|c|c|c|c|c|c|c|c|}
\hline \multicolumn{4}{|c|}{$0.5 \mathrm{mmol} \mathrm{scale}^{b}$} & \multicolumn{3}{|c|}{$50 \mathrm{mmol} \mathrm{scale}{ }^{c}$} & \multicolumn{3}{|c|}{$100 \mathrm{mmol} \mathrm{scale}{ }^{d}$} \\
\hline & $\begin{array}{l}\text { yield } \\
(\%)\end{array}$ & $\begin{array}{l}M_{\mathrm{W}} \\
(\mathrm{g} / \mathrm{mol})^{e}\end{array}$ & $\begin{array}{l}M_{\mathrm{n}} \\
(\mathrm{g} / \mathrm{mol})^{e}\end{array}$ & $\begin{array}{l}\text { yield } \\
(\%)\end{array}$ & $\begin{array}{l}M_{\mathrm{w}} \\
(\mathrm{g} / \mathrm{mol})^{e}\end{array}$ & $\begin{array}{l}M_{\mathrm{n}} \\
(\mathrm{g} / \mathrm{mol})^{e}\end{array}$ & $\begin{array}{l}\text { yield } \\
(\%)\end{array}$ & $\begin{array}{c}M_{\mathrm{W}} \\
(\mathrm{g} / \mathrm{mol})^{e}\end{array}$ & $\begin{array}{l}M_{\mathrm{n}} \\
(\mathrm{g} / \mathrm{mol})^{e}\end{array}$ \\
\hline $\mathrm{P} 1$ & 96 & 26600 & 14700 & 99 & 27700 & 14800 & 98 & 33600 & 18200 \\
\hline $\mathrm{P}^{f}$ & 99 & 17600 & 11600 & 99 & 16500 & 10400 & 96 & 27300 & 14200 \\
\hline
\end{tabular}

${ }^{a}$ Carried out at $100{ }^{\circ} \mathrm{C}$ in air in DMSO for $15 \mathrm{~h}$ and the yield was calculated based on the diamine monomers. $1 / 8\left[\mathrm{~S}_{8}\right]:[\mathbf{2 a}]:[\mathbf{3 a}]=3.0: 1.5: 1.0 ; 1 / 8\left[\mathrm{~S}_{8}\right]:[\mathbf{2 b}]:[\mathbf{3 e}]=3.0: 1.0$ : $1.0 ;[\mathbf{3 a}]=[\mathbf{3 e}]=0.5 \mathrm{M} \cdot{ }^{b} 0.5 \mathrm{mmol}$ of $\mathbf{3 a}$ and $\mathbf{3 e}$ were used, respectively. ${ }^{c} 50 \mathrm{mmol}$ of 3a and $\mathbf{3 e}$ were used, respectively. ${ }^{d} 100 \mathrm{mmol}$ of $\mathbf{3 a}$ and $\mathbf{3 e}$ were used, respectively. ${ }^{e} M_{\mathrm{w}}$ and $M_{\mathrm{n}}$ were determined by GPC in DMF based on polystyrene standard samples. ${ }^{f}$ Carried out for $25 \mathrm{~h}$ in the presence of $\mathrm{K}_{2} \mathrm{CO}_{3},\left[\mathrm{~K}_{2} \mathrm{CO}_{3}\right]=20 \%[3 \mathbf{e}]$.

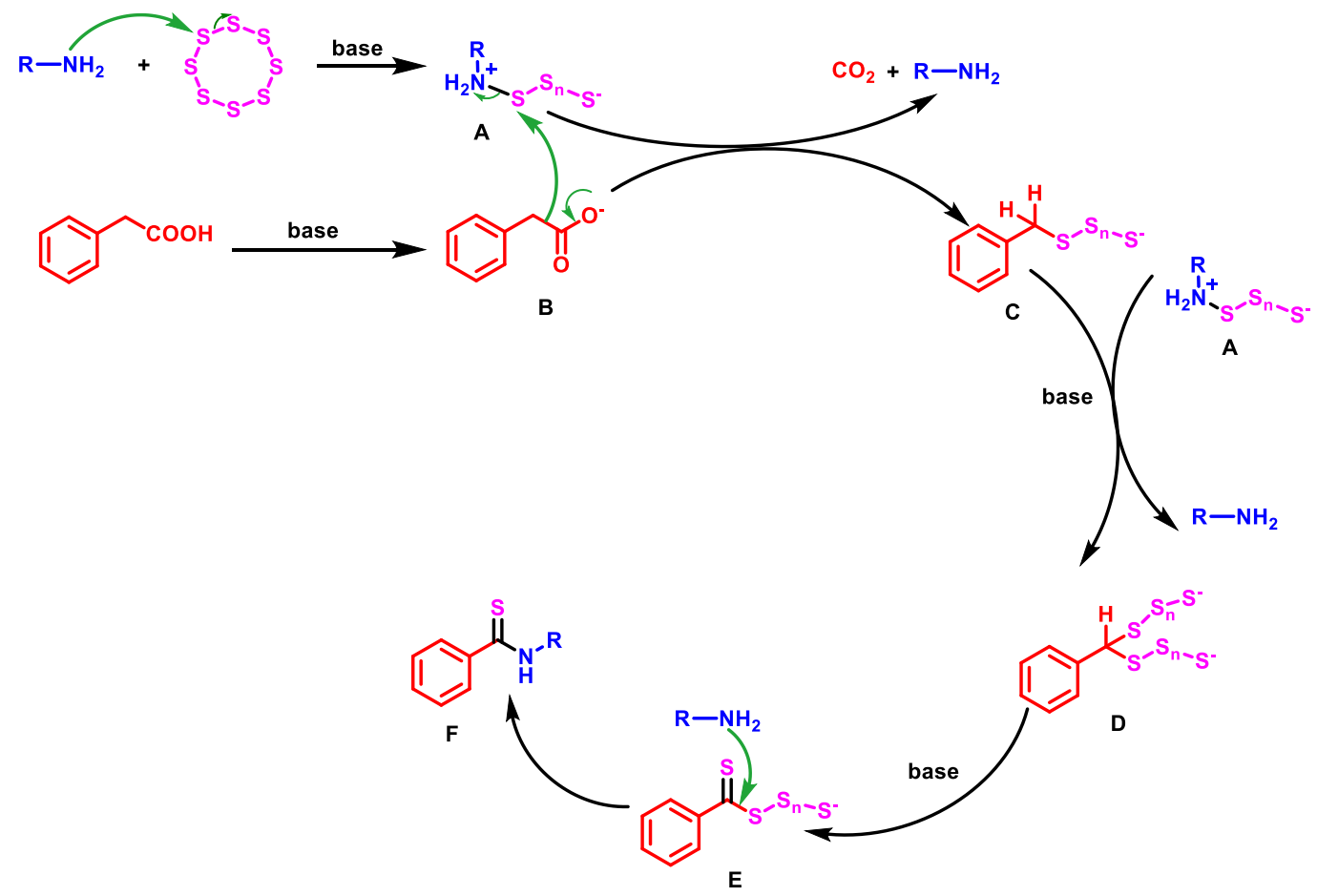

Scheme S2. The proposed mechanism for the reaction of sulfur, benzyl acid, and amine. 


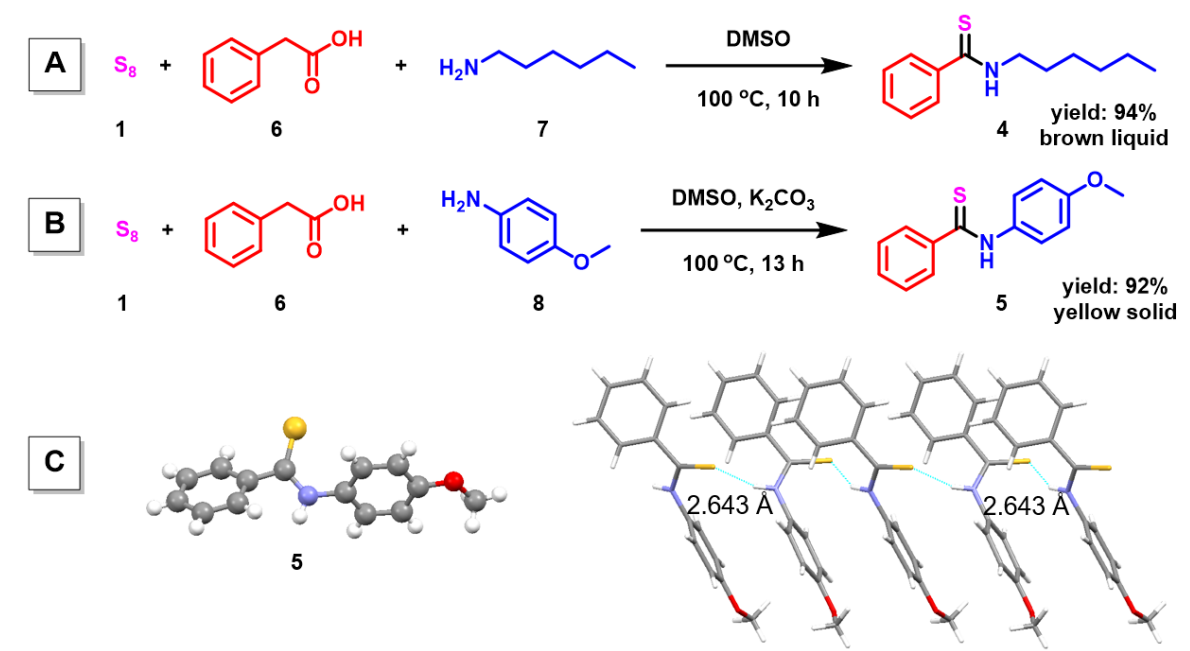

Figure S3. The synthetic routes of model compounds (A) 4 and (B) 5, (C) single crystal structure of model compound $\mathbf{5}$.

Table S8. Single crystal data and structure refinement for model compound $\mathbf{5}$

\begin{tabular}{|c|c|c|}
\hline CCDC number & \multicolumn{2}{|l|}{1959074} \\
\hline Empirical formula & \multicolumn{2}{|l|}{$\mathrm{C}_{14} \mathrm{H}_{13} \mathrm{NOS}$} \\
\hline Formula weight & \multicolumn{2}{|l|}{$243.31 \mathrm{~g} \mathrm{~mol}^{-1}$} \\
\hline Temperature & \multicolumn{2}{|l|}{$149.99(10) \mathrm{K}$} \\
\hline Wavelength & \multicolumn{2}{|l|}{$1.54184 \AA$} \\
\hline Crystal system, space group & \multicolumn{2}{|c|}{ Monoclinic, P 1 21/c 1} \\
\hline \multirow[t]{3}{*}{ Unit cell dimensions } & $\mathrm{a}=12.2884(4) \AA$ & $\alpha=90$ \\
\hline & $\mathrm{b}=12.8082(4) \AA$ & $\beta=106.568(4)$ \\
\hline & $\mathrm{c}=8.0660(3) \AA$ & $\gamma=90$ \\
\hline Volume & $1216.82(7) \AA^{3}$ & \\
\hline Z & 4 & \\
\hline Density (calculated) & $1.328 \mathrm{~g} \mathrm{~cm}^{-3}$ & \\
\hline Absorption coefficient & $2.207 \mathrm{~mm}^{-1}$ & \\
\hline $\mathrm{F}(000)$ & 512.0 & \\
\hline Crystal size & $0.06 \times 0.05 \times 0.04$ & \\
\hline Theta range for data collection & 6.6980 to 72.8230 & \\
\hline Index ranges & $-13<=\mathrm{h}<=14,-15<$ & $<=12,-9<=1<=9$ \\
\hline Reflections collected & 6249 & \\
\hline Independent reflections & $2140[\mathrm{R}(\mathrm{int})=0.02$ & \\
\hline Completeness to theta $=66.97^{\circ}$ & $98.29 \%$ & \\
\hline Absorption correction & Semi-empirical fro & equivalents \\
\hline Max. and min. transmission & 1.00000 and 0.768 & \\
\hline Refinement method & Full-matrix least-s & ares on $\mathrm{F}^{2}$ \\
\hline Data / restraints / parameters & $2140 / 0 / 155$ & \\
\hline Goodness-of-fit on $\mathrm{F}^{2}$ & 1.039 & \\
\hline Final R indices [I $>2 \operatorname{sigma}(\mathrm{I})]$ & $\mathrm{R} 1=0.0433, \mathrm{wR} 2$ & 0.1160 \\
\hline $\mathrm{R}$ indices (all data) & $\mathrm{R} 1=0.0507, \mathrm{wR} 2$ & 0.1208 \\
\hline Largest diff. peak and hole & 0.418 and $-0.250 \mathrm{e}$ & \\
\hline
\end{tabular}



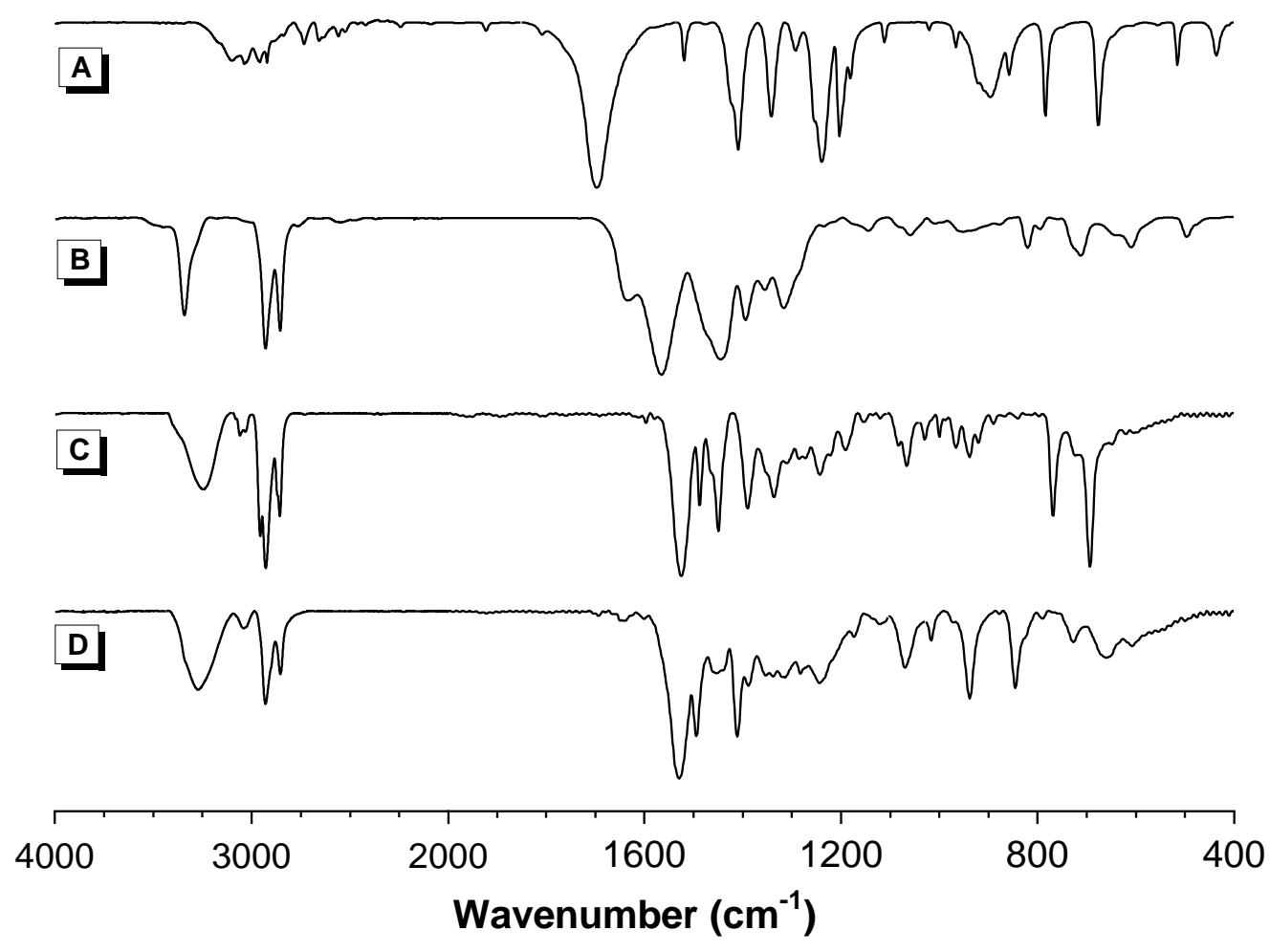

Figure S4. FT-IR spectra of (A) 2a, (B) 3a, (C) 4, and (D) P1.

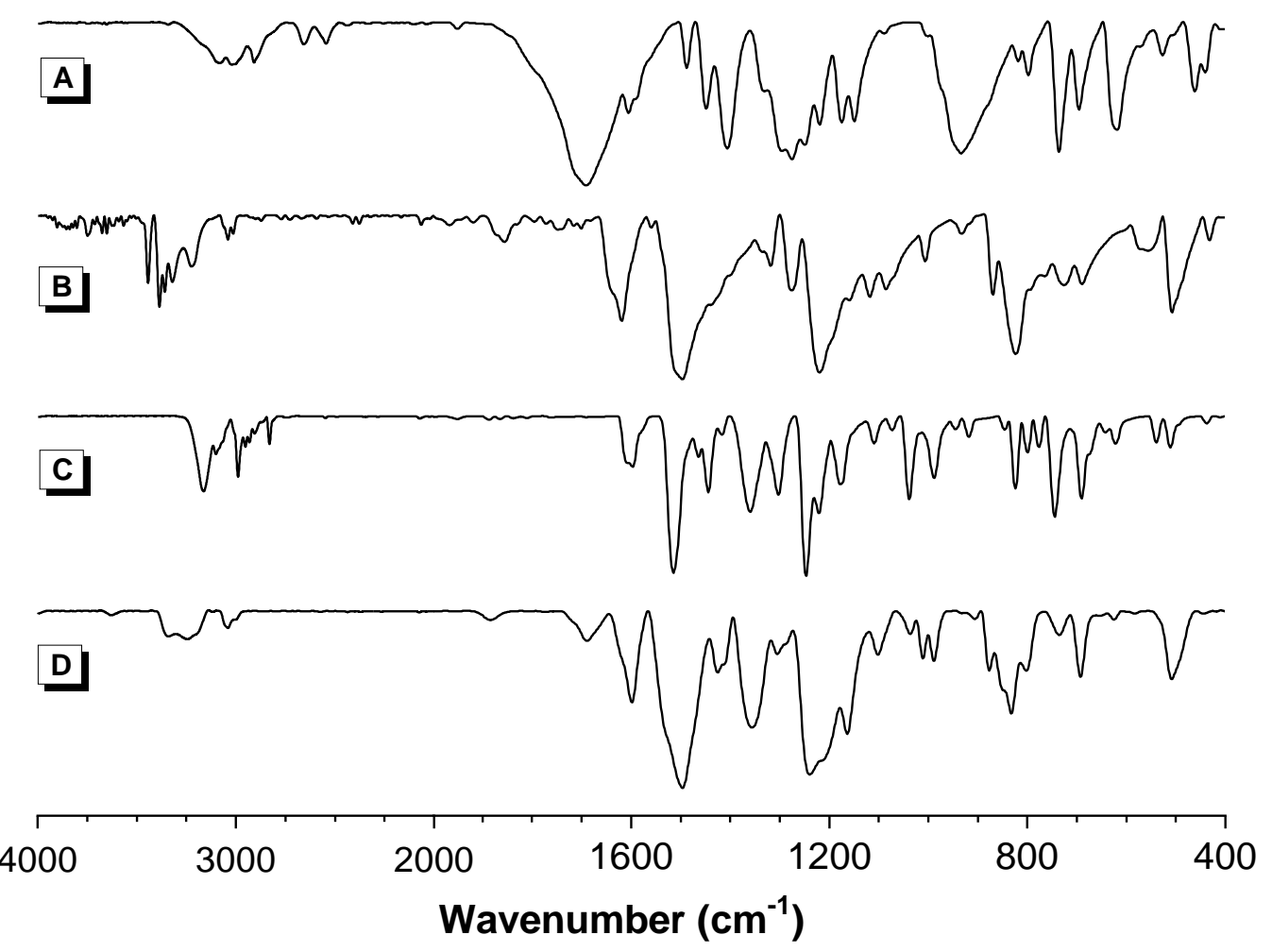

Figure S5. FT-IR spectra of (A) 2b, (B) 3e, (C) 5, and (D) P8. 


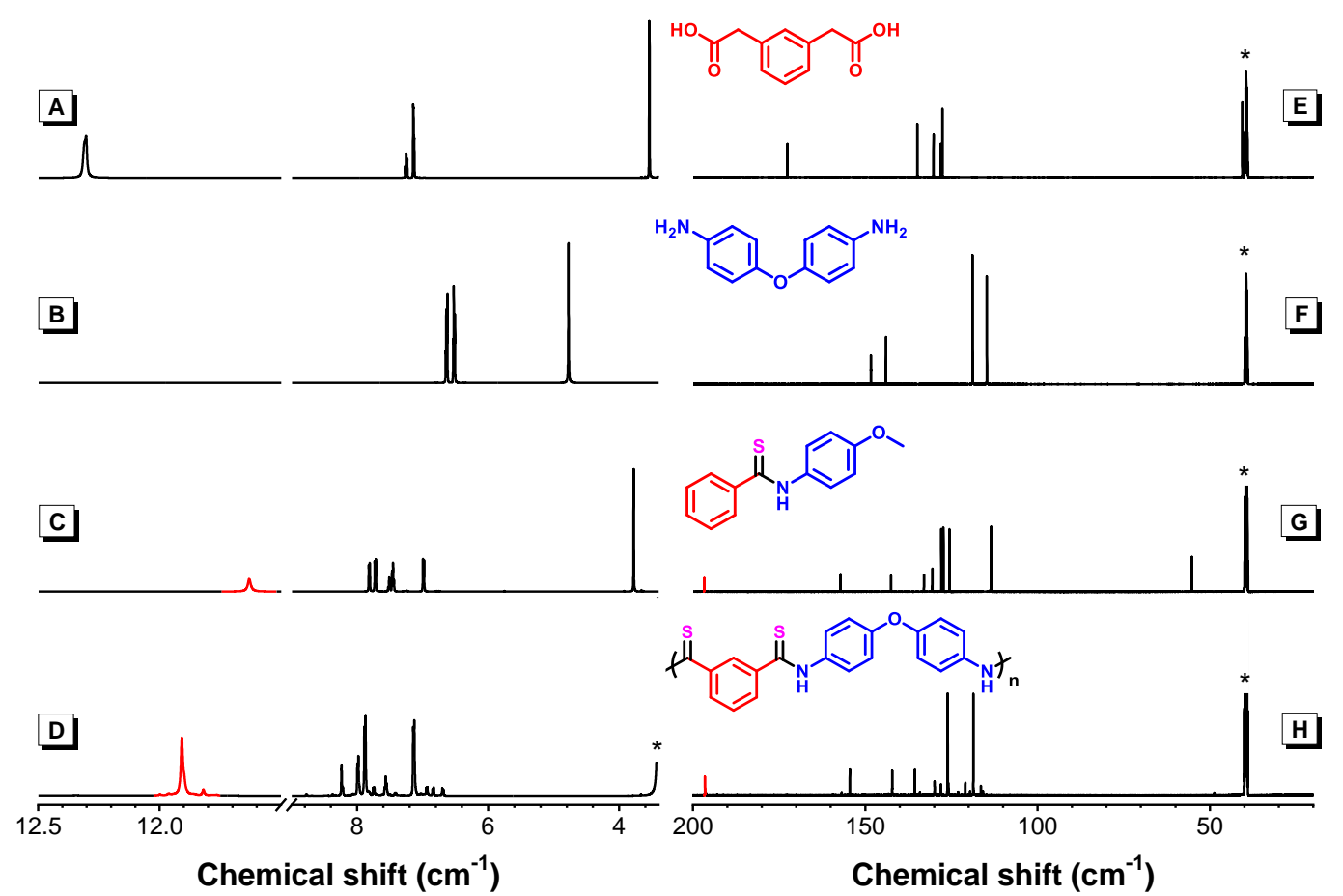

Figure S6. ${ }^{1} \mathrm{H}$ NMR spectra of (A) 2b, (B) 3e, (C) 5, and (D) P8 in DMSO-d6. ${ }^{13} \mathrm{C}$ NMR spectra of (E) 2b, (F) 3e, (G) 5, and (H) P8 in DMSO-d6. The solvent peaks were marked with asterisks.
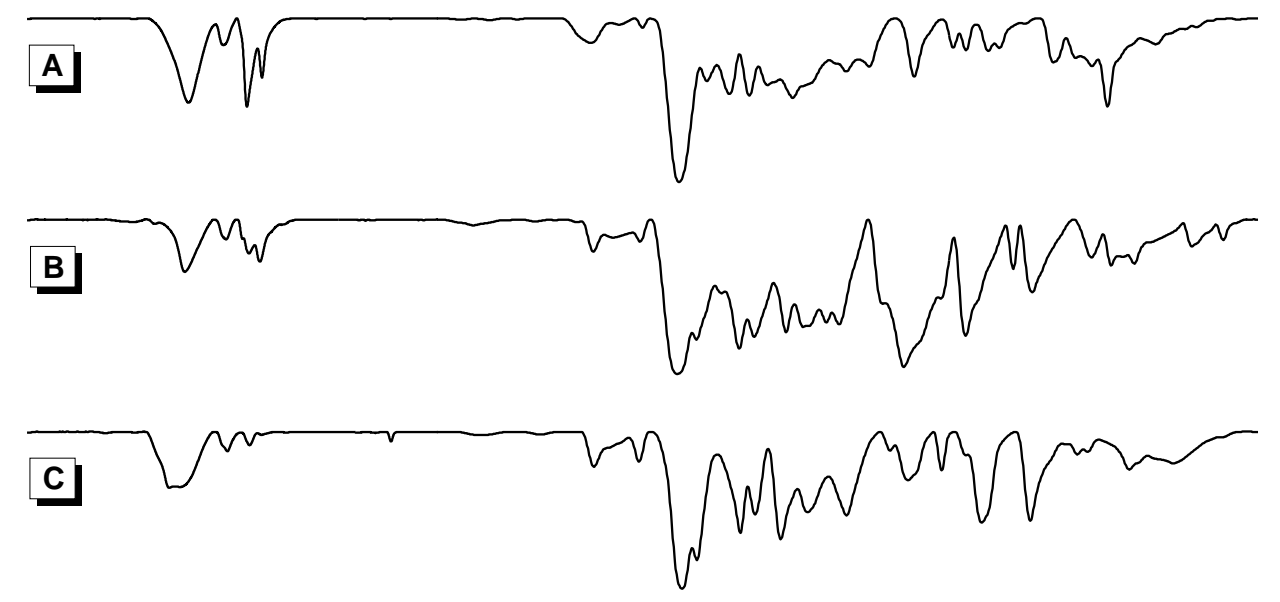

\begin{tabular}{|c|c|c|c|c|c|c|}
\hline 4000 & 3000 & 2000 & 1600 & 1200 & 800 & 400 \\
\hline \multicolumn{7}{|c|}{ Wavenumber $\left(\mathrm{cm}^{-1}\right)$} \\
\hline
\end{tabular}

Figure S7. FT-IR spectra of (A) P2, (B) P3, and (C) P4. 


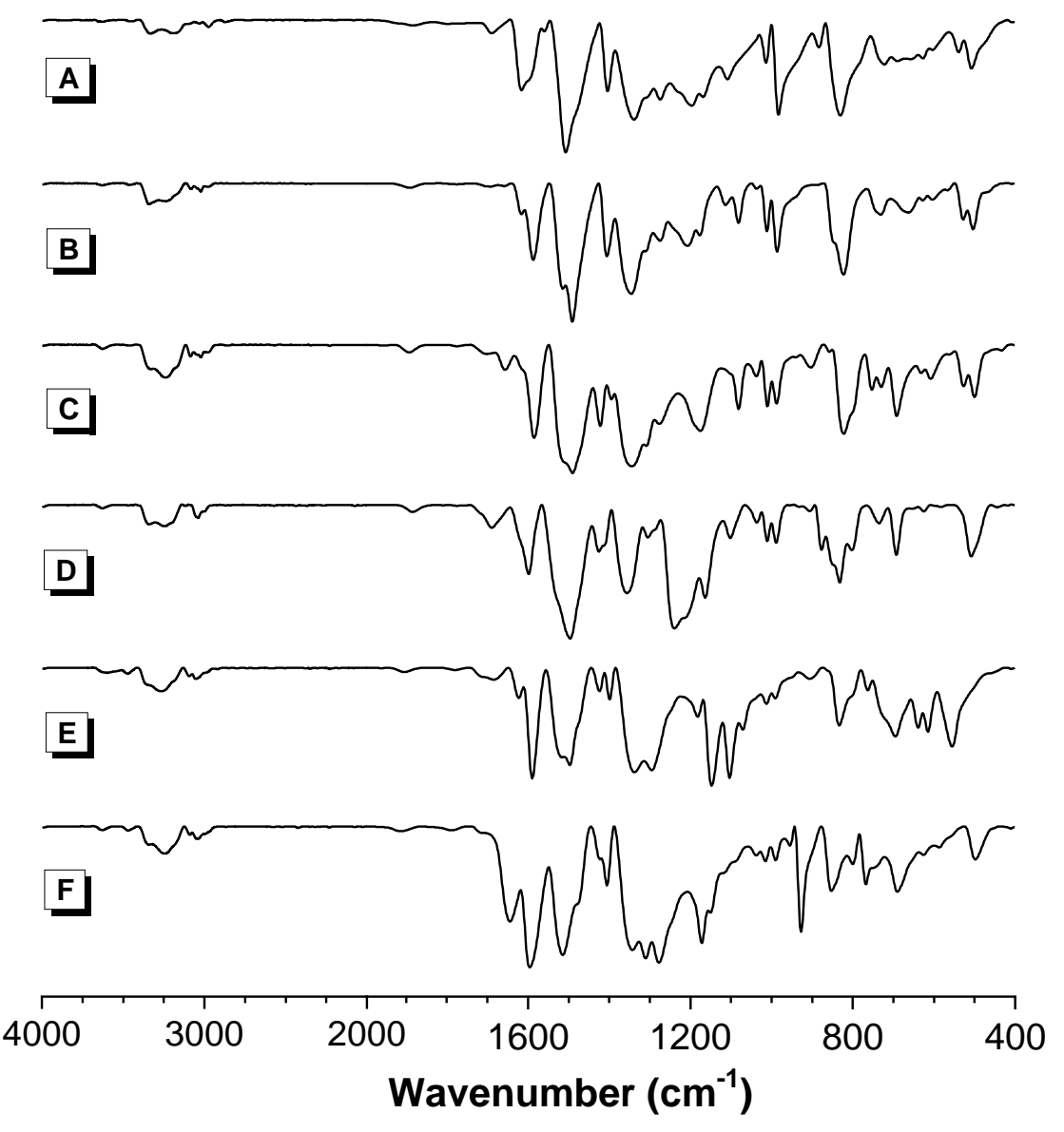

Figure S8. FT-IR spectra of (A) P5, (B) P6, (C) P7, (D) P8, (E) P9, and (F) P10.

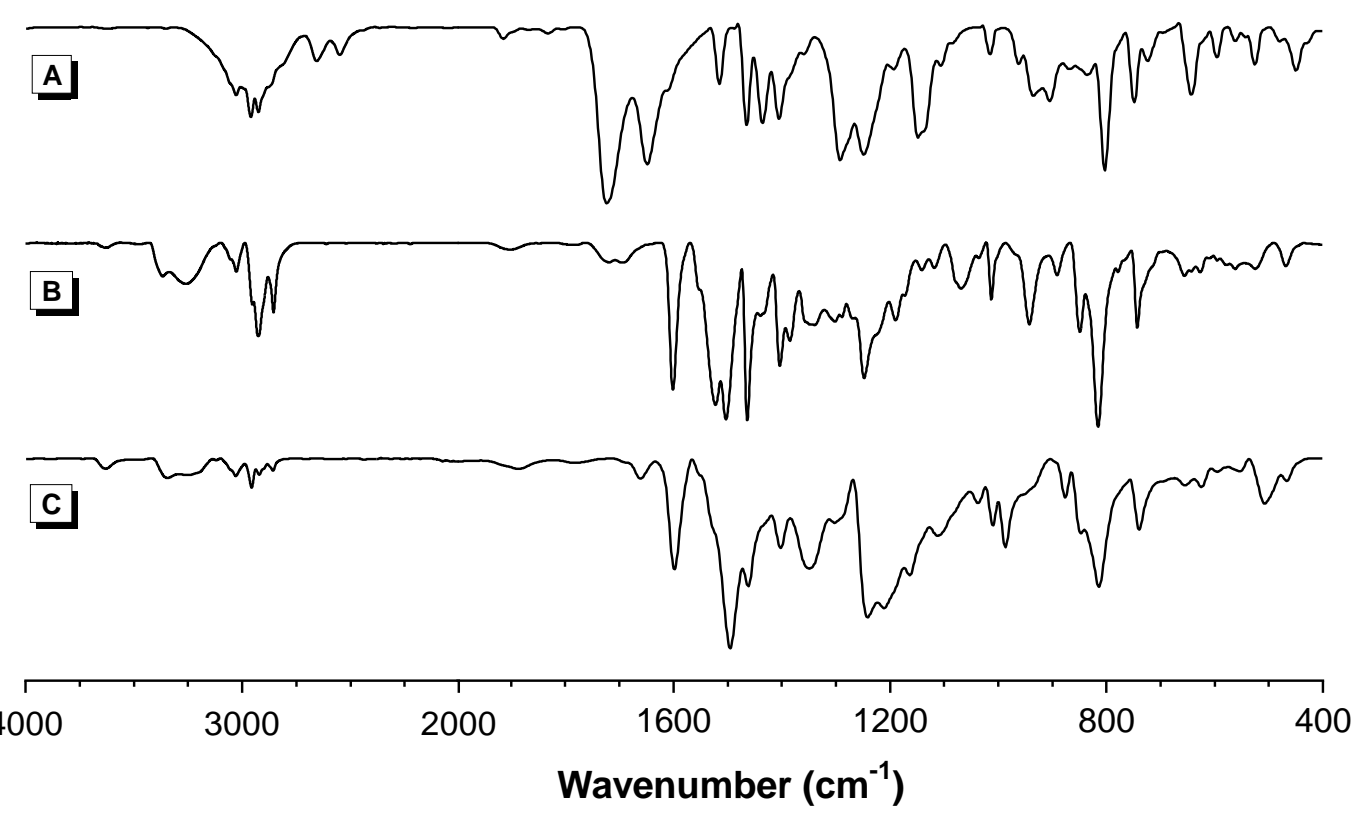

Figure S9. FT-IR spectra of (A) 2c, (B) P11, and (C) P12. 


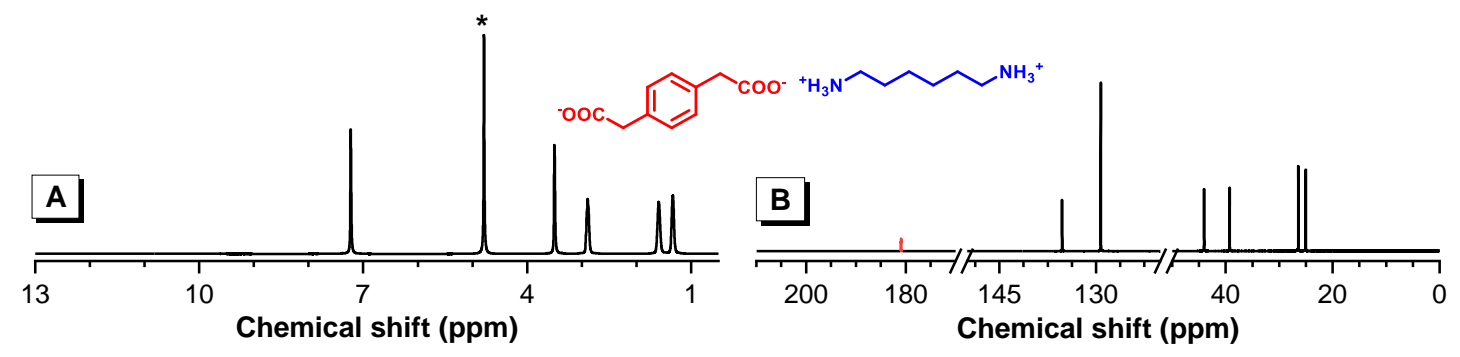

Figure S10. (A) ${ }^{1} \mathrm{H}$ NMR and (B) ${ }^{13} \mathrm{C}$ NMR spectra of ammonium salt formed from 2 a and 3a in $\mathrm{D}_{2} \mathrm{O}$. The solvent peak was marked with asterisk.
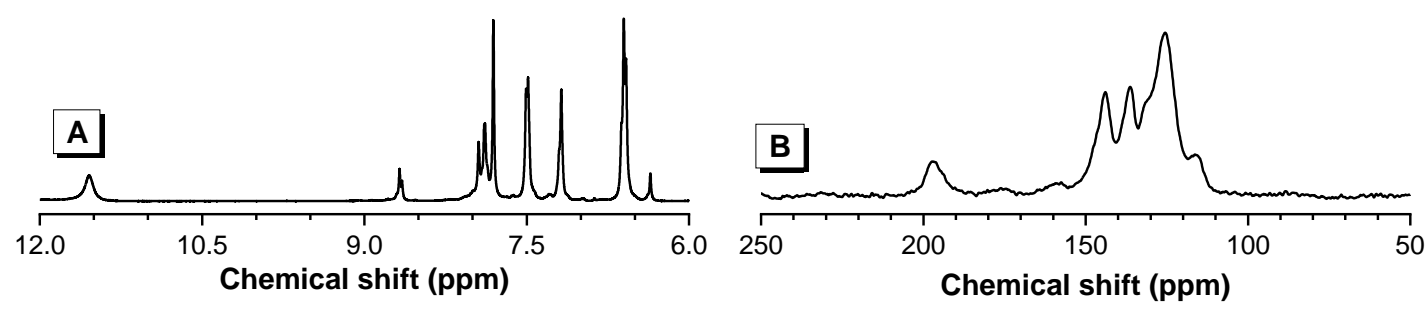

Figure S11. (A) ${ }^{1} \mathrm{H}$ NMR spectrum of P5 in DMSO- $d_{6}$. P5 was prepared in DMSO- $d_{6}$ in situ. (B) Solid state ${ }^{13} \mathrm{C}$ NMR spectrum of P5.

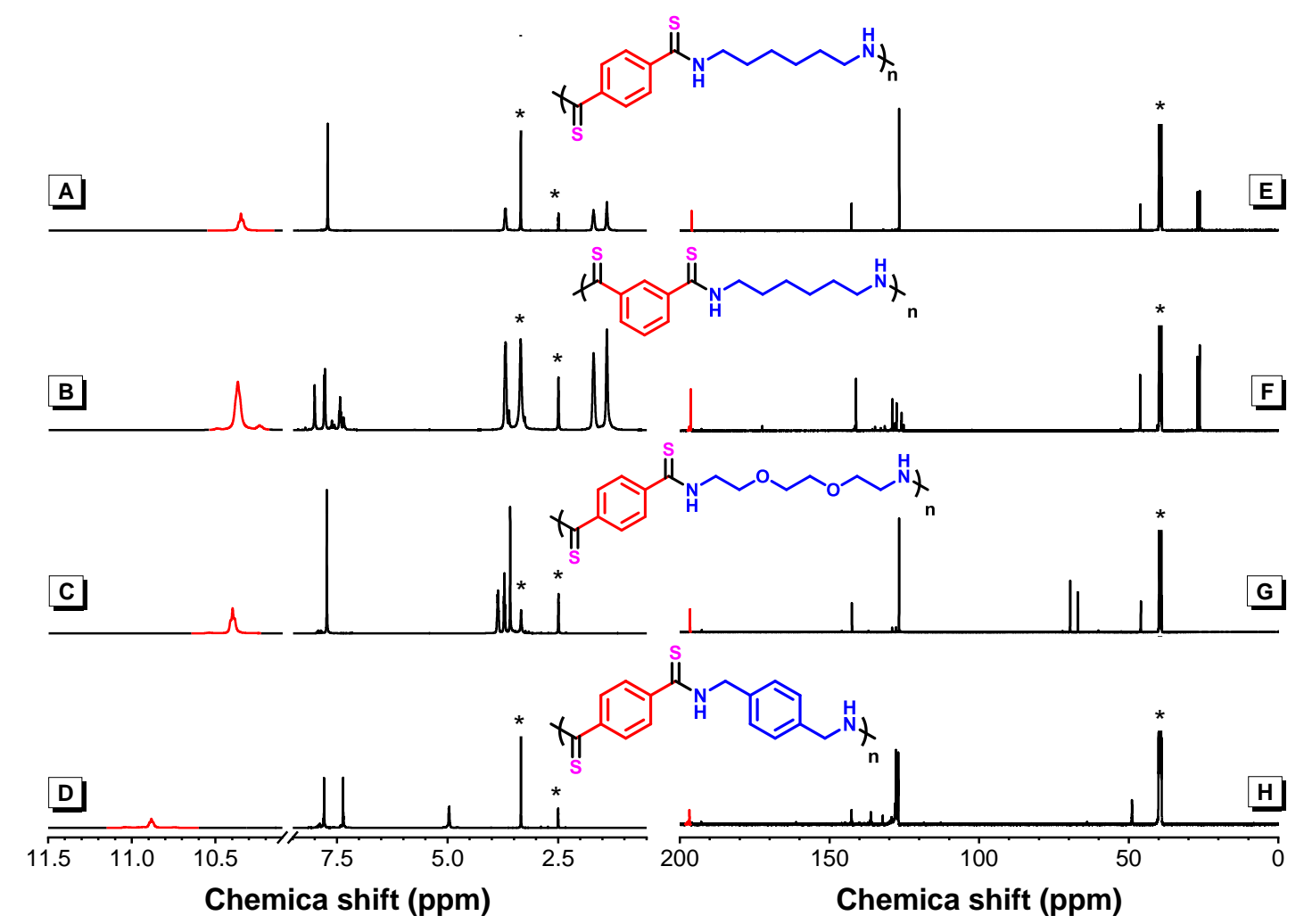

Figure S12. ${ }^{1} \mathrm{H}$ NMR spectra of (A) P1, (B) P2, (C) P3, and (D) P4 in DMSO- $d_{6} .{ }^{13} \mathrm{C}$ NMR spectra of (E) P1, (F) P2, (G) P3, and (H) P4 in DMSO-d6. The solvent peaks were marked with asterisks. 


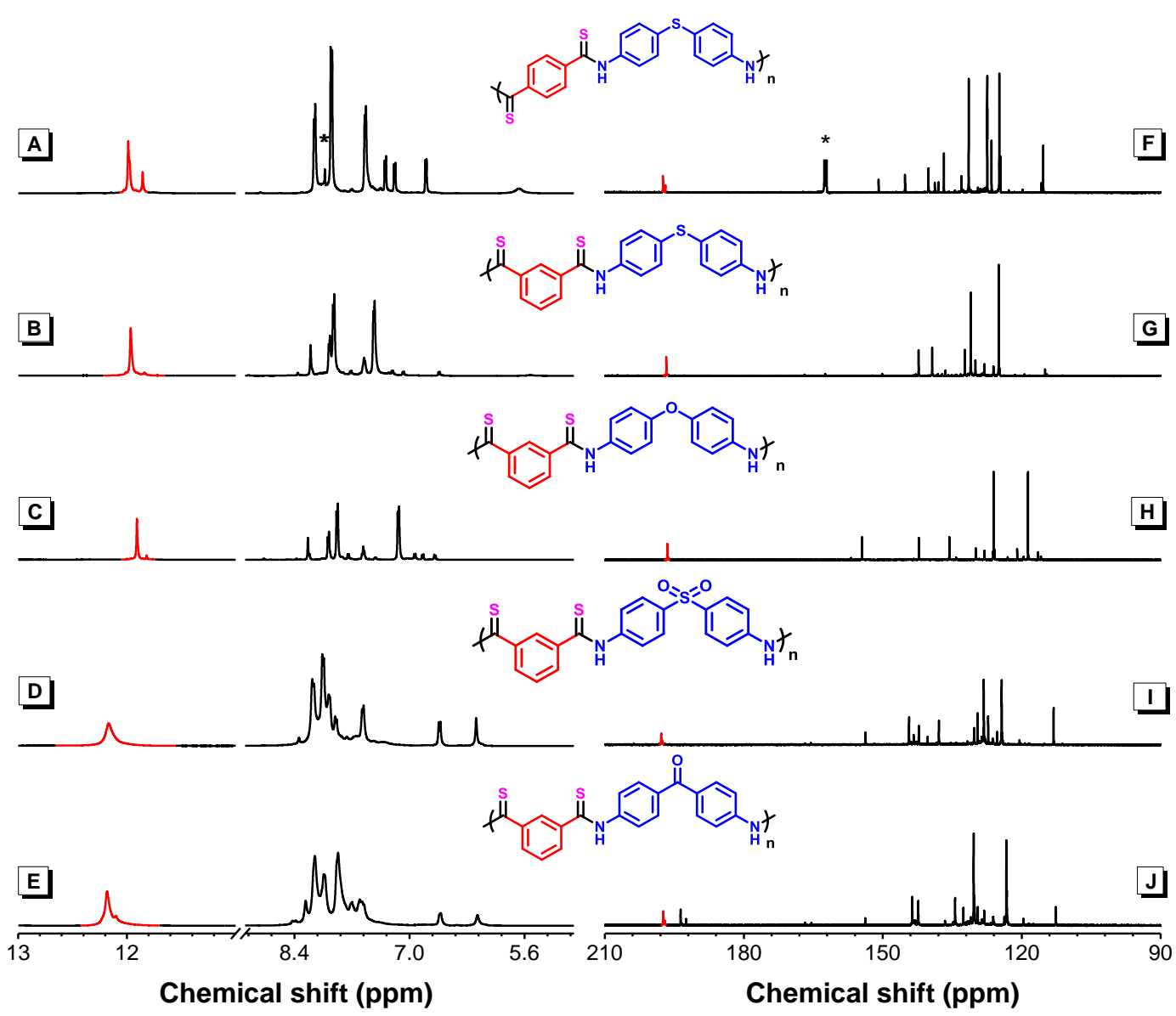

Figure S13. ${ }^{1} \mathrm{H}$ NMR spectra of (A) P6 in DMF- $d_{7}$, (B) P7, (C) P8, (D) P9, and (E) P10 in DMSO-d6. ${ }^{13} \mathrm{C}$ NMR spectra of (F) P6 in DMF-d7, (G) P7, (H) P8, (I) P9, and (J) $\mathrm{P} 10$ in DMSO- $d_{6}$. The solvent peaks were marked with asterisks.

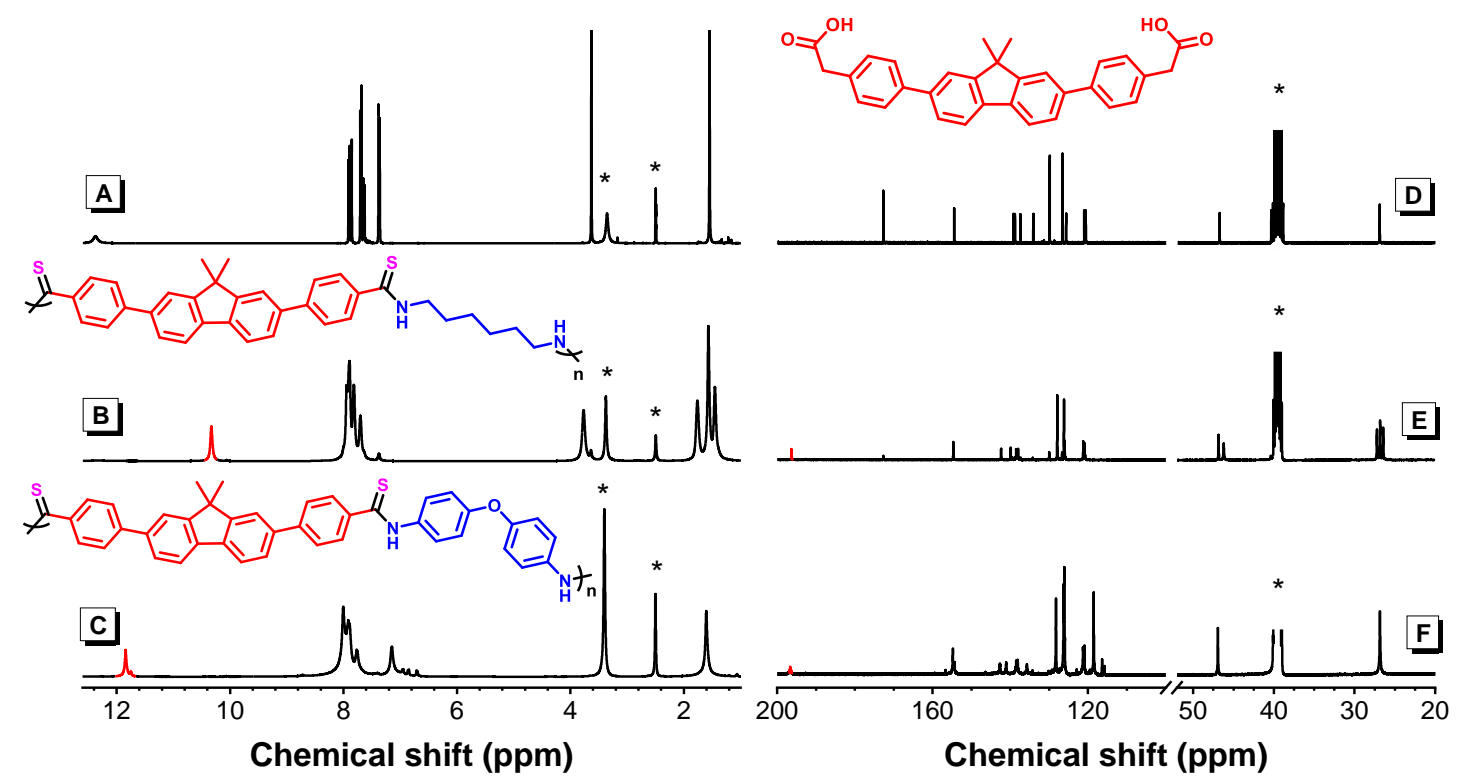

Figure S14. ${ }^{1} \mathrm{H}$ NMR spectra of (A) 2c, (B) P11, and (C) P12 in DMSO- $d_{6} .{ }^{13} \mathrm{C}$ NMR spectra of (D) 2c, (E) P11, and (F) P12 in DMSO- $d_{6}$. The solvent peaks were marked with asterisks. 




Figure S15. S 2p XPS of elemental sulfur, model compound 5, P1, P5, and P8.

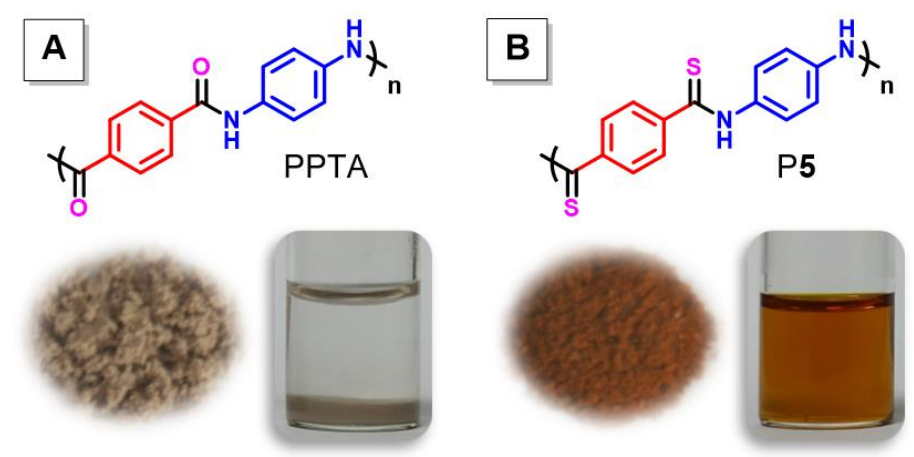

Figure S16. Solubility test of (A) PPTA and (B) P5 with $10 \mathrm{mg}$ polymer in $2 \mathrm{~mL}$ DMF. 

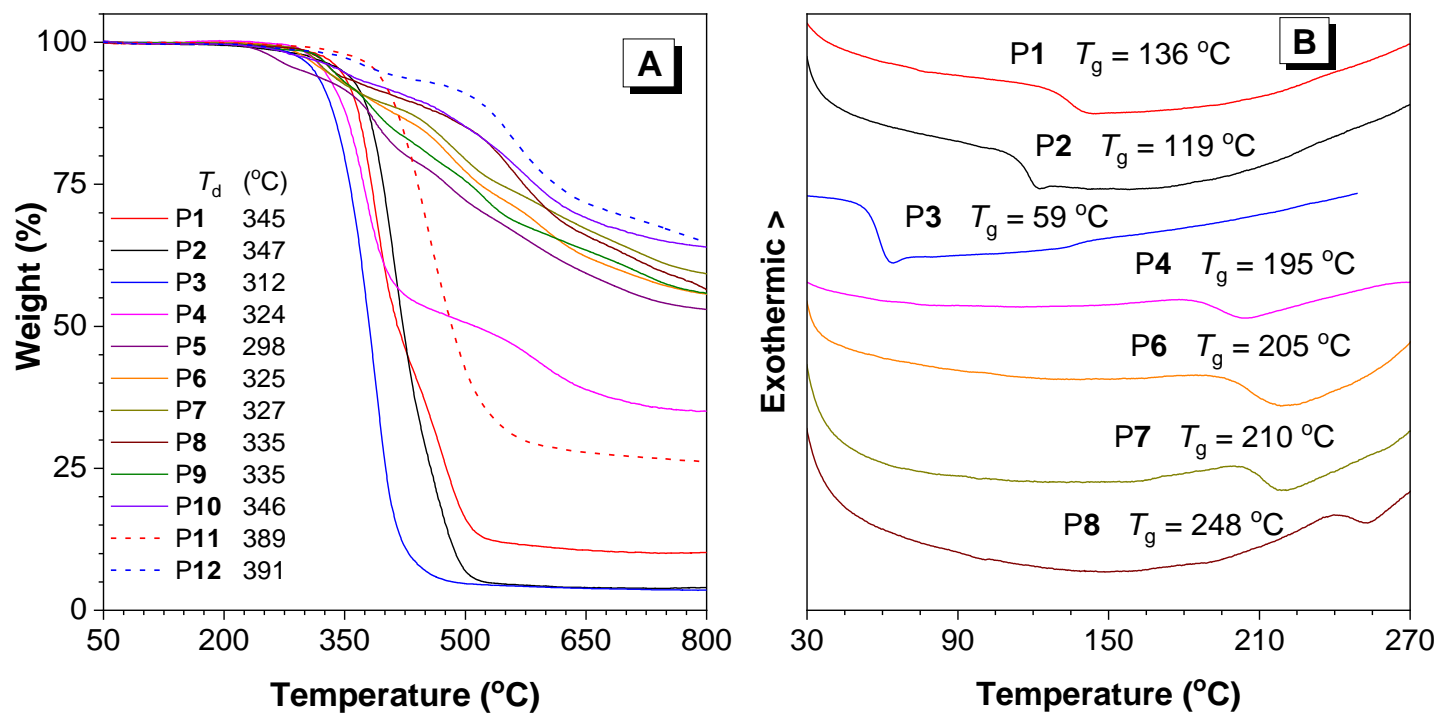

Figure S17. (A) TGA curves of polythioamides P1-P12 with a heating rate of $10{ }^{\circ} \mathrm{C} / \mathrm{min}$ under nitrogen. (B) DSC curves of polythioamides with a heating rate of $10{ }^{\circ} \mathrm{C} / \mathrm{min}$ from 30 to $270{ }^{\circ} \mathrm{C}$ under nitrogen.

Table S9. Gold extraction with different dosages of polythioamides ${ }^{a}$

\begin{tabular}{ccccc} 
entry & $m_{\mathrm{p}}(\mathrm{mg})$ & efficiency of P1 $(\%)$ & efficiency of P5 $(\%)$ & efficiency of P8 $(\%)$ \\
\hline 1 & 0.5 & 20.65 & 32.69 & 23.49 \\
2 & 1 & 40.48 & 59.73 & 46.82 \\
3 & 2 & 77.15 & 99.04 & 91.04 \\
4 & 5 & 97.97 & 99.52 & 99.98 \\
5 & 10 & 99.95 & 99.90 & $>99.99$
\end{tabular}

${ }^{a} \mathrm{P} 1, \mathrm{P} 5$, and $\mathrm{P} 8$ were prepared with the condition from Table S5. $m_{\mathrm{p}}(\mathrm{mg})$ : the amount of polymer powder. $\left[\mathrm{Au}^{3+}\right]_{0}=100 \mathrm{mg} / \mathrm{L}, \mathrm{VAu}^{3+}=10 \mathrm{~mL}$. Polymer powder and the aqueous solution of $\mathrm{Au}^{3+}$ were stirred at room temperature for $1 \mathrm{~h}$ before centrifugation. 
Table S10. Time-dependent gold extraction ${ }^{a}$

\begin{tabular}{cccc}
\hline entry & $t(\mathrm{~min})$ & efficiency of P5 $(\%)$ & efficiency of P8 $(\%)$ \\
\hline 1 & 1 & 97.96 & 98.02 \\
2 & 2 & 98.13 & 98.67 \\
3 & 5 & 98.75 & 99.58 \\
4 & 10 & 99.23 & 99.70 \\
5 & 20 & 99.34 & 99.97 \\
6 & 30 & 99.45 & 99.99 \\
7 & 40 & 99.60 & 99.99 \\
8 & 60 & 99.90 & $>99.99$
\end{tabular}

${ }^{a} \mathrm{P} 5$ and P8 were prepared with the condition from Table S5. $\left[\mathrm{Au}^{3+}\right]_{0}=100 \mathrm{mg} / \mathrm{L}, \mathrm{VAu}^{3+}$ $=10 \mathrm{~mL}, m_{\mathrm{P} 5}=m_{\mathrm{P} 8}=10 \mathrm{mg}$. Polymer powder and the aqueous solution of $\mathrm{Au}^{3+}$ were stirred at room temperature for different time before centrifugation.

Table S11. Gold extraction efficiency of DMF solution of P8 with different initial concentrations of $\mathrm{Au}^{3+a}$

\begin{tabular}{cccc}
\hline entry & $\mathrm{V}_{\mathrm{P}}(\mu \mathrm{L})$ & {$\left[\mathrm{Au}^{3+}\right]_{0}(\mathrm{mg} / \mathrm{L})$} & efficiency $(\%)$ \\
\hline 1 & 300 & 100 & $>99.99$ \\
2 & 150 & 50 & $>99.99$ \\
3 & 30 & 10 & 99.94 \\
4 & 3 & 1 & 97.68 \\
5 & 0.3 & 0.1 & 94.25 \\
6 & 0.03 & 0.01 & 90.94
\end{tabular}

${ }^{a} \mathrm{P} 8$ was prepared with the condition from Table S5. $\mathrm{VAu}^{3+}=10 \mathrm{~mL}$. Polymer solution and the aqueous solution of $\mathrm{Au}^{3+}$ were stirred at room temperature for $1 \mathrm{~h}$ before centrifugation. $\mathrm{V}_{\mathrm{P}}(\mu \mathrm{L})$ : the volume of DMF solution of $\mathrm{P} 8,[\mathrm{P8}]=33.3 \mathrm{mg} / \mathrm{mL}$ in DMF.

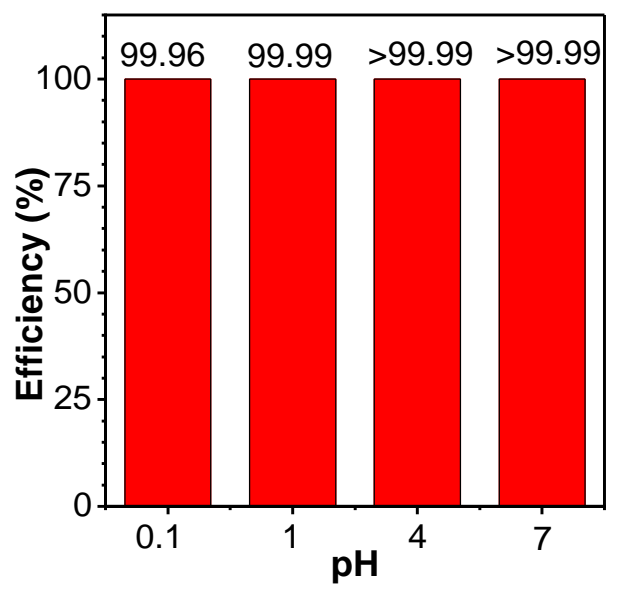

Figure S18. Extraction efficiency of $\mathrm{Au}^{3+}$ with solid powder of $\mathrm{P8}$ at different $\mathrm{pH}$ values with $10 \mathrm{~mL}$ of $\mathrm{Au}^{3+}$ solution $(100 \mathrm{mg} / \mathrm{L})$. 


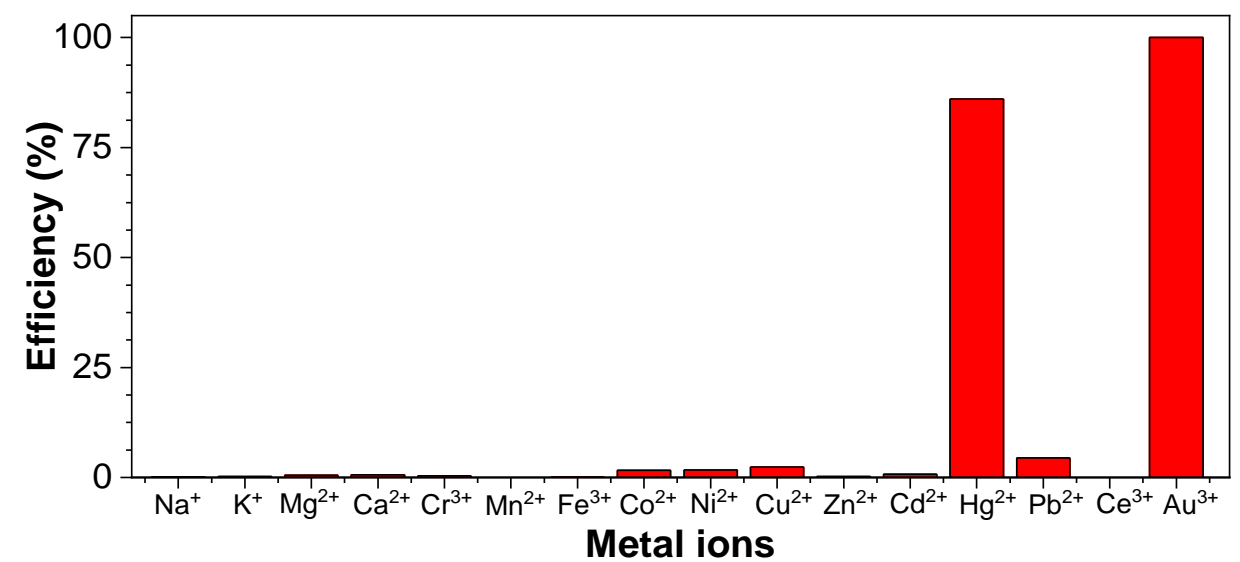

Figure S19. The extraction efficiency of different metal ions using solid powder of P8. $m_{\mathrm{P} 8}=10 \mathrm{mg}, \mathrm{VM}^{\mathrm{n}+}=10 \mathrm{~mL},\left[\mathrm{M}^{\mathrm{n}+}\right]=100 \mathrm{mg} / \mathrm{L}$. Polymer powder and the aqueous solution of metal ions were stirred at room temperature for $1 \mathrm{~h}$ before centrifugation.

Table S12. The extraction efficiency of solid powder of $\mathrm{P} 8$ with different metal ions ${ }^{a}$

\begin{tabular}{ccc}
\hline metal ion & $\begin{array}{c}\text { efficiency with single } \\
\text { metal ion }(\%)\end{array}$ & $\begin{array}{c}\text { efficiency with mixed } \\
\text { metal ions }(\%)\end{array}$ \\
\hline $\mathrm{Na}^{+}$ & 0.12 & 0 \\
$\mathrm{~K}^{+}$ & 0.23 & 0 \\
$\mathrm{Mg}^{2+}$ & 0.51 & 0 \\
$\mathrm{Ca}^{2+}$ & 0.62 & 0 \\
$\mathrm{Cr}^{3+}$ & 0.40 & 1.03 \\
$\mathrm{Mn}^{2+}$ & 0 & 0.80 \\
$\mathrm{Fe}^{3+}$ & 0.10 & 0.20 \\
$\mathrm{Co}^{2+}$ & 1.62 & 1.71 \\
$\mathrm{Ni}^{2+}$ & 1.69 & 0.97 \\
$\mathrm{Cu}^{2+}$ & 2.35 & 0 \\
$\mathrm{Zn}^{2+}$ & 0.19 & 0.47 \\
$\mathrm{Cd}^{2+}$ & 0.78 & 0.13 \\
$\mathrm{Hg}^{2+}$ & 86.01 & 7.01 \\
$\mathrm{~Pb}^{2+}$ & 4.48 & 1.48 \\
$\mathrm{Ce}^{3+}$ & 0 & 0 \\
$\mathrm{Au}^{3+}$ & $>99.99$ & $>99.99$
\end{tabular}

${ }^{a} \mathrm{P} 8$ was prepared with the condition from Table S5. $m_{\mathrm{P} 8}=10 \mathrm{mg}, \mathrm{V}_{\mathrm{M}^{\mathrm{n}}}=10 \mathrm{~mL},\left[\mathrm{M}^{\mathrm{n}+}\right]$ $=100 \mathrm{mg} / \mathrm{L}$. Polymer powder and the aqueous solution of metal ions were stirred at room temperature for $1 \mathrm{~h}$ before centrifugation. 
Table S13. Gold extraction from discarded CPU by P8 ${ }^{a}$

\begin{tabular}{crcc}
\hline $\mathrm{M}^{\mathrm{n}+}$ & {$\left[\mathrm{M}^{\mathrm{n}+}\right]_{0}(\mathrm{mg} / \mathrm{L})$} & {$\left[\mathrm{M}^{\mathrm{n}+}\right](\mathrm{mg} / \mathrm{L})$} & efficiency $(\%)$ \\
\hline $\mathrm{Ni}^{2+}$ & 95.62 & 95.62 & 0 \\
$\mathrm{Cu}^{2+}$ & 1478.04 & 1474.80 & 0.22 \\
$\mathrm{Au}^{3+}$ & 8.32 & 0.24 & 97.12
\end{tabular}

${ }^{a} \mathrm{P} 8$ was prepared with the condition from Table S5. $m_{\mathrm{P} 8}=10 \mathrm{mg}, \mathrm{V}_{\mathrm{M}^{\mathrm{n}}}=2 \mathrm{~mL}$. Polymer powder and the aqueous solution of metal ions were stirred at room temperature for 1 $\mathrm{h}$ before centrifugation. $\left[\mathrm{M}^{\mathrm{n}+}\right]_{0}$ : the initial concentration of different metal ions, $\left[\mathrm{M}^{\mathrm{n}+}\right]$ : the remaining concentration of metal ions after the treatment of P8.
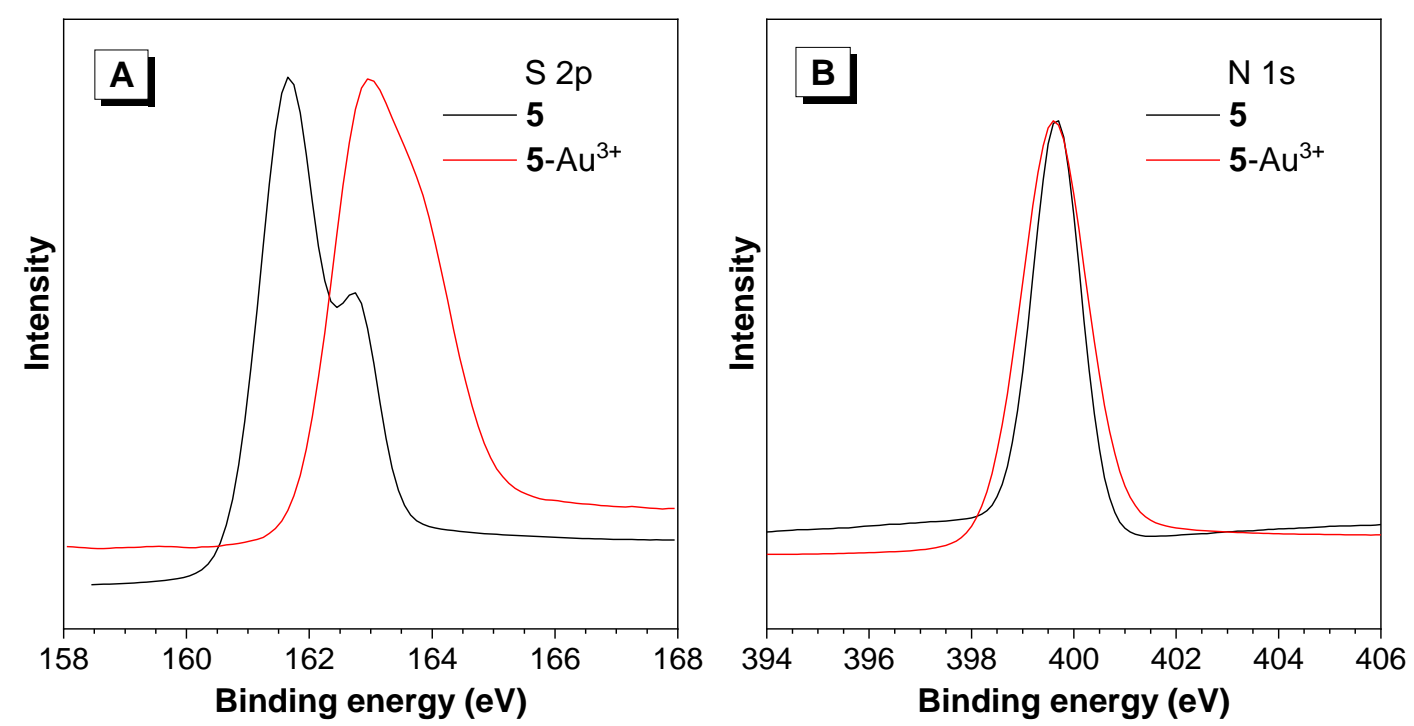

Figure S20. (A) S $2 p$ XPS of model compound 5 and 5- $\mathrm{Au}^{3+}$ and (B) N 1s XPS of model compound $\mathbf{5}$ and $\mathbf{5}-\mathrm{Au}^{3+}$.

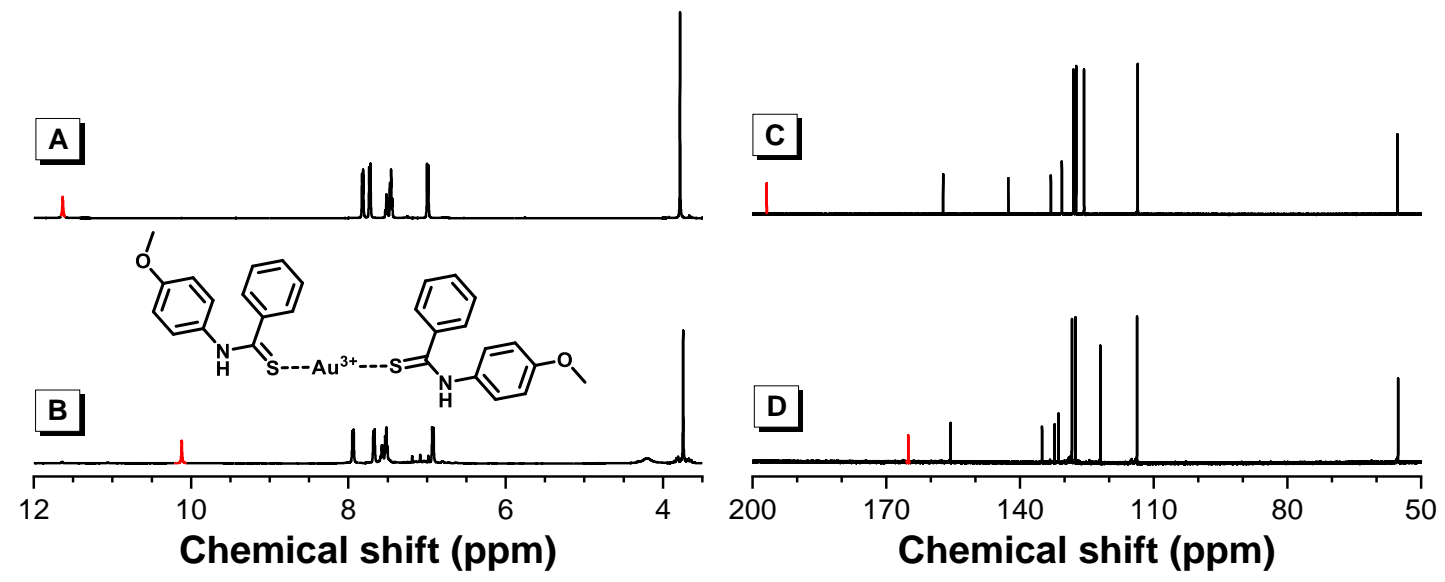

Figure S21. ${ }^{1} \mathrm{H}$ NMR spectra of (A) 5 and (B) 5- $\mathrm{Au}^{3+}$ in DMSO- $d_{6} \cdot{ }^{13} \mathrm{C}$ NMR spectra of (C) 5 and (D) $5-\mathrm{Au}^{3+}$ in DMSO- $d_{6}$. 


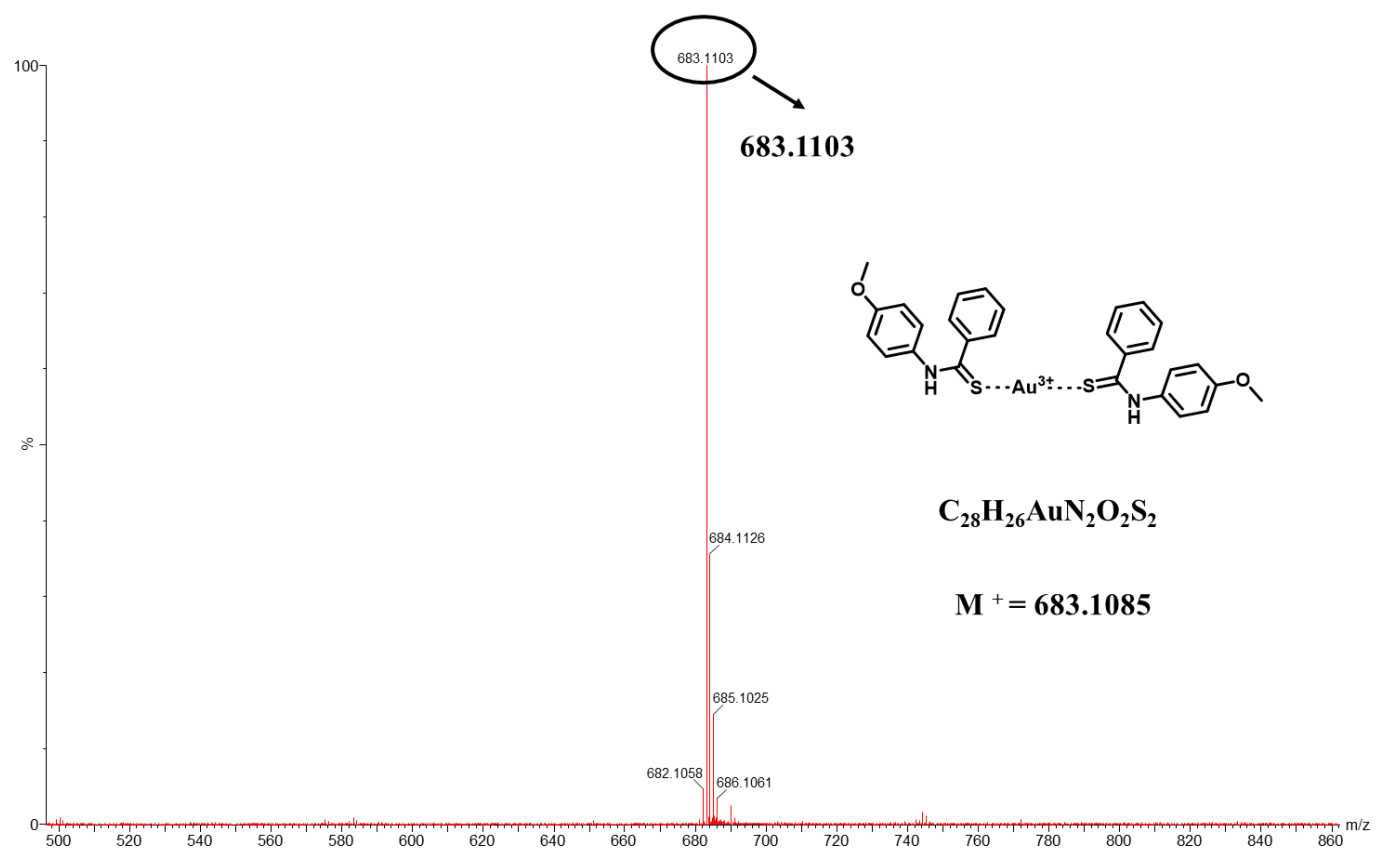

Figure S22. MALDI-TOF MS spectrum of complex 5- $\mathrm{Au}^{3+}$.

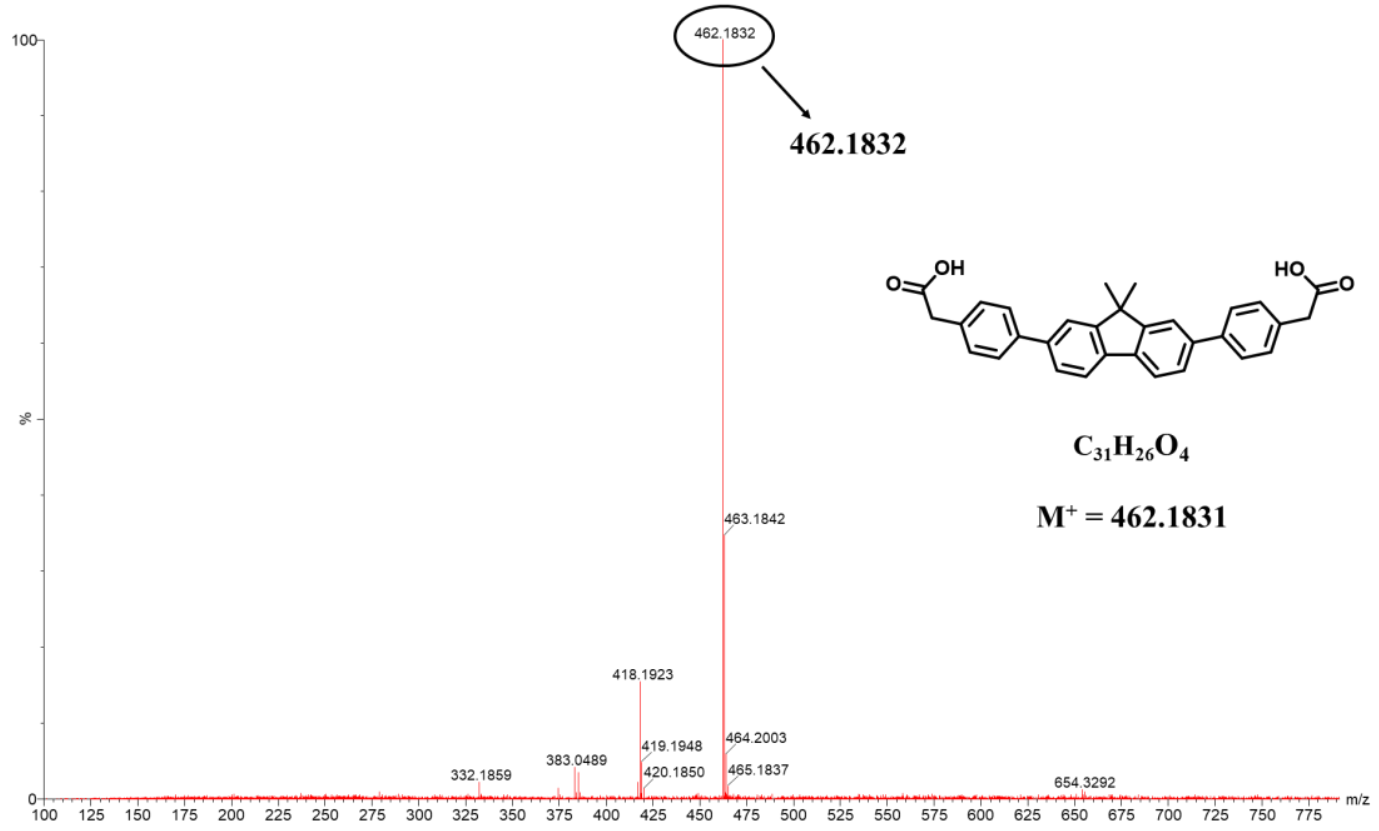

Figure S23. MALDI-TOF MS spectrum of 2c. 


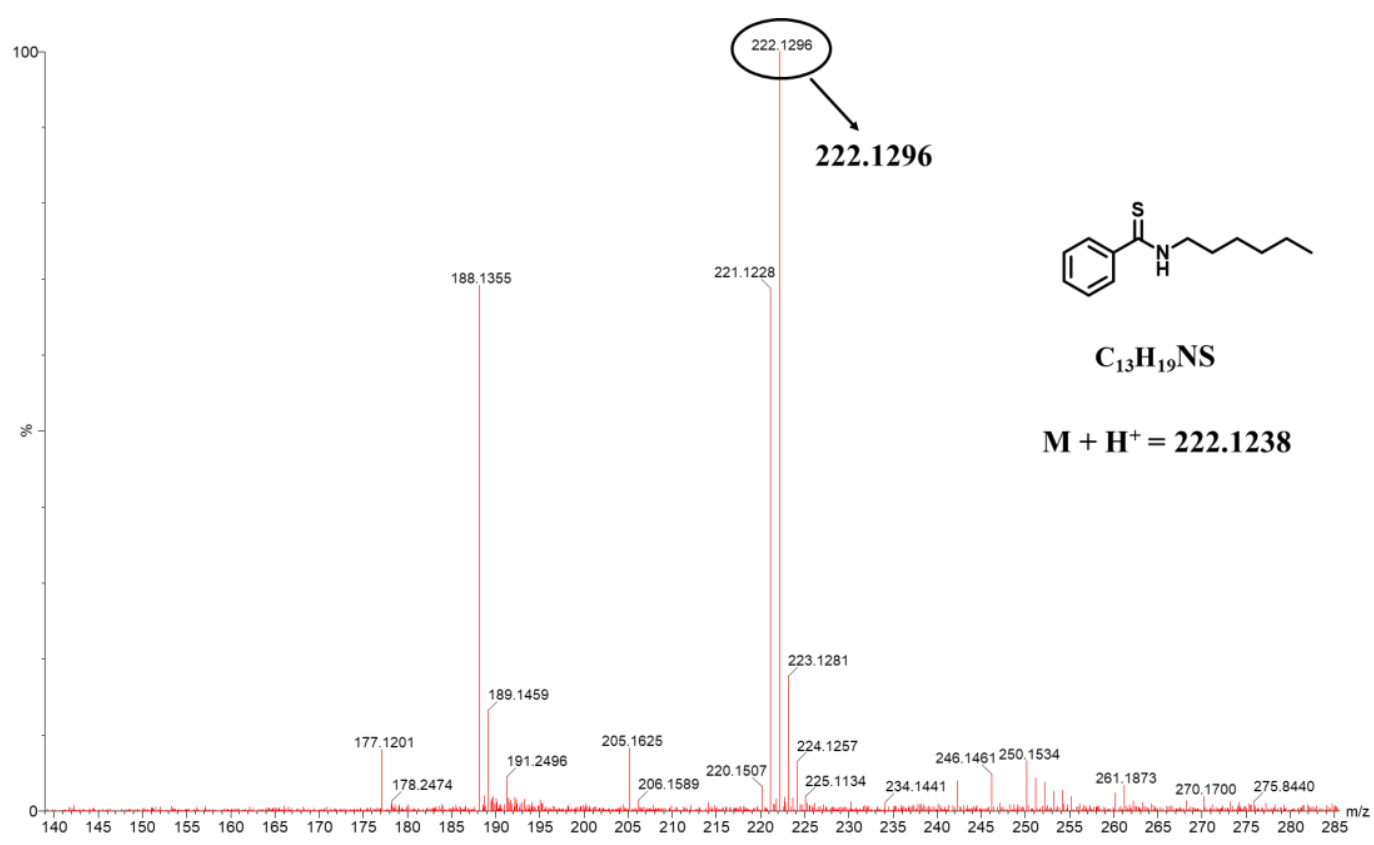

Figure S24. MALDI-TOF MS spectrum of model compound 4.

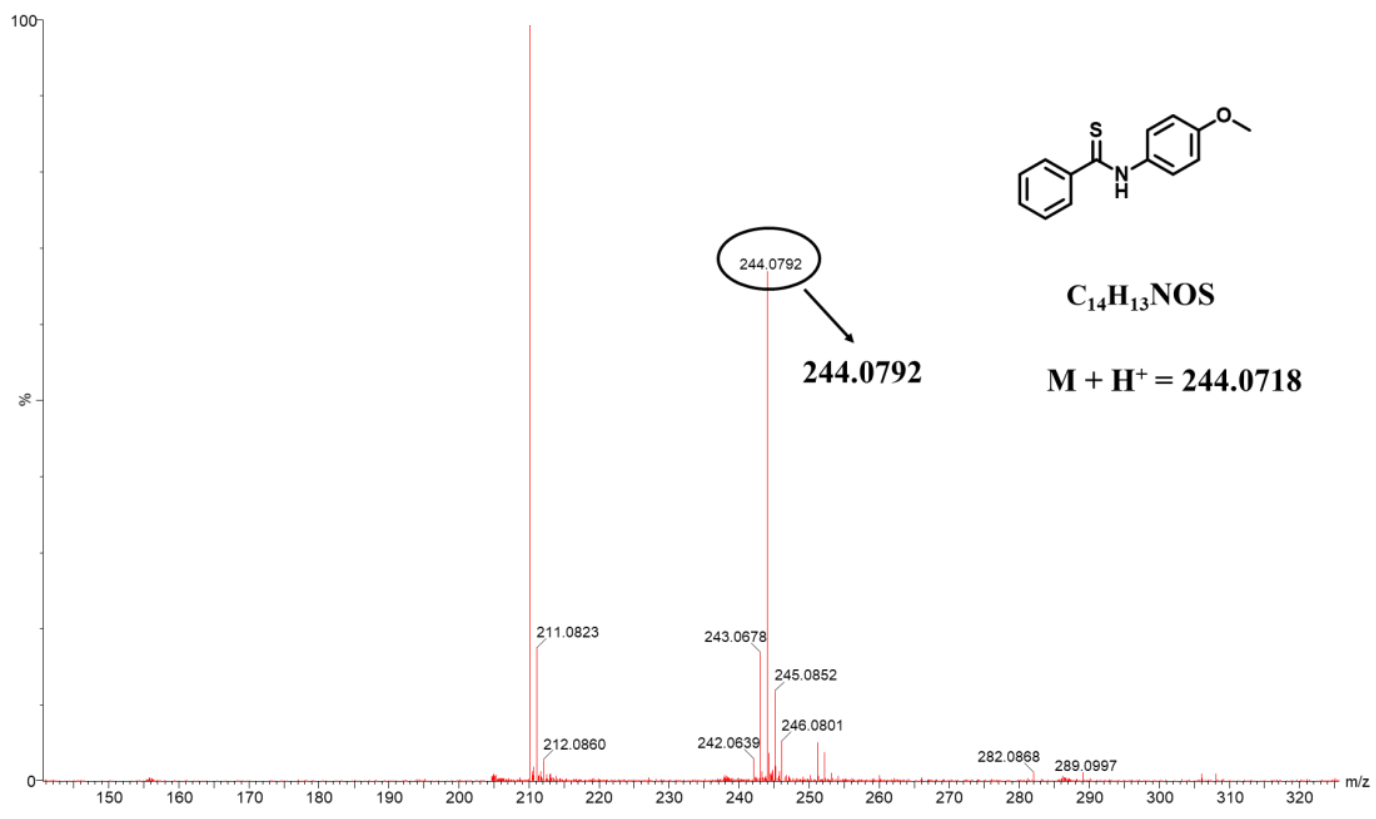

Figure S25. MALDI-TOF MS spectrum of model compound $\mathbf{5}$. 


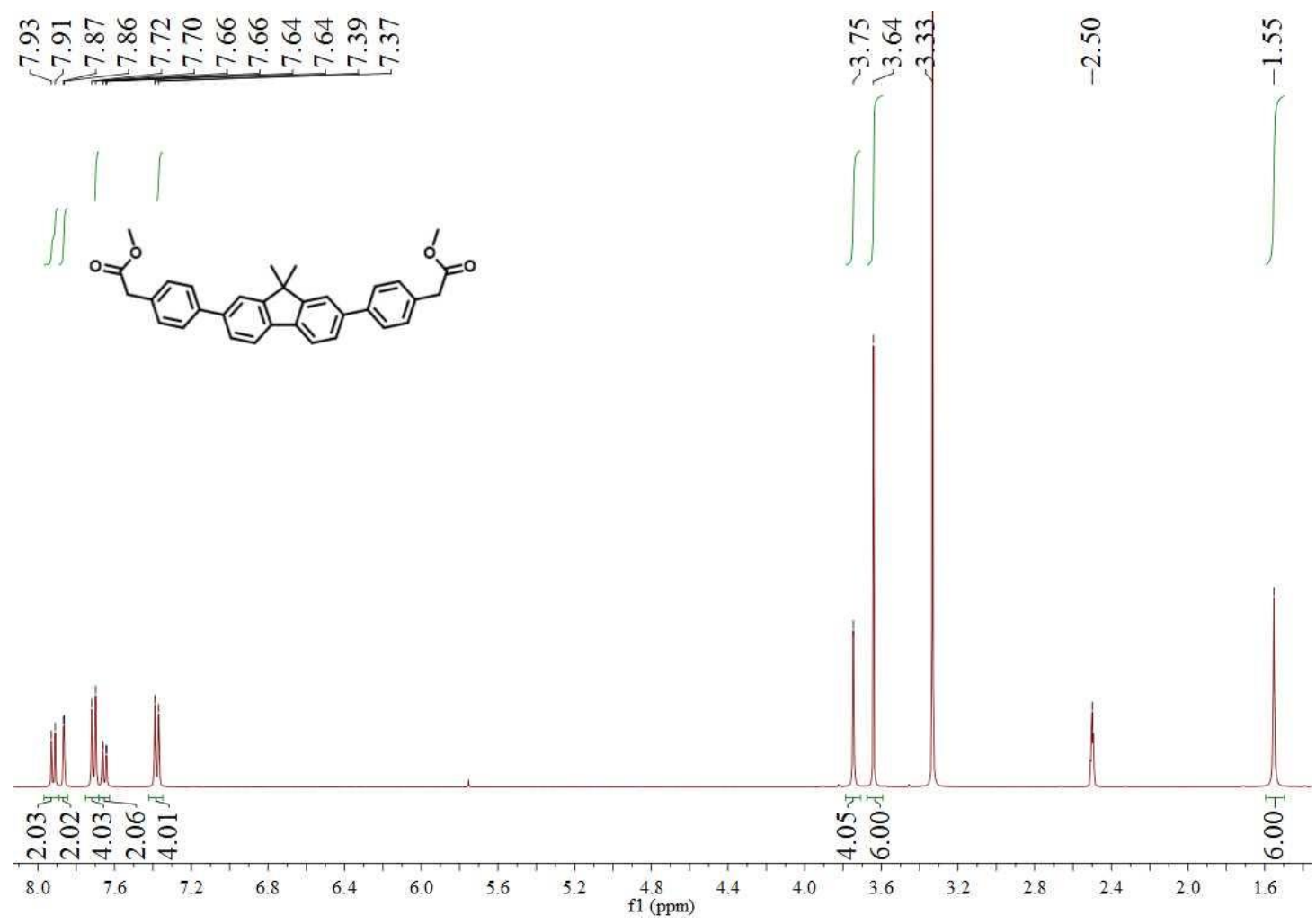

Figure S26. ${ }^{1} \mathrm{H}$ NMR spectrum of $\mathbf{1 1}$ in DMSO- $d_{6}$.
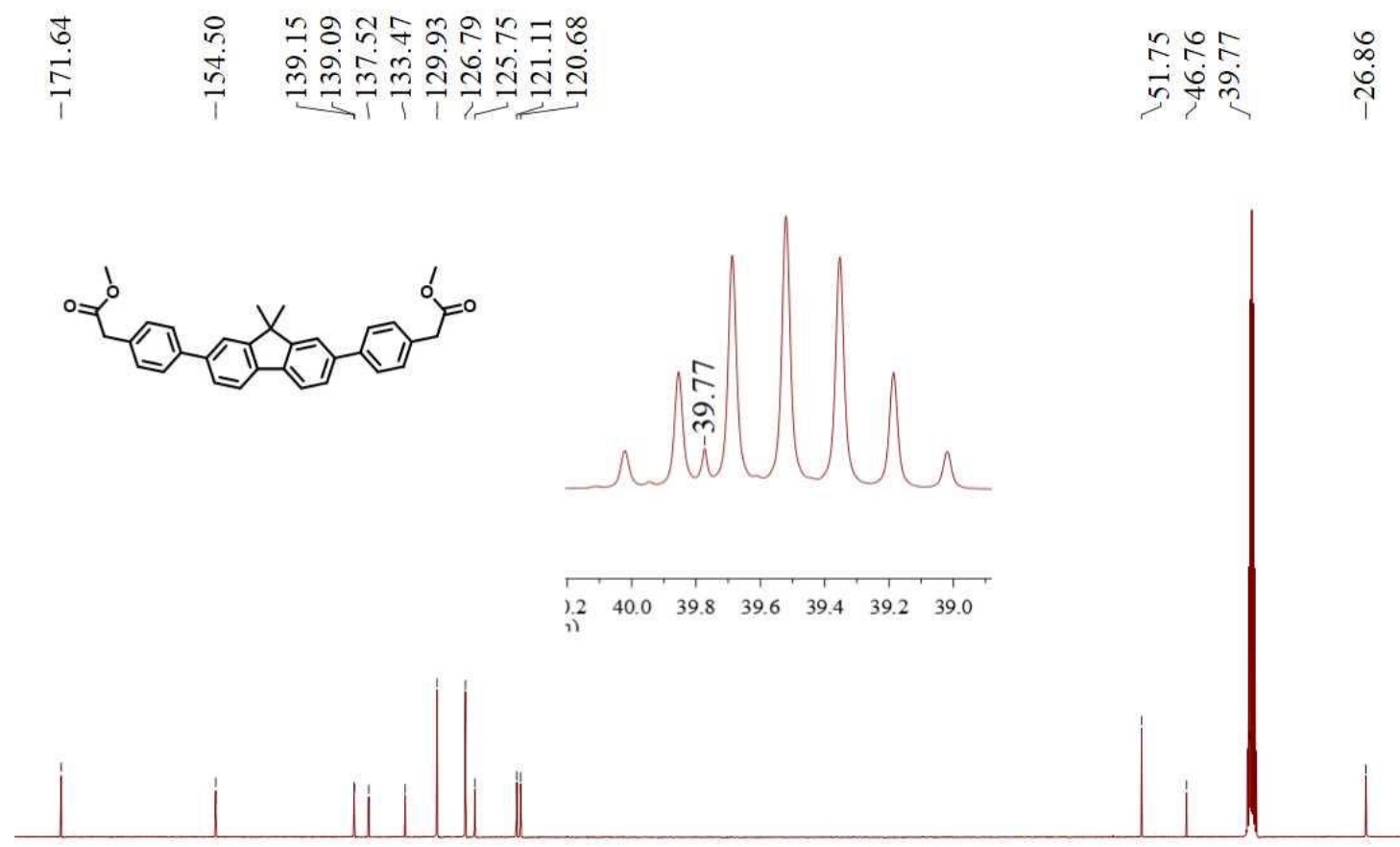

$\begin{array}{lllllllllllllllllllllllllllllllllll}175 & 165 & 155 & 145 & 135 & 125 & 115 & 105 & 95 & 90 & 85 & 80 & 75 & 70 & 65 & 60 & 55 & 50 & 45 & 40 & 35 & 30 & 25\end{array}$

Figure S27. ${ }^{13} \mathrm{C}$ NMR spectrum of $\mathbf{1 1}$ in DMSO- $d_{6}$. 


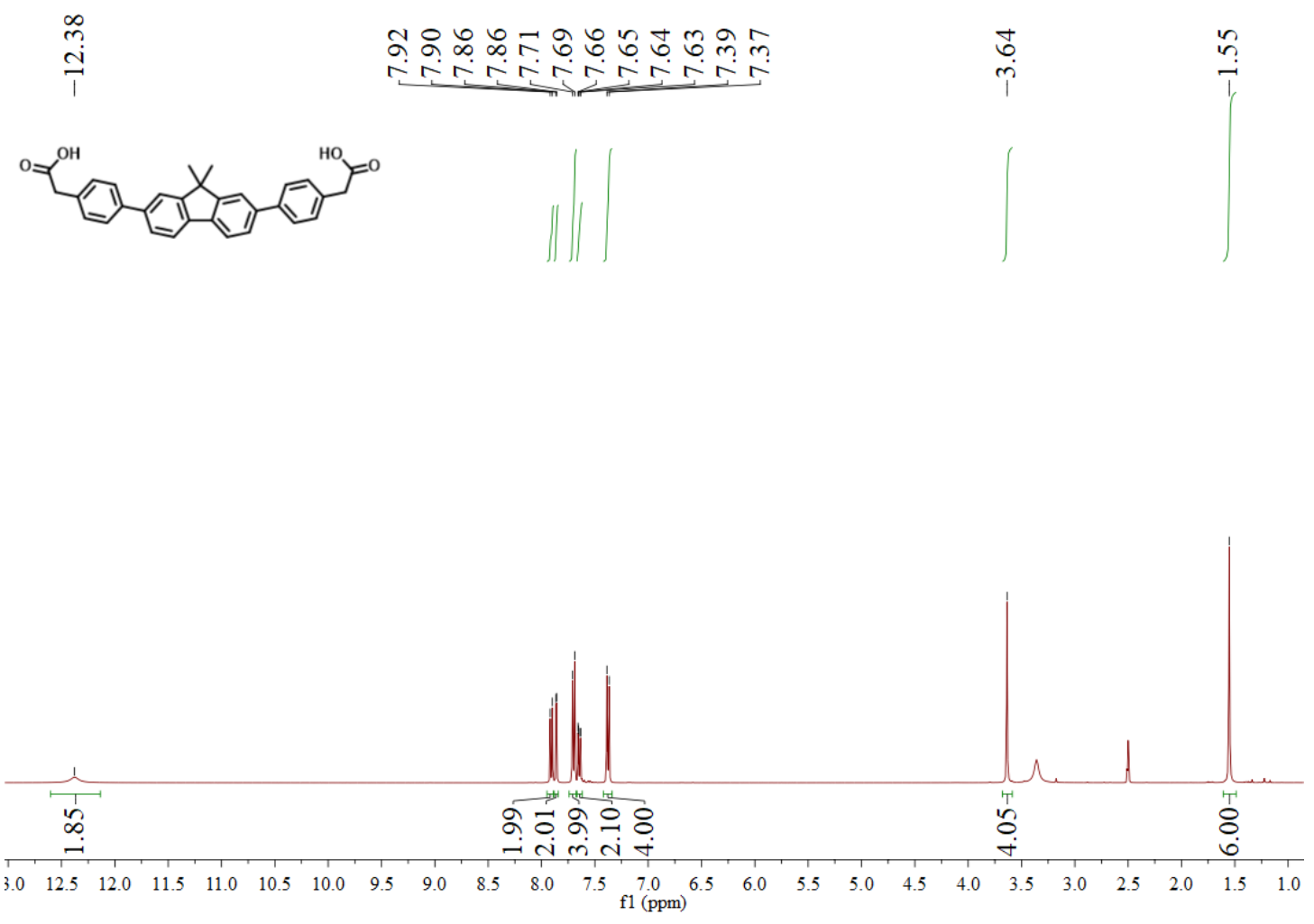

Figure S28. ${ }^{1} \mathrm{H}$ NMR spectrum of $2 \mathrm{c}$ in DMSO- $d_{6}$.

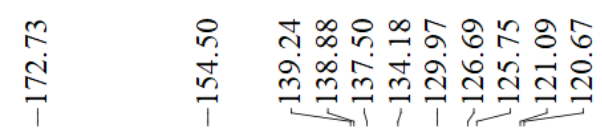

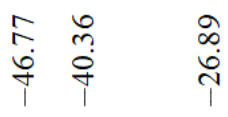<smiles></smiles>

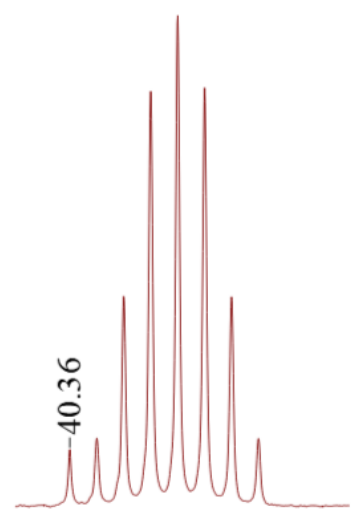

$\begin{array}{lllll}40.5 & 40.0 & 39.5 & 39.0 & 38.5\end{array}$

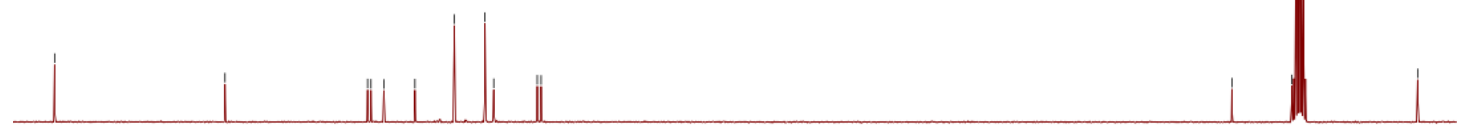

\begin{tabular}{lllllllllllllllllllllll}
\hline 175 & 165 & 155 & 145 & 135 & 125 & 115 & 105 & 95 & 90 & 85 & 80 & 75 & 70 & 65 & 60 & 55 & 50 & 45 & 40 & 35 & 30 & 25
\end{tabular}

Figure S29. ${ }^{13} \mathrm{C}$ NMR spectrum of $2 \mathrm{c}$ in DMSO- $d_{6}$. 
至
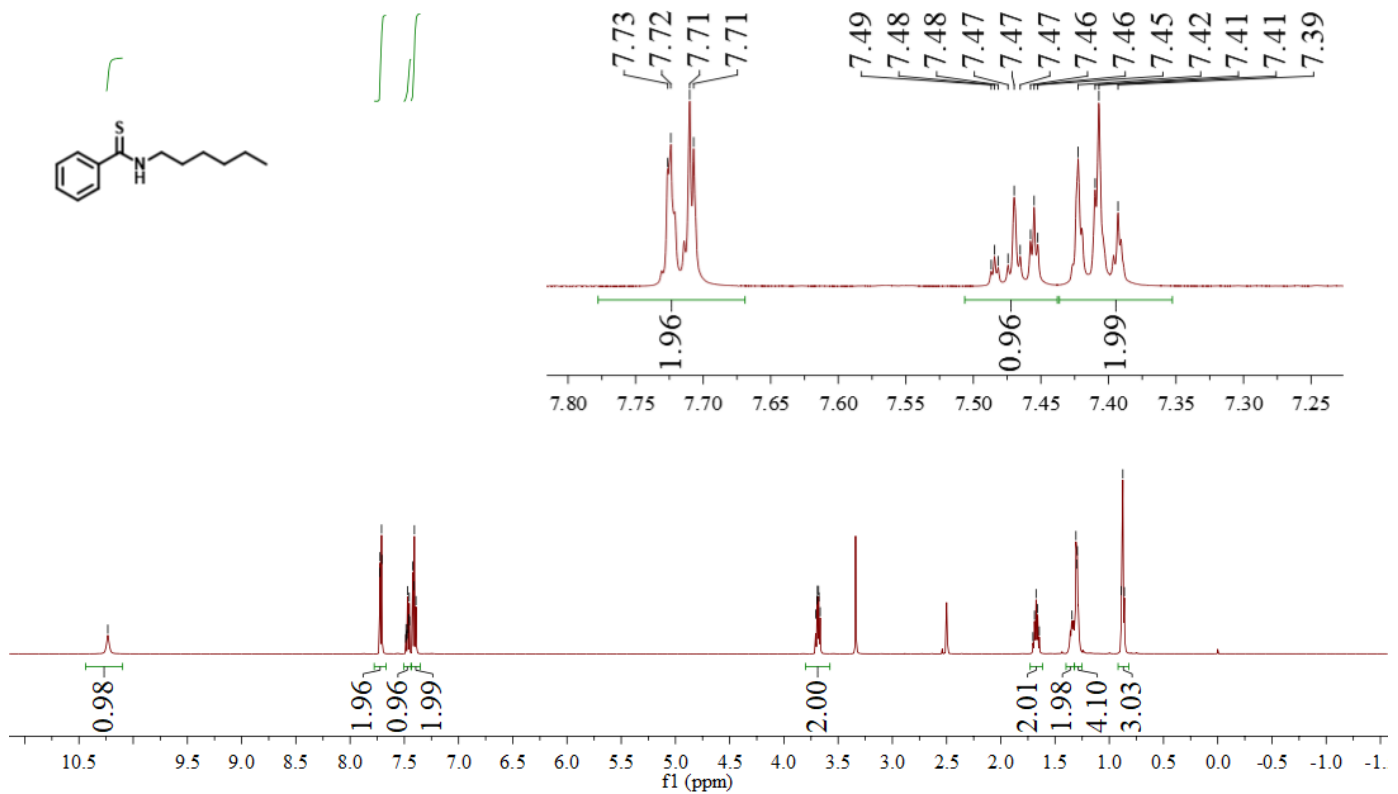

Figure S30. ${ }^{1} \mathrm{H}$ NMR spectrum of model compound 4 in DMSO- $d_{6}$.


Figure S31. ${ }^{13} \mathrm{C}$ NMR spectrum of model compound 4 in DMSO- $d_{6}$. 


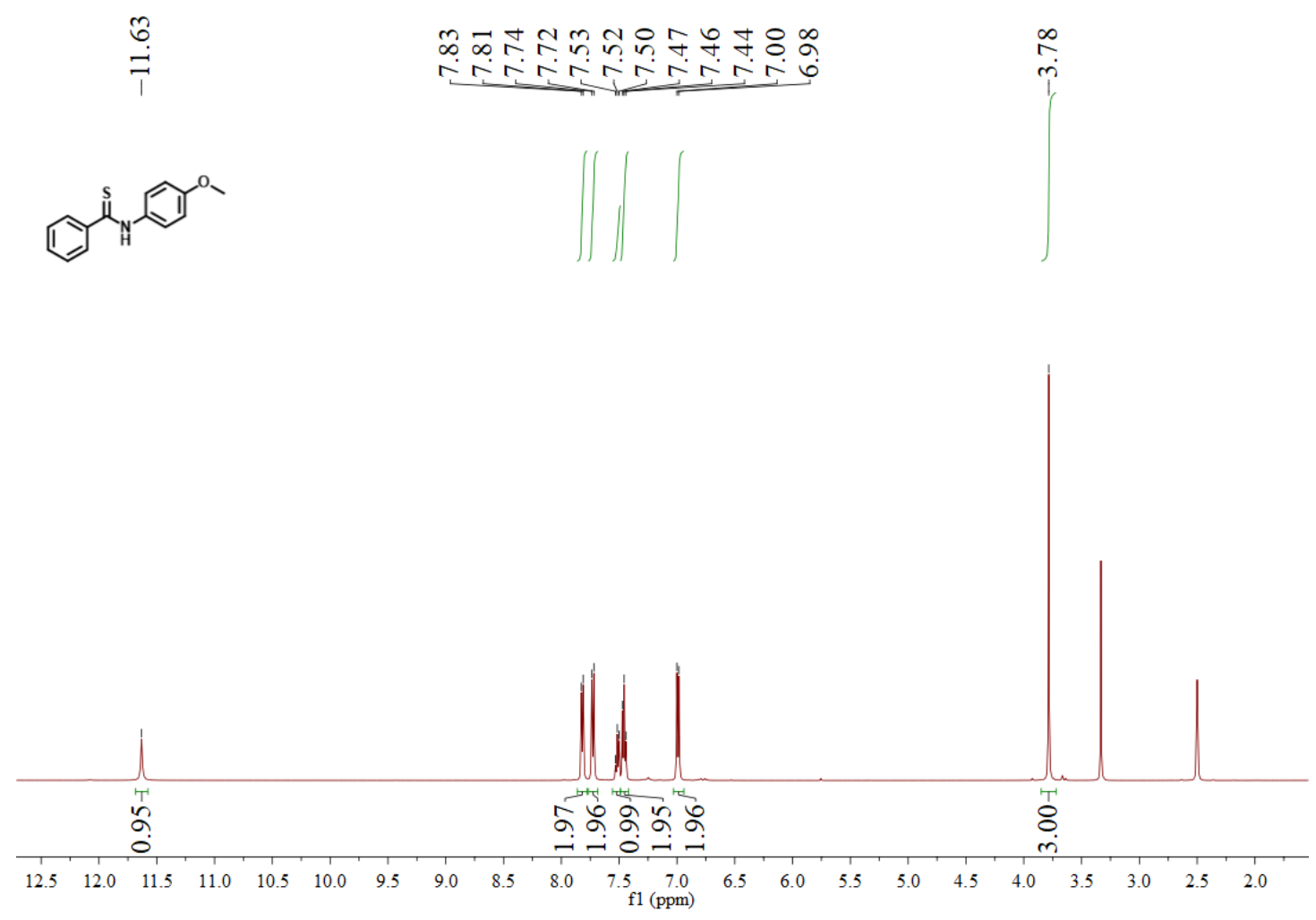

Figure S32. ${ }^{1} \mathrm{H}$ NMR spectrum of model compound 5 in DMSO- $d_{6}$.
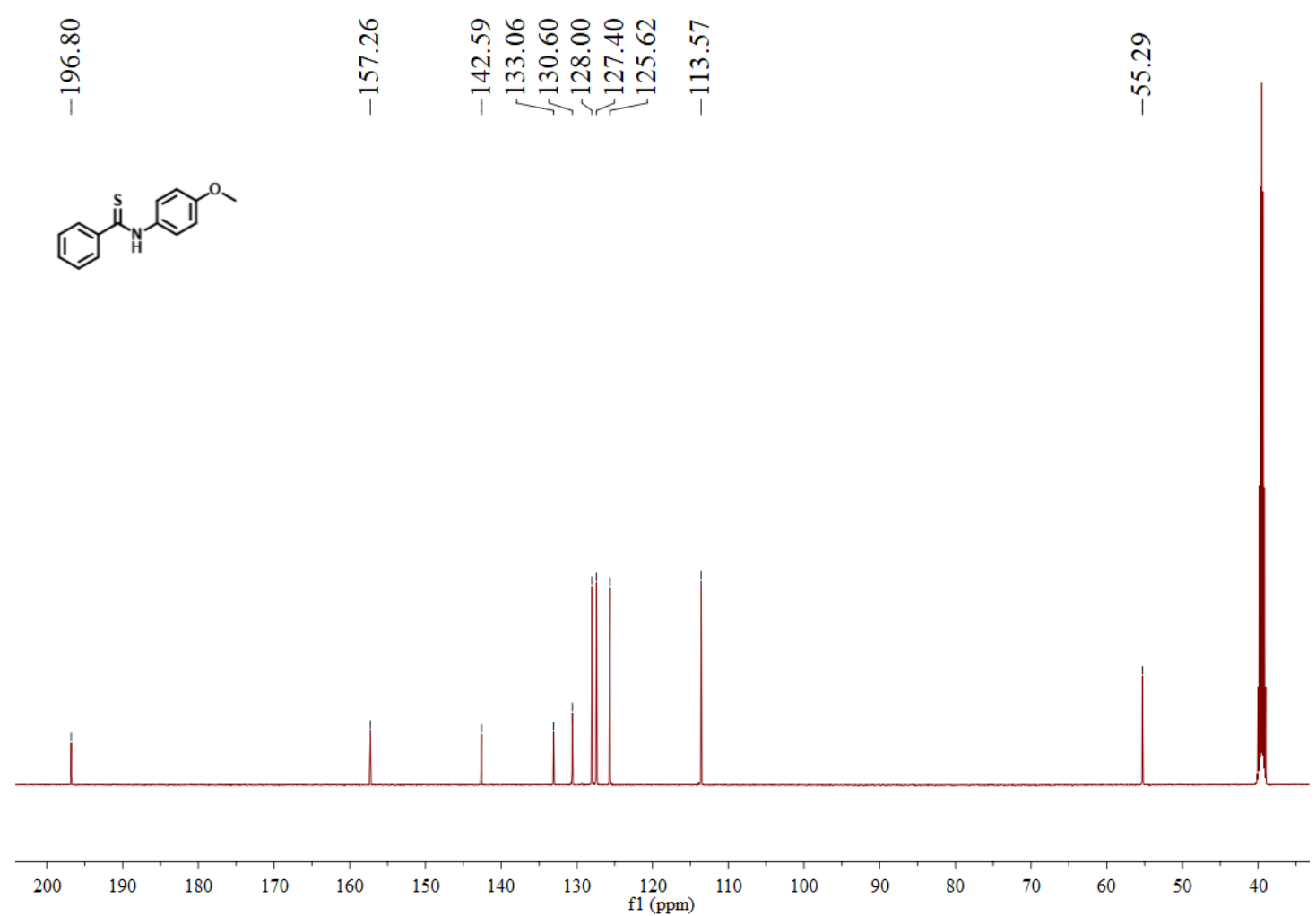

Figure S33. ${ }^{13} \mathrm{C}$ NMR spectrum of model compound 5 in DMSO- $d_{6}$. 




Figure S34. ${ }^{1} \mathrm{H}$ NMR spectrum of P1 in DMSO- $d_{6}$.
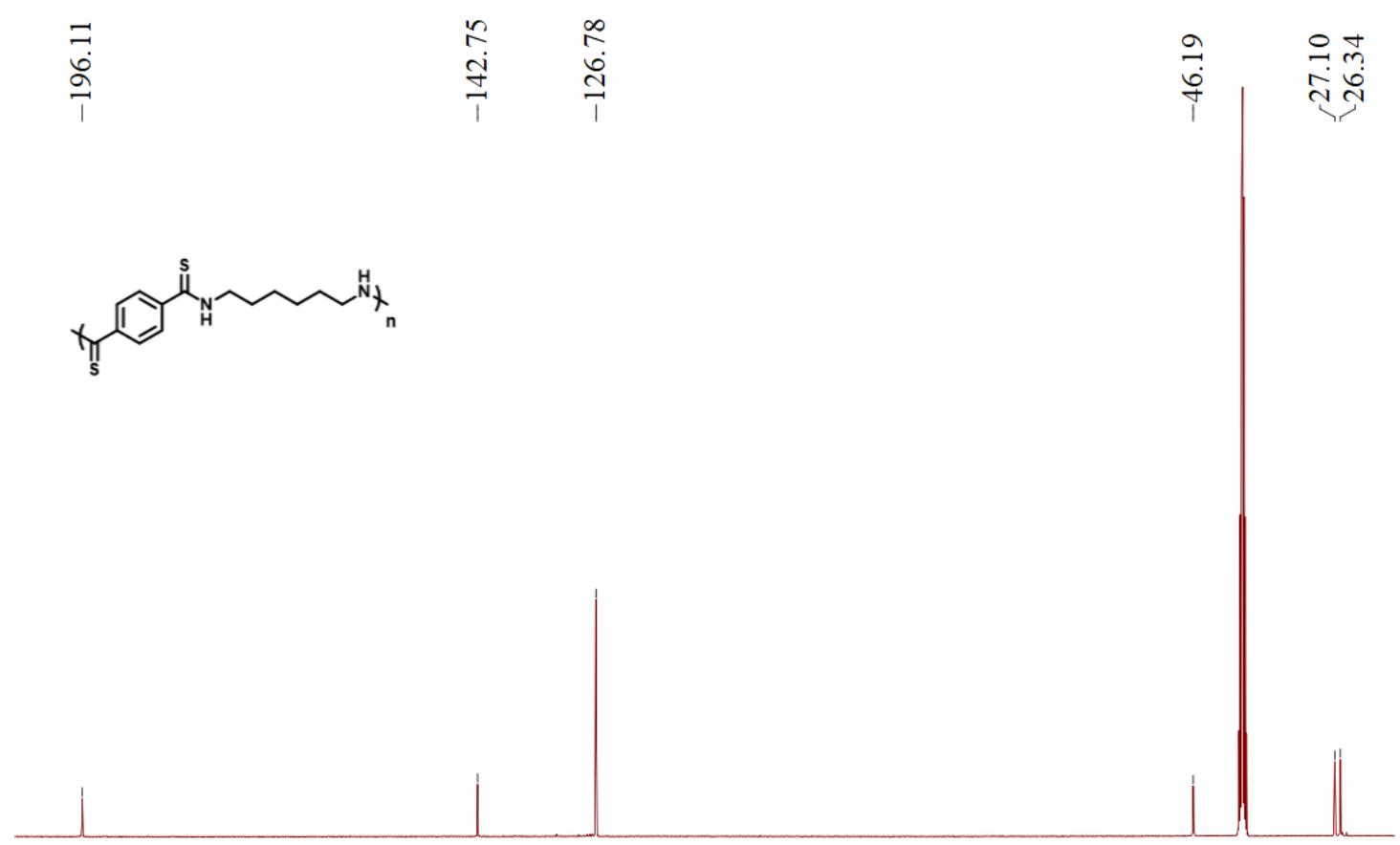

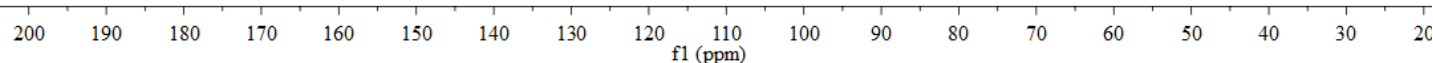

Figure S35. ${ }^{13} \mathrm{C}$ NMR spectrum of P1 in DMSO- $d_{6}$. 


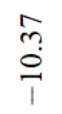

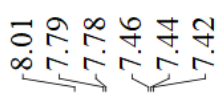
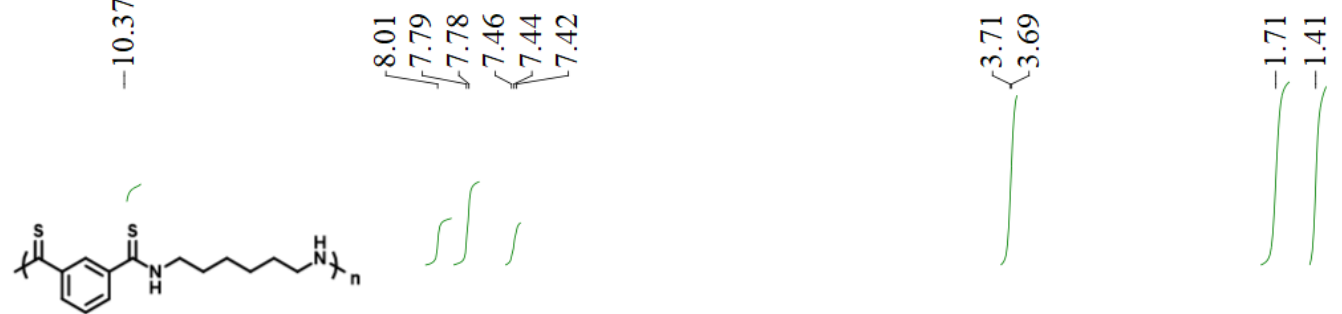

$\iint$



Figure S36. ${ }^{1} \mathrm{H}$ NMR spectrum of $\mathrm{P} 2$ in DMSO- $d_{6}$.

\begin{tabular}{l}
1 \\
$\substack{1 \\
\hdashline}$ \\
$\stackrel{1}{1}$
\end{tabular}

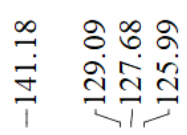


Figure S37. ${ }^{13} \mathrm{C}$ NMR spectrum of P2 in DMSO- $d_{6}$.

S36 
구워
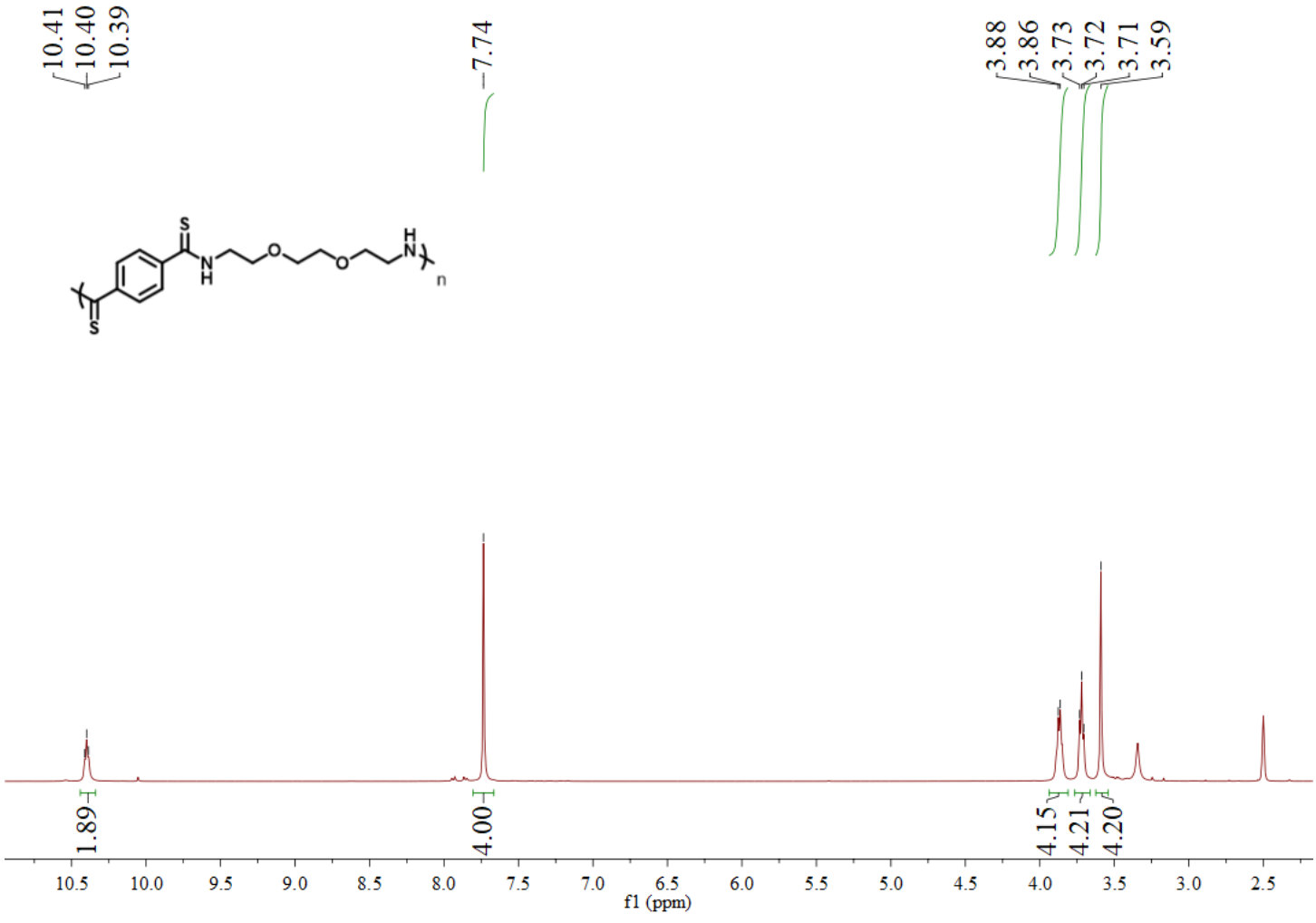

Figure S38. ${ }^{1} \mathrm{H}$ NMR spectrum of P3 in DMSO- $d_{6}$.

\begin{tabular}{l}
8 \\
0 \\
$\circ$ \\
\hdashline
\end{tabular}

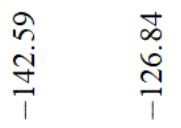

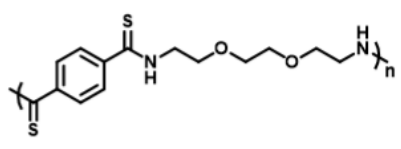

0.0
0
010
10
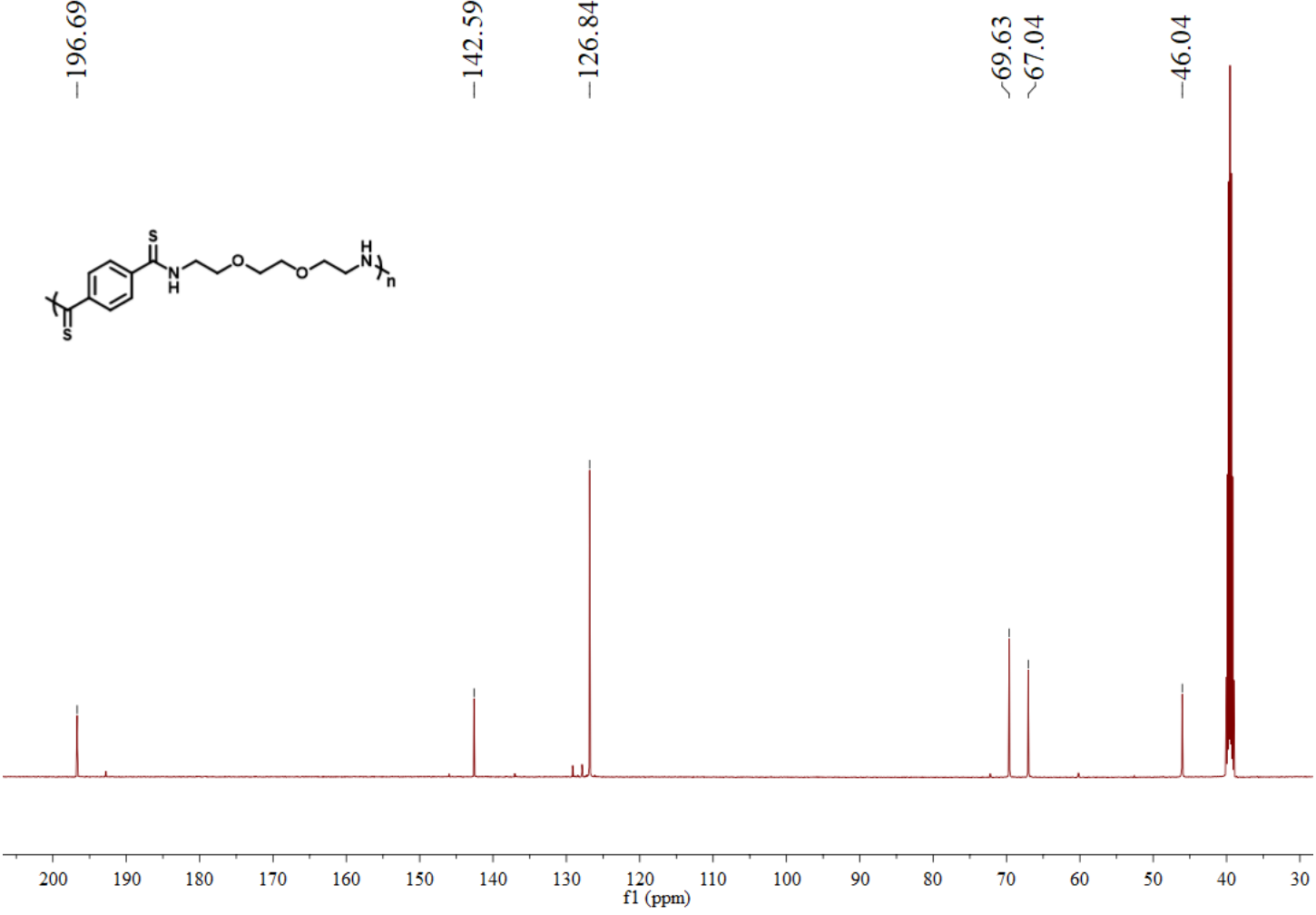

Figure S39. ${ }^{13} \mathrm{C}$ NMR spectrum of $\mathrm{P} 3$ in DMSO- $d_{6}$.

S37 


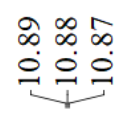


Figure S40. ${ }^{1} \mathrm{H}$ NMR spectrum of P4 in DMSO- $d_{6}$.

$\circ$
$\infty$
$\stackrel{0}{1}$

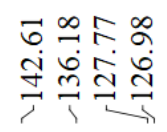
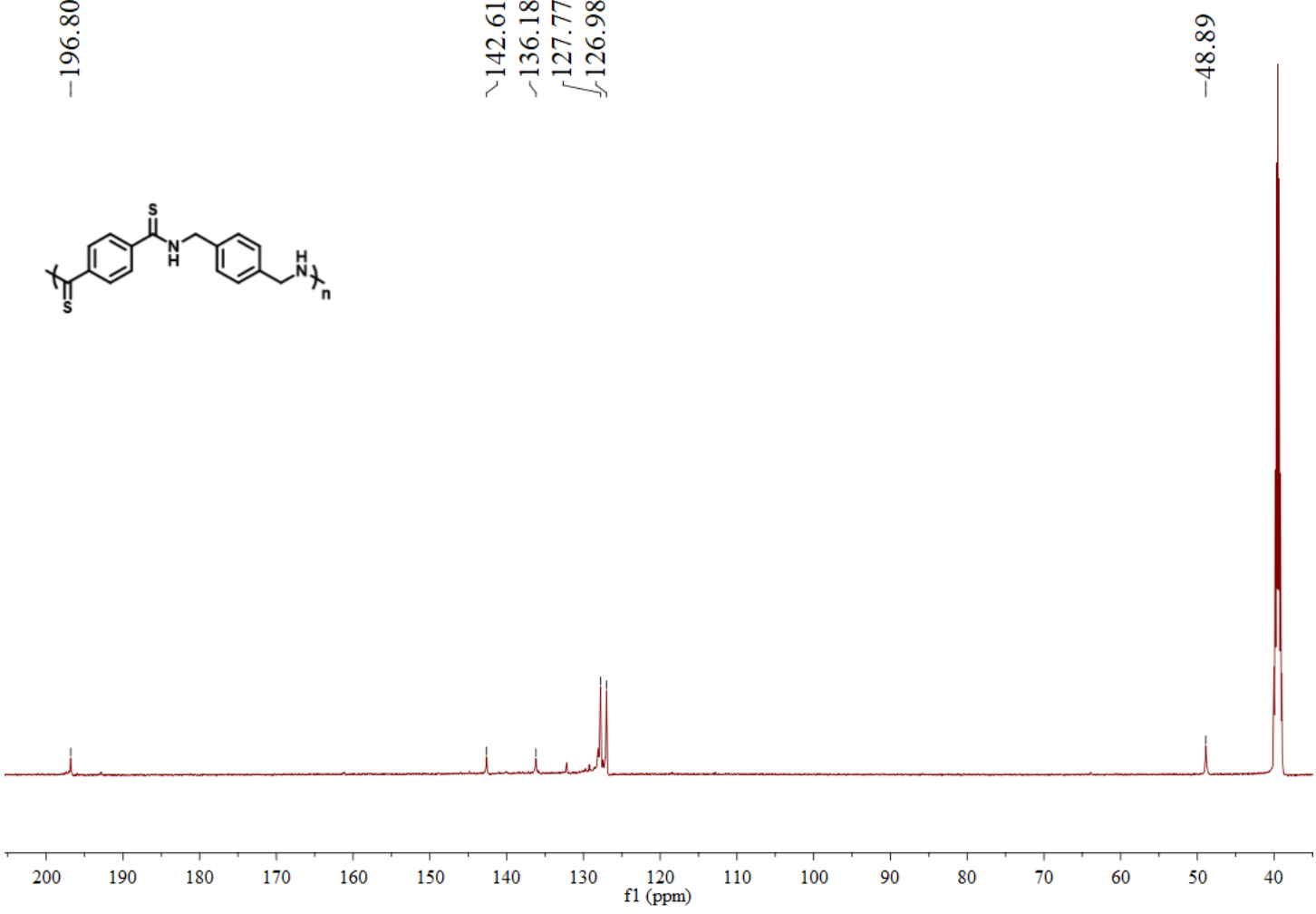

Figure S41. ${ }^{13} \mathrm{C}$ NMR spectrum of P4 in DMSO- $d_{6}$.

S38 


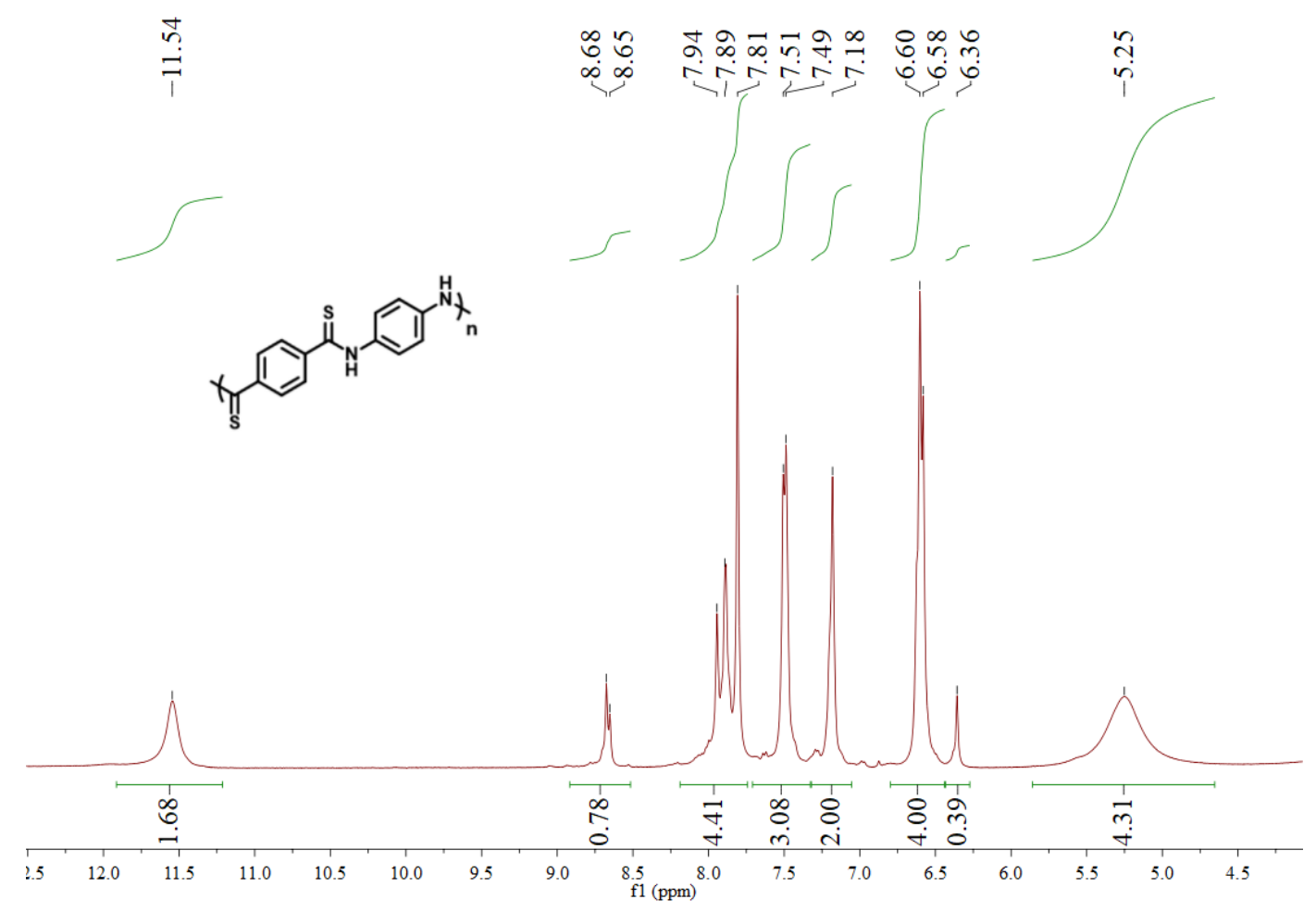

Figure S42. ${ }^{1} \mathrm{H}$ NMR spectrum of P5 in DMSO- $d_{6}$.
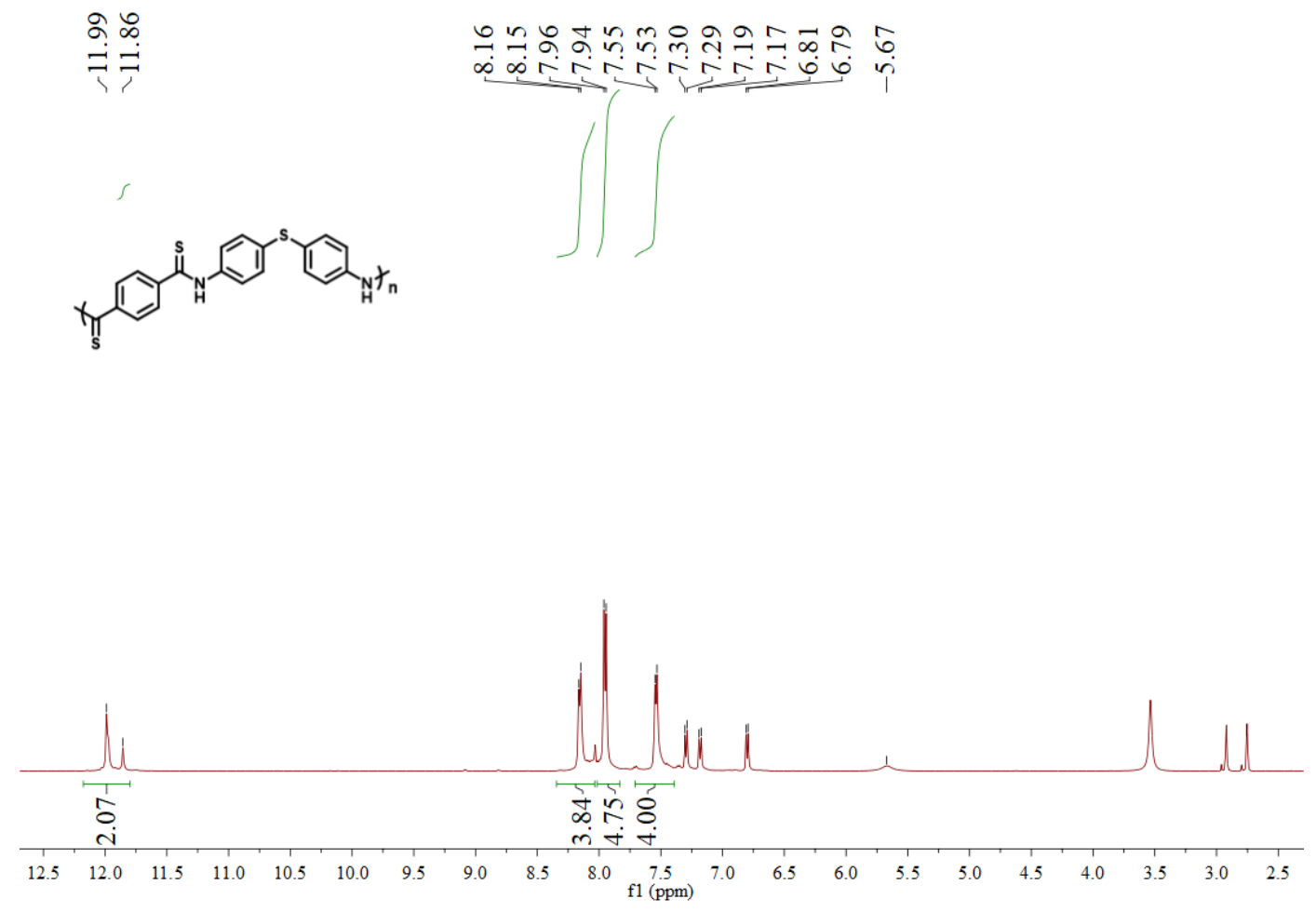

Figure S43. ${ }^{1} \mathrm{H}$ NMR spectrum of $\mathrm{P} 6$ in DMF- $d 7$. 


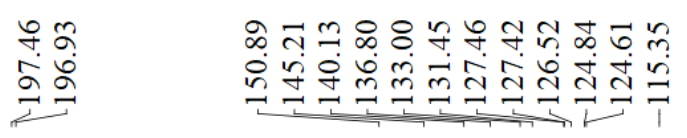
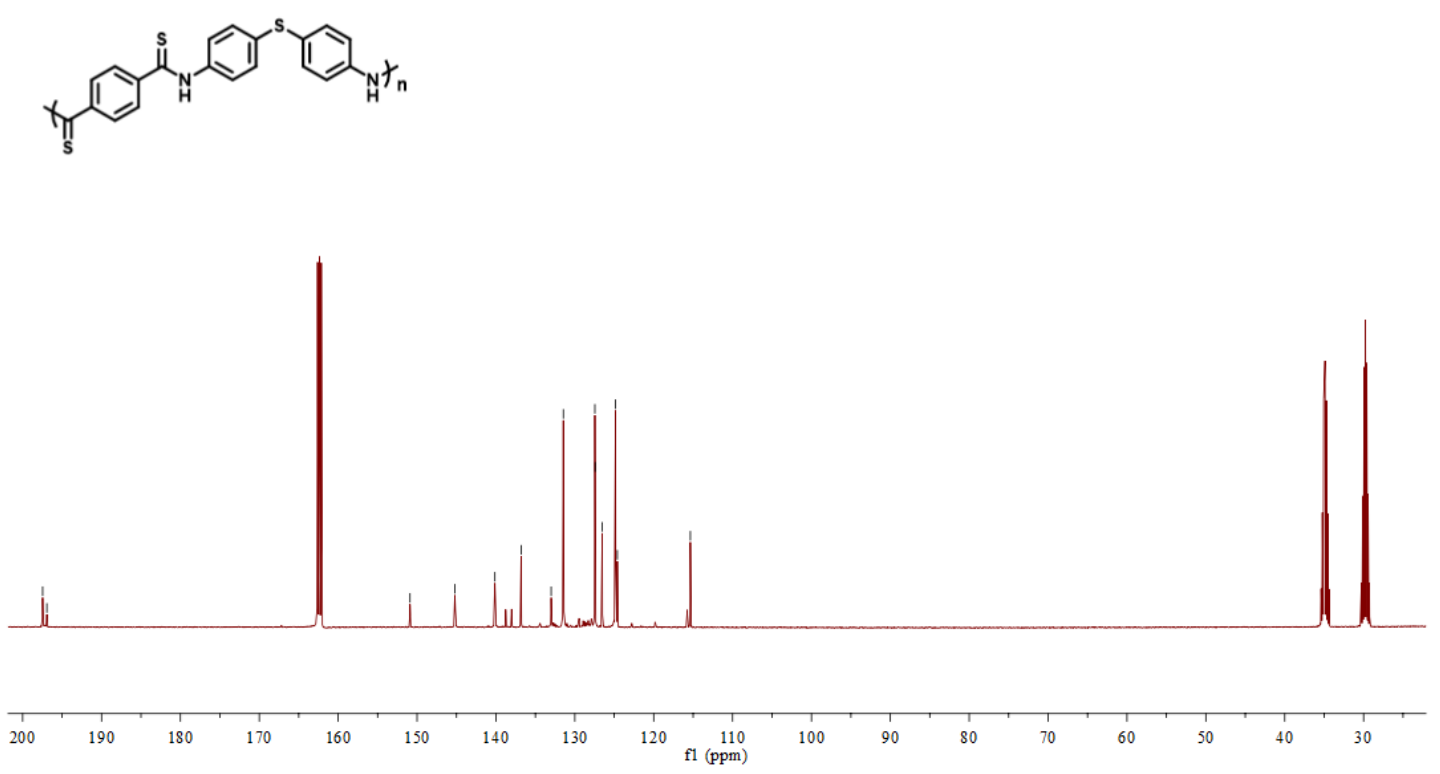

Figure S44. ${ }^{13} \mathrm{C}$ NMR spectrum of P6 in DMF- $d_{7}$.
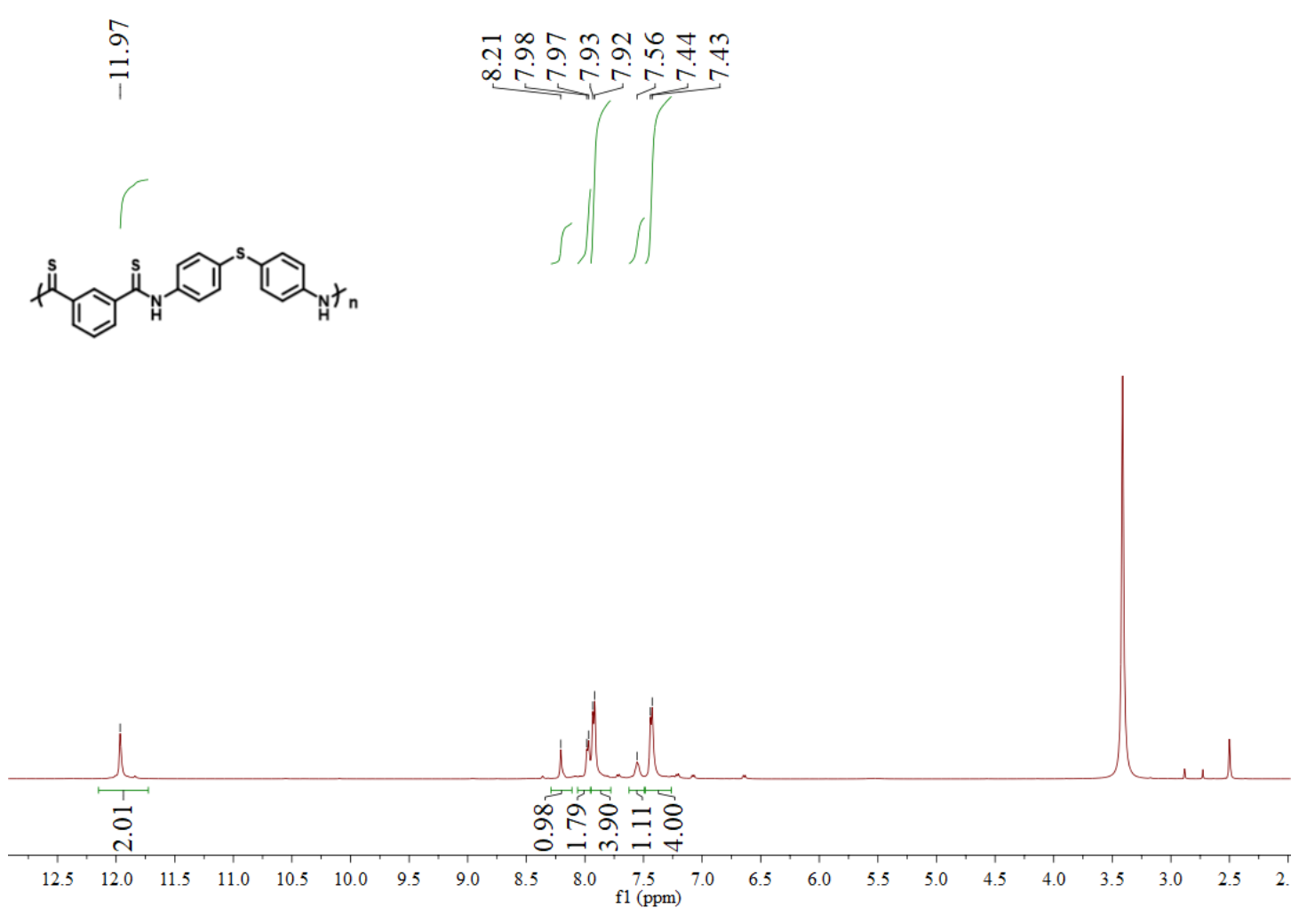

Figure S45. ${ }^{1} \mathrm{H}$ NMR spectrum of P7 in DMSO- $d_{6}$.

S40 
$\underset{\substack{0 \\ \stackrel{1}{5}}}{\stackrel{1}{5}}$

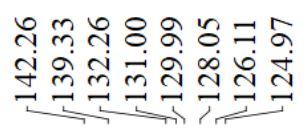
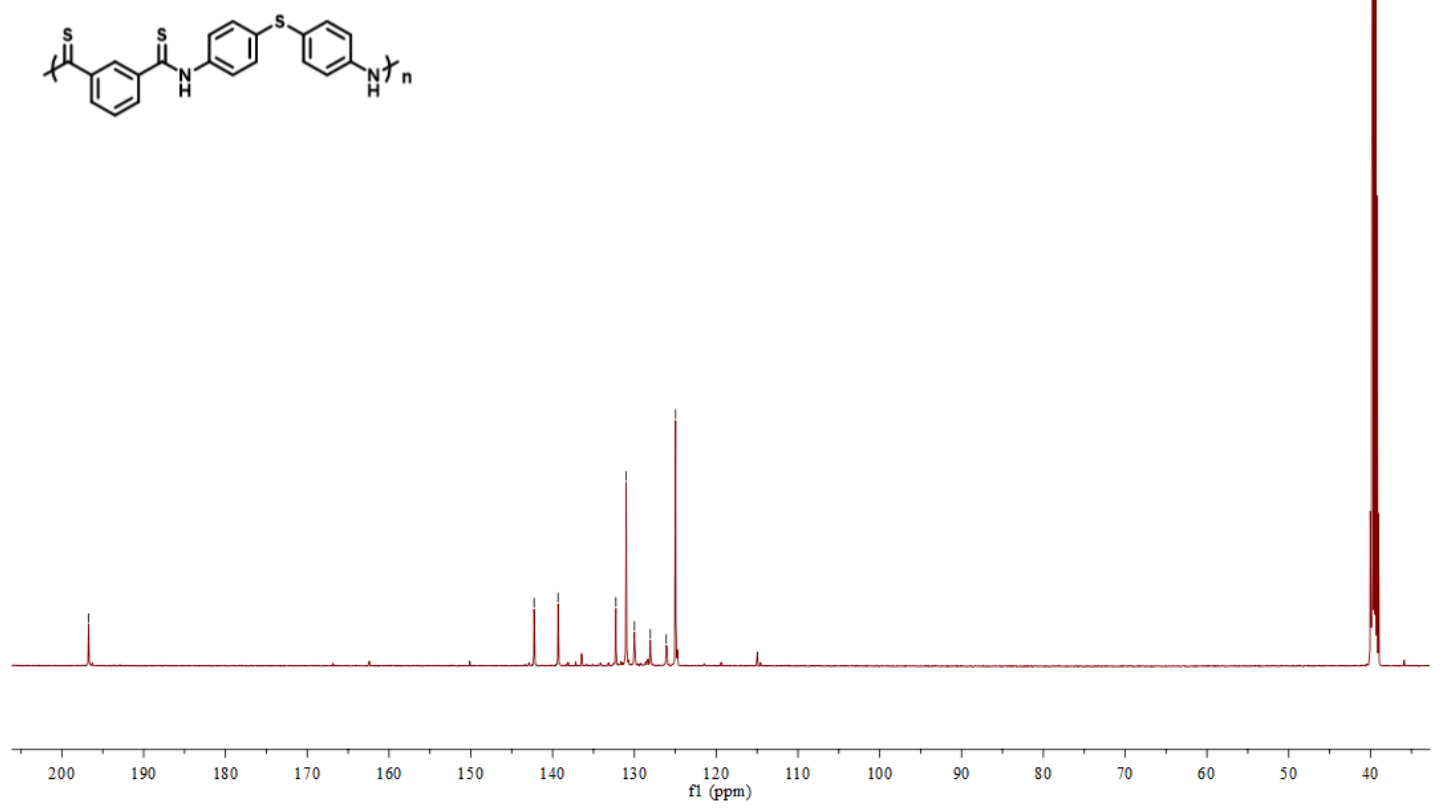

Figure S46. ${ }^{13} \mathrm{C}$ NMR spectrum of P7 in DMSO- $d_{6}$.
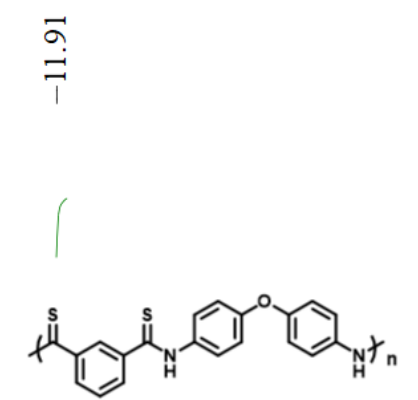

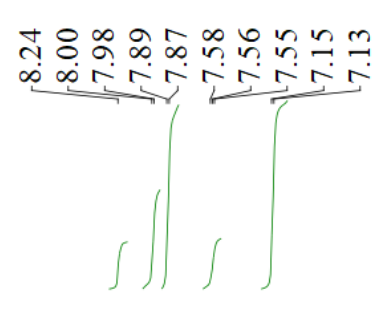

Figure S47. ${ }^{1} \mathrm{H}$ NMR spectrum of P8 in DMSO- $d_{6}$.

S41 
$\vec{n}$
$\stackrel{9}{1}$

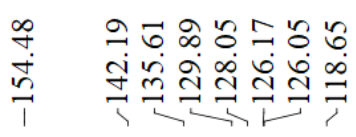
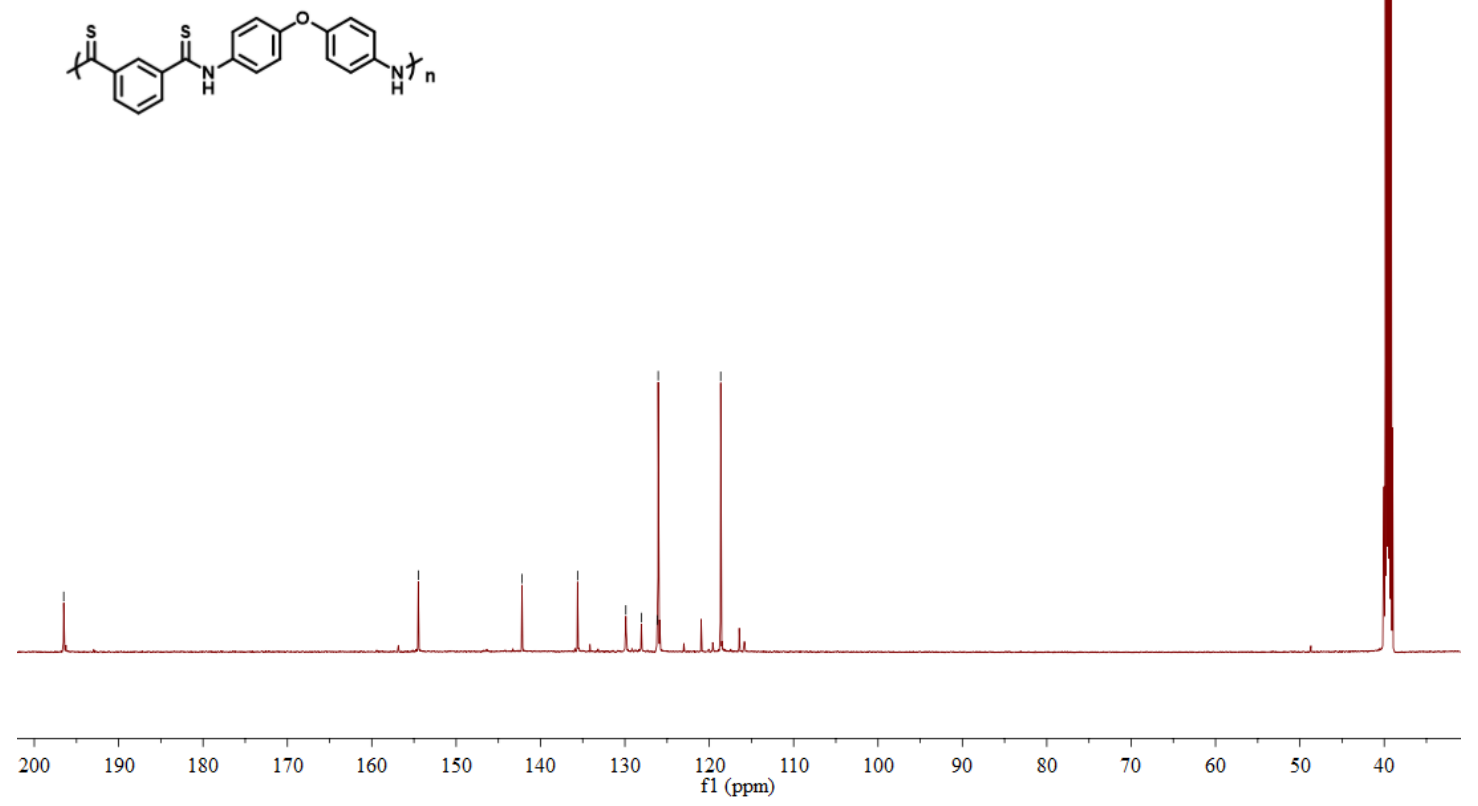

Figure S48. ${ }^{13} \mathrm{C}$ NMR spectrum of P8 in DMSO- $d_{6}$.

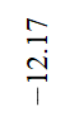

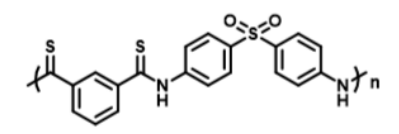

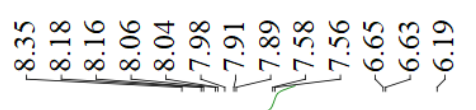

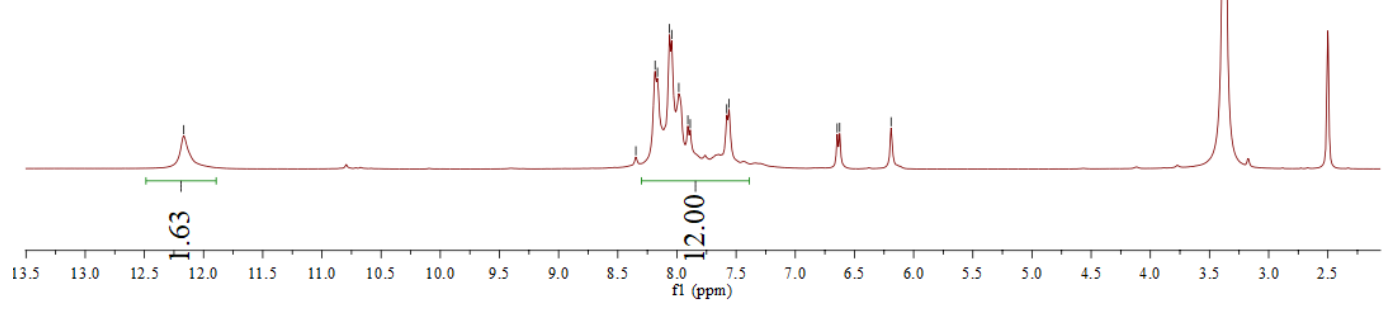

Figure S49. ${ }^{1} \mathrm{H}$ NMR spectrum of $\mathrm{P} 9$ in DMSO- $d_{6}$.

S42 


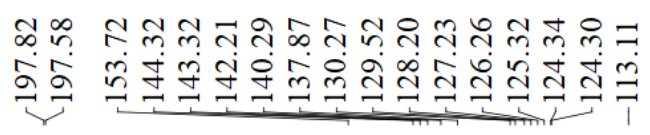


Figure S50. ${ }^{13} \mathrm{C}$ NMR spectrum of $\mathrm{P} 9$ in DMSO- $d_{6}$.

界
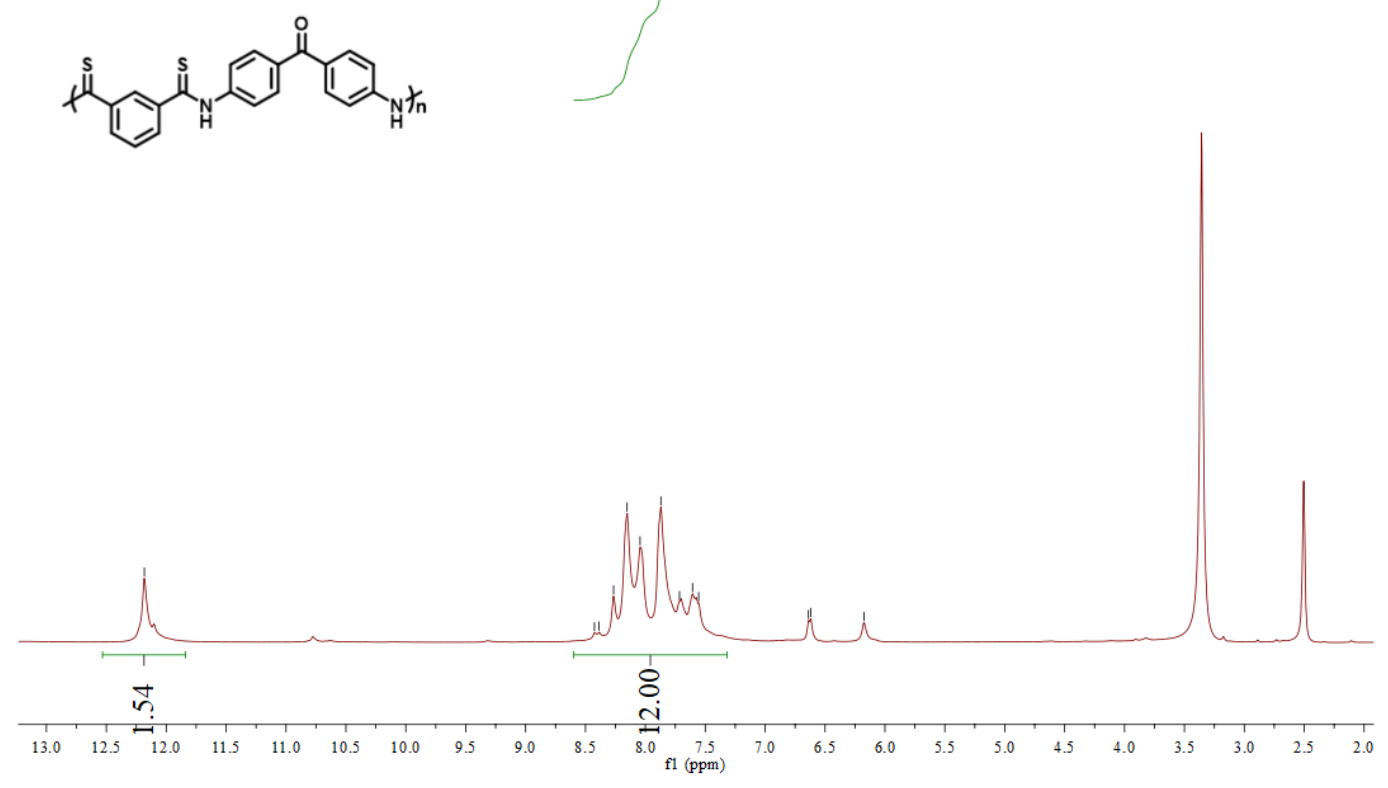

Figure S51. ${ }^{1} \mathrm{H}$ NMR spectrum of P10 in DMSO- $d_{6}$.

S43 


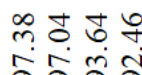

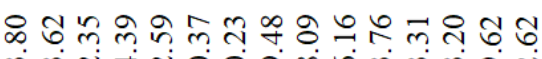

ำ

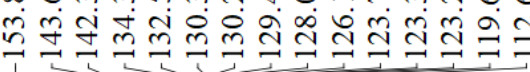
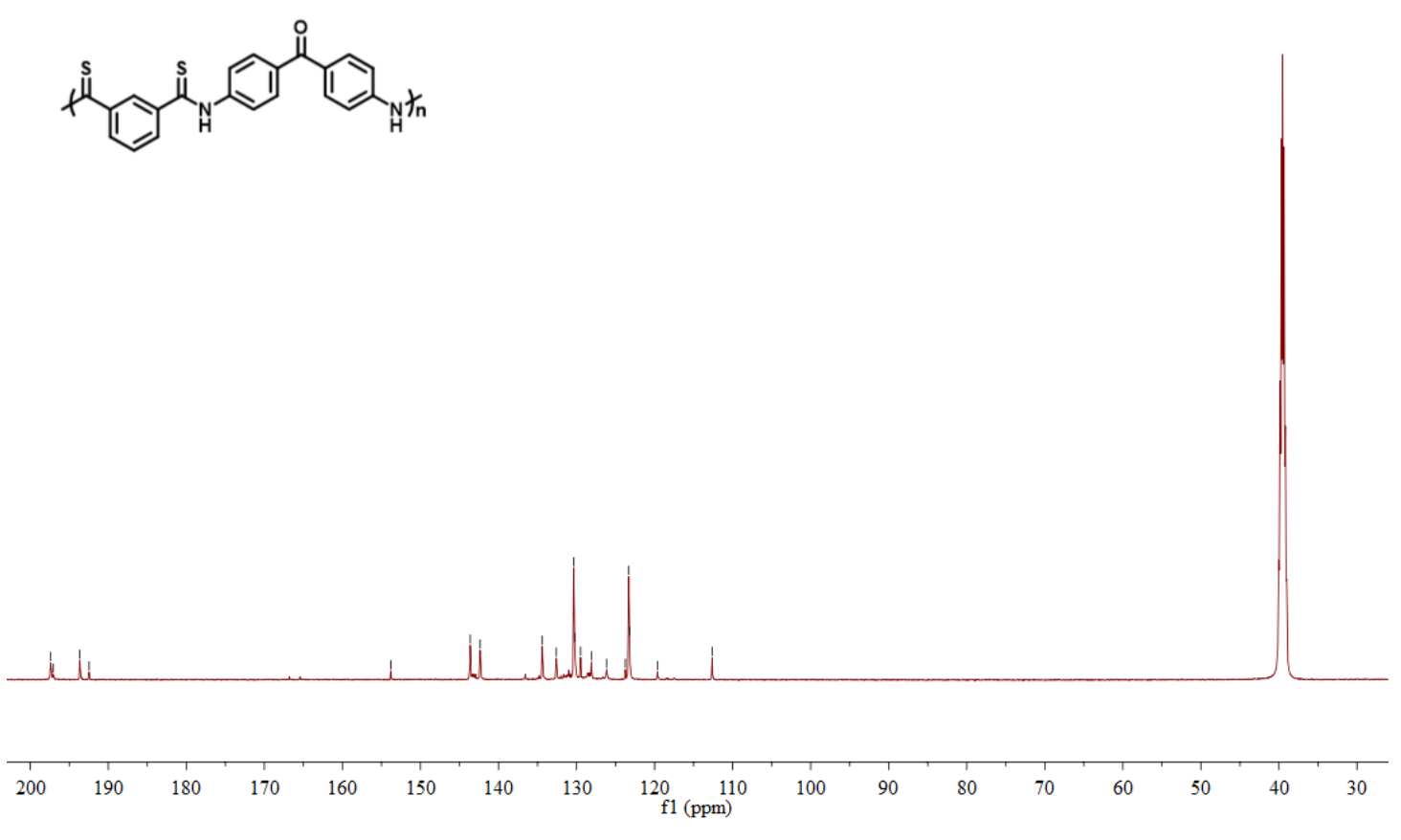

Figure S52. ${ }^{13} \mathrm{C}$ NMR spectrum of P10 in DMSO- $d_{6}$.
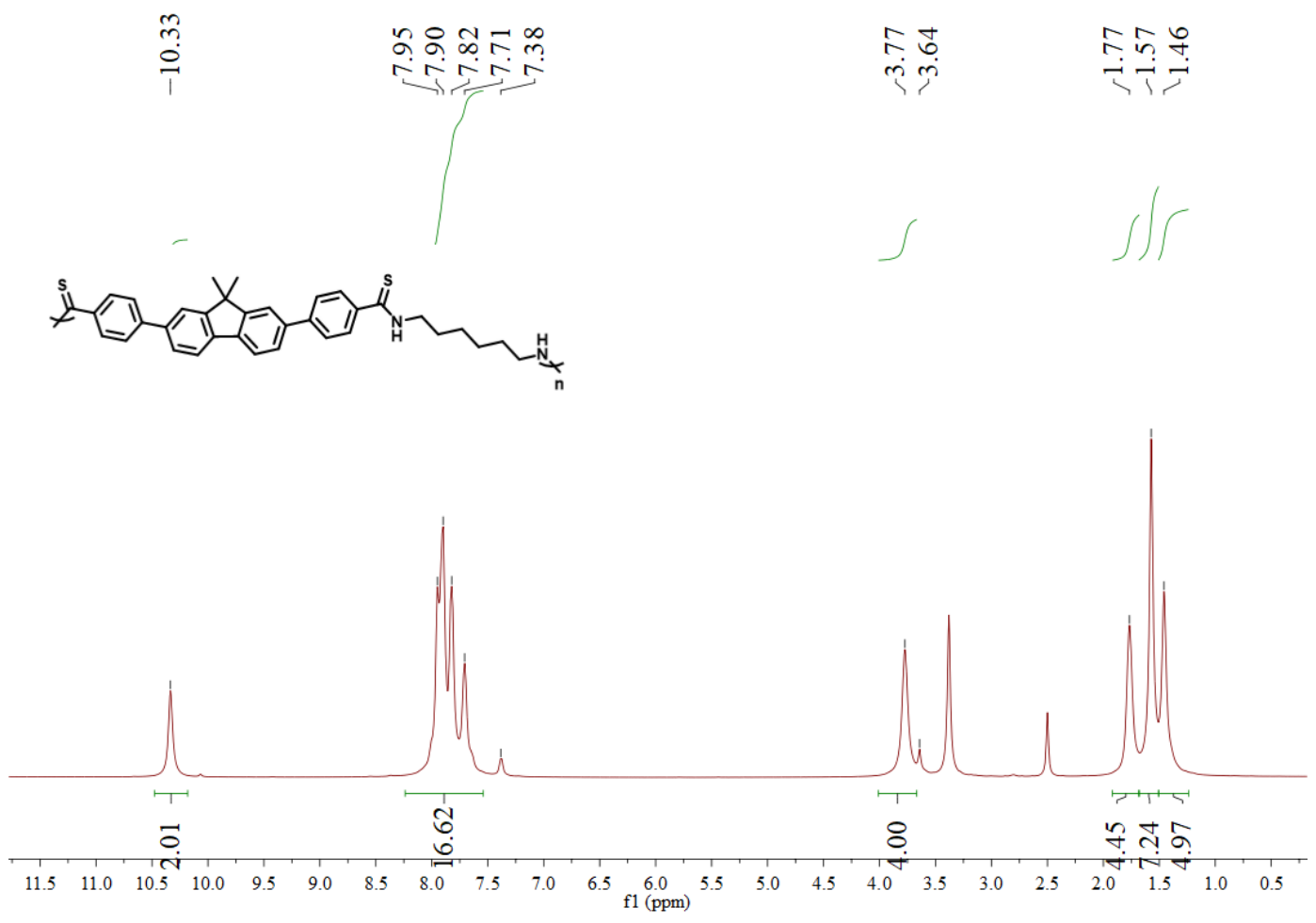

Figure S53. ${ }^{1} \mathrm{H}$ NMR spectrum of P11 in DMSO- $d_{6}$.

S44 

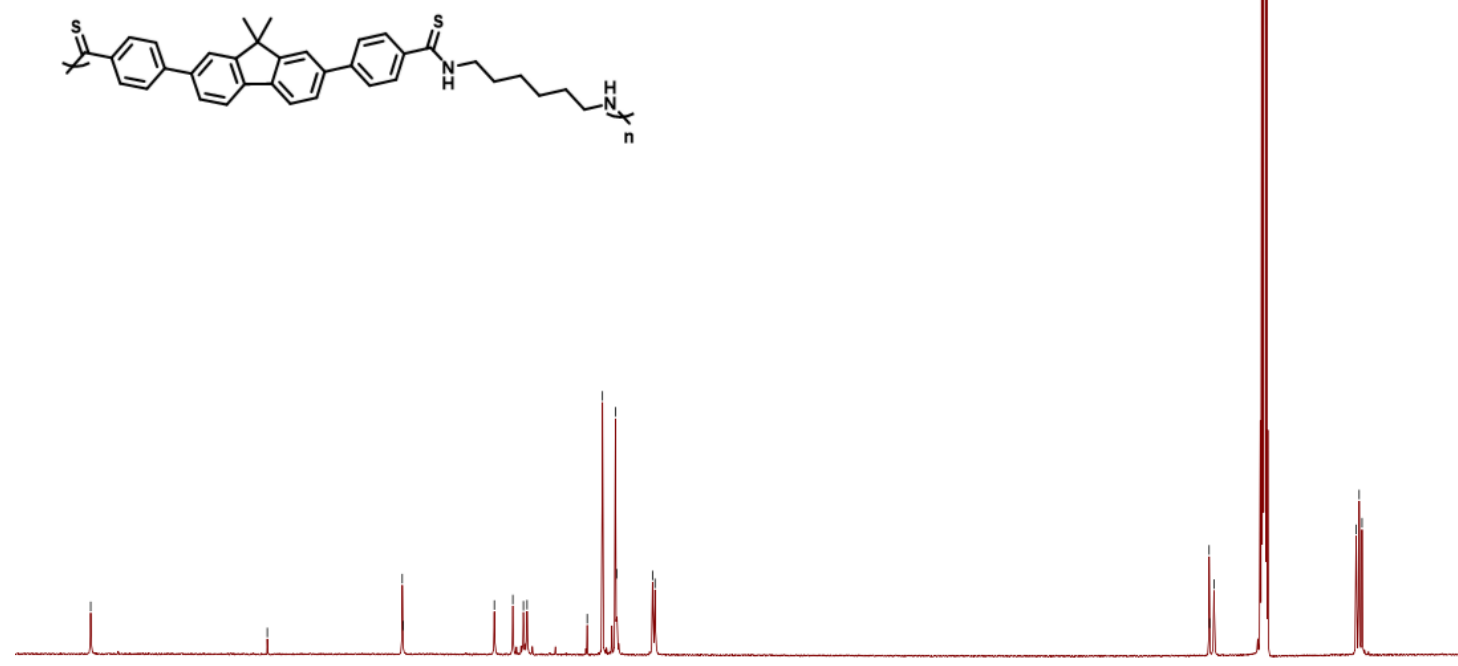

$200 \quad 190$

Figure S54. ${ }^{13} \mathrm{C}$ NMR spectrum of P11 in DMSO- $d_{6}$.
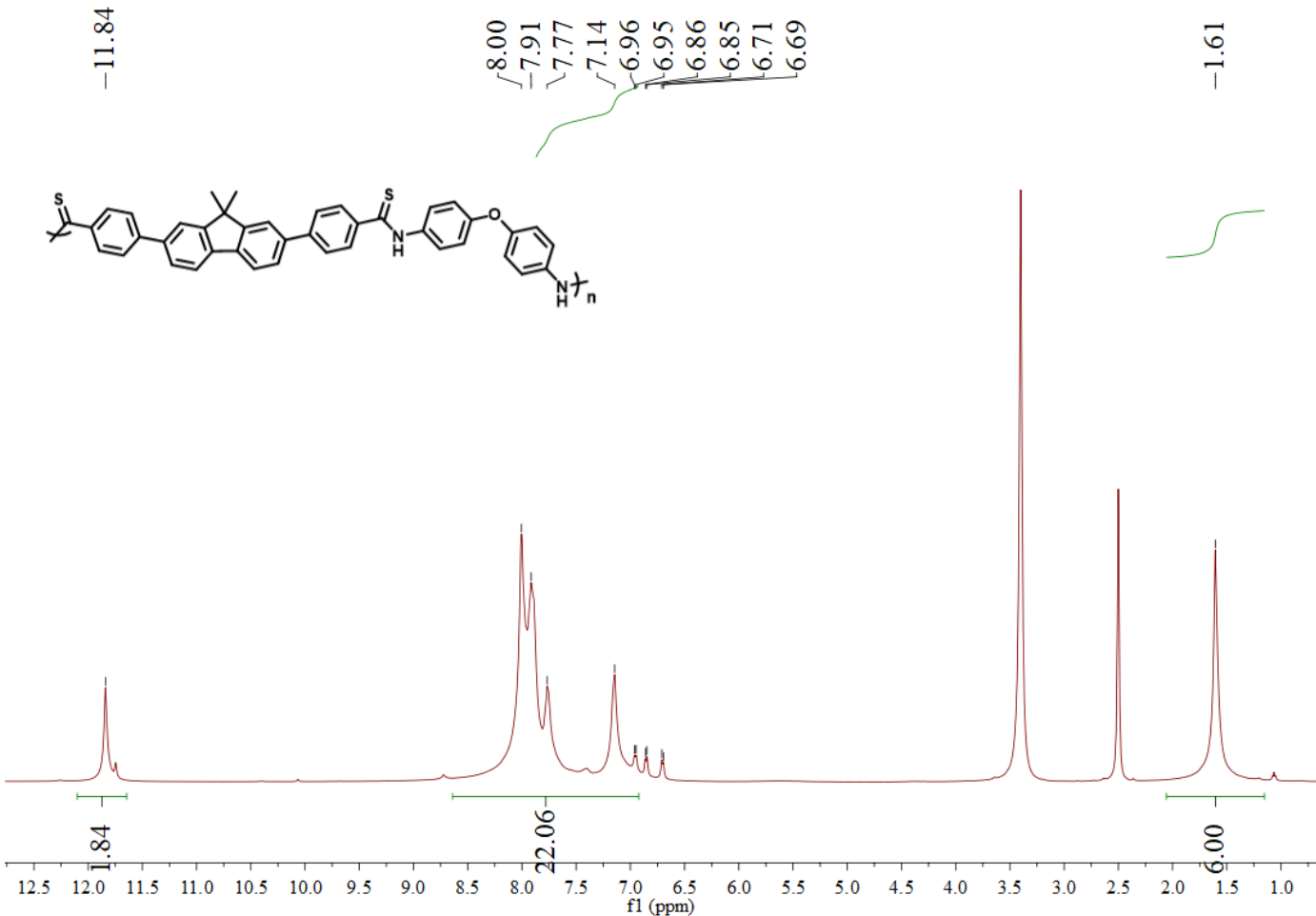

Figure S55. ${ }^{1} \mathrm{H}$ NMR spectrum of P12 in DMSO- $d_{6}$. 

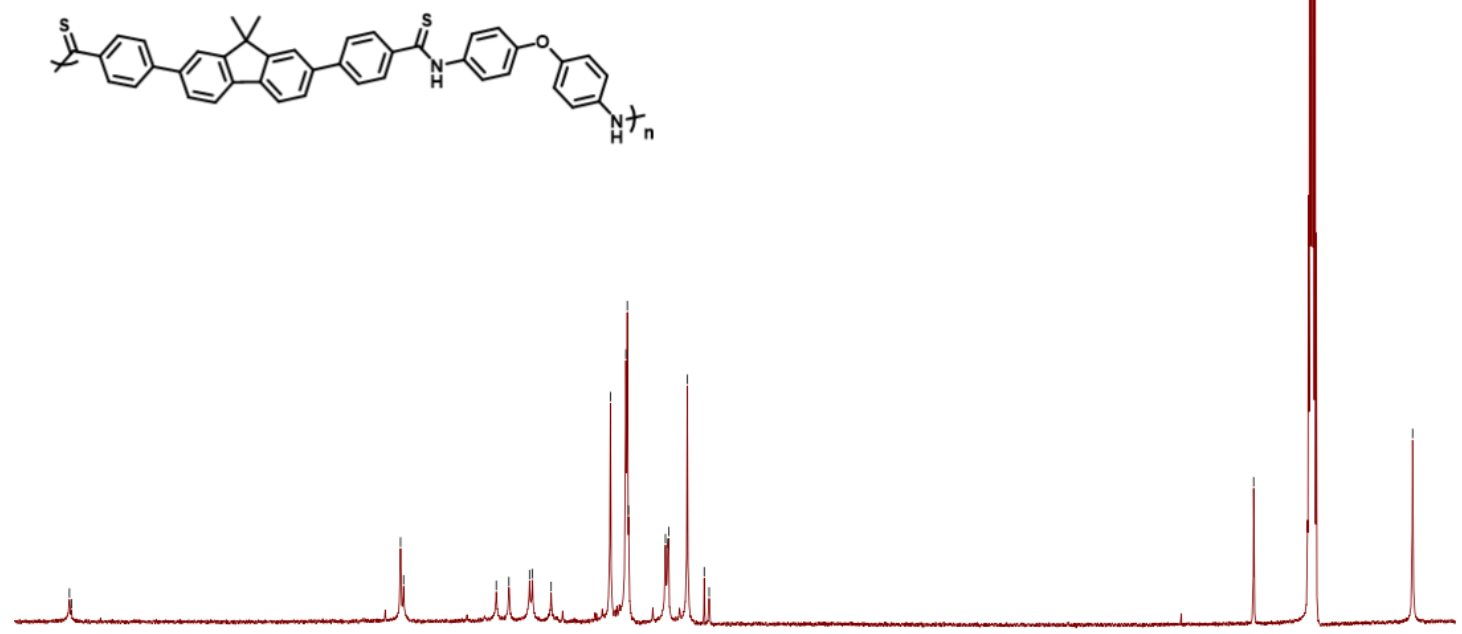

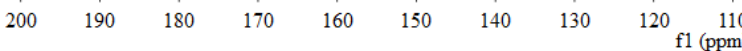

Figure S56. ${ }^{13} \mathrm{C}$ NMR spectrum of P12 in DMSO- $d_{6}$.
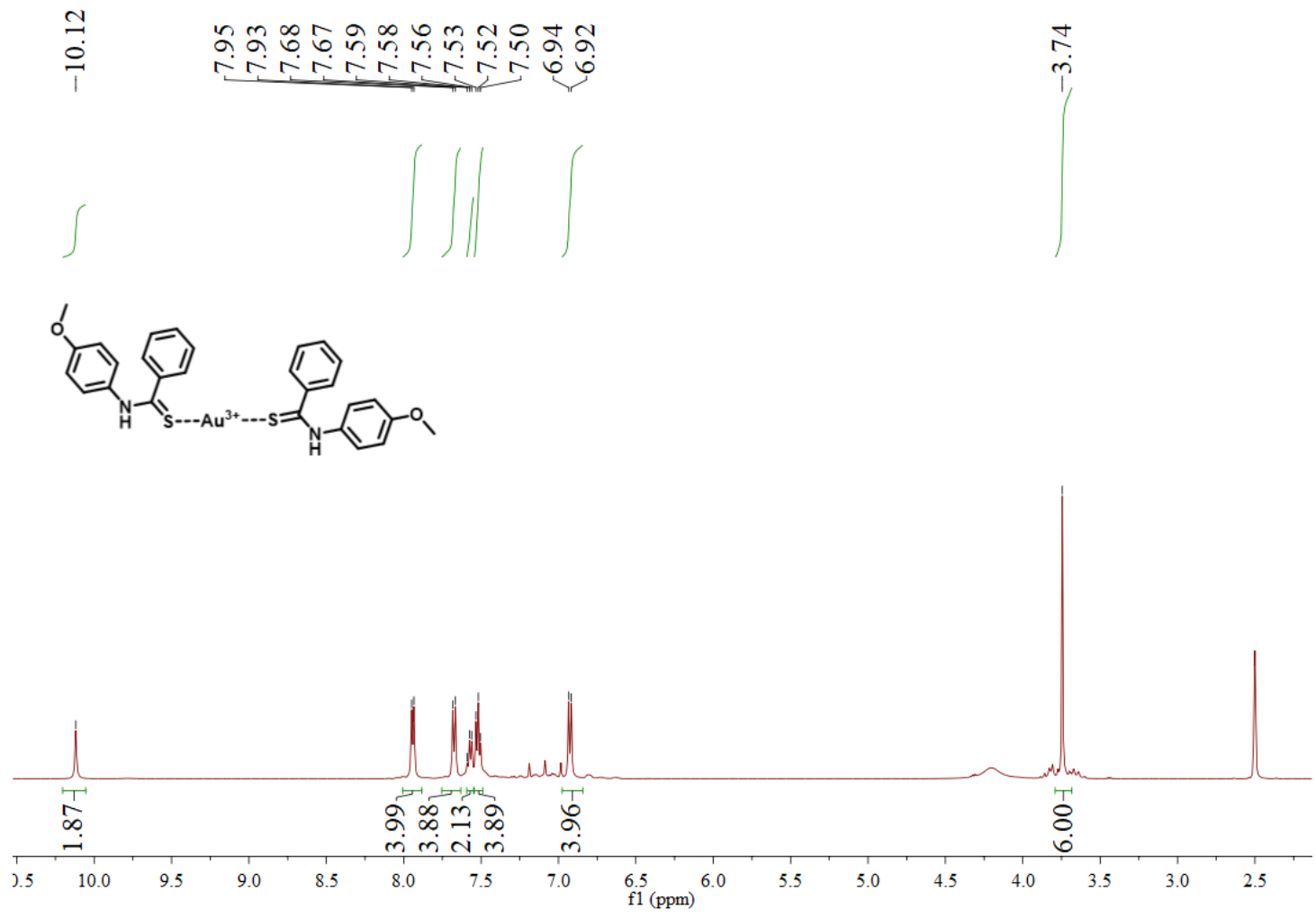

Figure S57. ${ }^{1} \mathrm{H}$ NMR spectrum of $5-\mathrm{Au}^{3+}$ in DMSO- $d_{6}$. 

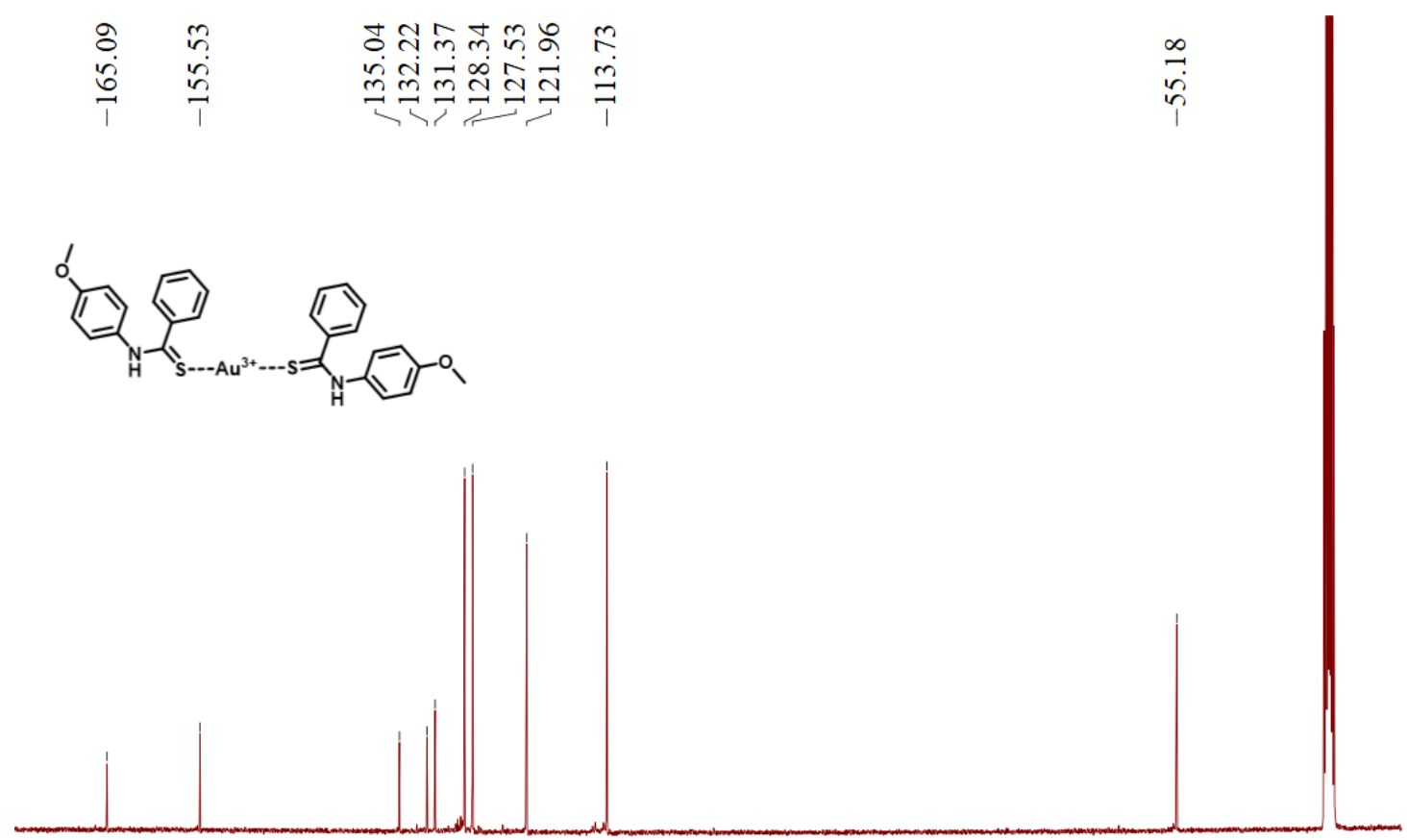

105

$\begin{array}{lllllllllllll}90 & 85 & 80 & 75 & 70 & 65 & 60 & 55 & 50 & 45 & 40 & 35\end{array}$

Figure S58. ${ }^{13} \mathrm{C}$ NMR spectrum of 5- $\mathrm{Au}^{3+}$ in DMSO- $d_{6}$.

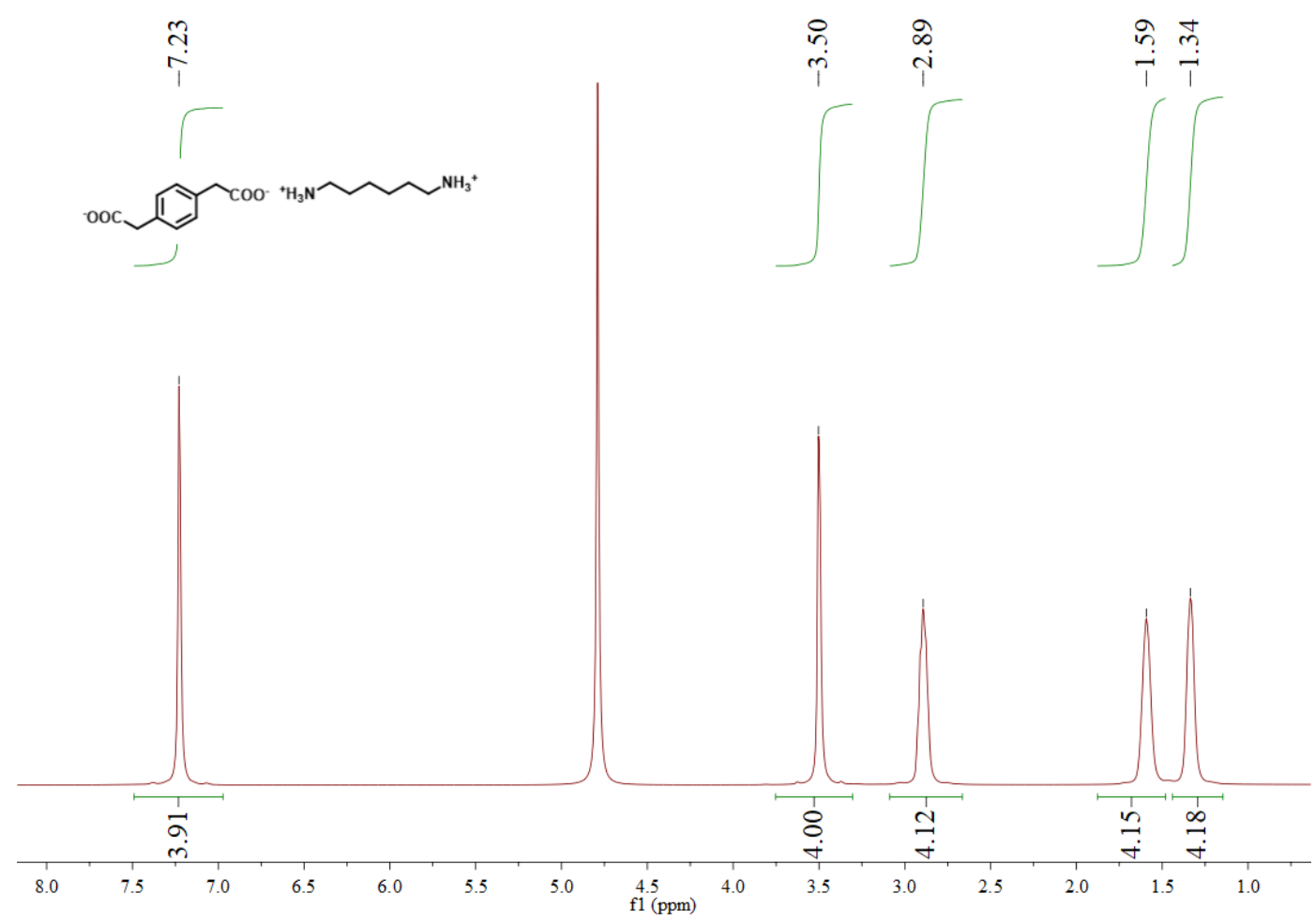

Figure S59. ${ }^{1} \mathrm{H}$ NMR spectrum of ammonium salt formed from $\mathbf{2 a}$ and $\mathbf{3 a}$ in $\mathrm{D}_{2} \mathrm{O}$. 




Figure S60. ${ }^{13} \mathrm{C}$ NMR spectrum of ammonium salt formed from $\mathbf{2 a}$ and $\mathbf{3 a}$ in $\mathrm{D}_{2} \mathrm{O}$. 